\title{
THE CHI-CHI, TAIWAN EARTHQUAKE OF 21 SEPTEMBER 1999
}

\section{Report of the NZSEE Reconnaissance Team}

\author{
D. R. Brunsdon ${ }^{1}$, R. A. Davey ${ }^{2}$, C. J. Graham ${ }^{3}$, G. K. Sidwell ${ }^{4}$, \\ P. Villamor ${ }^{5}$, R. H. White ${ }^{6}$, J. X. Zhao ${ }^{5}$
}

\begin{abstract}
This report on the 21 September 1999 Taiwan earthquake describes the event and its impacts, along with the observations of the New Zealand Society for Earthquake Engineering Reconnaissance Team. The report covers the effects of the earthquake on the ground, lifelines, buildings, bridges, other structures and the community. The emergency management response is outlined, along with the response of the earthquake engineering community. Lessons for New Zealand are presented and discussed.
\end{abstract}

\section{CONTENTS}

1. Introduction

2.

2.1 Tectonic and Geologic Context

2.2 Active Faults

2.3 References

3. The Earthquake and Fault Rupture

3.1 Introduction

3.2 Strong-motion Records

3.3 Ground Response

3.4 References

4. Lifelines

4.1 Introduction

4.2 Electricity

4.3 Telecommunications
4.4 Water and Wastewater

4.5 Gas

4.6 Transportation Networks

5. Building Structures

5.1 The Design and Construction Process

5.2 Adobe and Unreinforced Masonry Construction

5.3 'Up to Heaven' Housing

5.4 Multi-storeyed Apartments and Hotels

5.5 Multi-storeyed Commercial Buildings

5.6 Industrial Facilities

5.7 School Buildings

5.8 Contents and Non-structural Elements

6. Bridges

6.1 Design Codes and Standards

6.2 Expressways and Arterial Routes

6.3 Other Bridges

${ }^{1}$ Spencer Holmes Ltd, Wellington (Fellow)

${ }^{2}$ Opus International Consultants Ltd, Wellington

${ }^{3}$ Worley Consultants Ltd, Hamilton (Member)

${ }^{4}$ Connell Wagner Ltd (Member)

${ }^{5}$ Institute of Geological and Nuclear Sciences, Lower Hutt (Member)

${ }^{6}$ Thames Valley Combined District Civil Defence 
Other Civil Engineering Structures

7.1 Dams

7.2 Port Facilities

7.3 Retaining Walls

7.4 Tanks and Silos

8. Social and Economic Impacts

8.1 Social Aspects

8.2 Economic Impacts

9. Emergency Management

9.1 Organisational Structures and Preparations

9.2 Response

9.3 Recovery Planning

10. Response of Engineers and Scientists

10.1 Earthquake Information

10.2 Damage Assessment and Scientific Reconnaissance

10.3 Building Safety Inspections

10.4 Briefing of Overseas Technical Teams

10.5 References

11

Lessons for New Zealand

11.1 General

11.2 Principal Lessons

11.3 References

12

Acknowledgements

\section{INTRODUCTION}

At 1.47 am on Tuesday 21 September, 1999 an earthquake of magnitude $\mathrm{M}_{\mathrm{w}}=7.6$ hit central Taiwan. The epicentre was near the town of Chi-Chi, $120 \mathrm{~km}$ south of Taiwan's capital city of Taipei. More than 2,400 people were killed, and more than 10,000 were injured. At least 16,500 buildings collapsed or were severely damaged, and more than 100,000 people were rendered homeless.

Taiwan is an island of 36,000 square kilometres (15\% of New Zealand's land area) situated approximately $200 \mathrm{~km}$ off the southeastern coast of China. It has a population of approximately $22,000,000$ people.

The Republic of China was officially declared in 1911 in Nanjing, China, and the government of the Republic of China moved to Taiwan in 1949. Taiwan's economy has transformed in the subsequent 50 years from being simply a producer of rice and sugar to manufacturing-based featuring automated electronics and computer components. The economic growth rate over the past 30 years has averaged a remarkable $9 \%$.

The key characteristic of this earthquake was a fault rupture over a length of $83 \mathrm{~km}$. As a consequence, a number of cities and towns were severely affected by the earthquake. Figure 1.1 shows the relationship between the fault rupture, the affected provinces and Taiwan's major cities.

The maximum recorded peak ground accelerations were $1.01 \mathrm{~g}$ horizontally and $0.53 \mathrm{~g}$ vertically (not at the same location). Intensities proved difficult to assess, due principally to the limited number of buildings of early construction. It is considered that the peak intensity of the earthquake was Modified Mercalli X.

The total direct cost of this earthquake is estimated to be at least NZ\$21 billion (to the end of November 1999).

The seven-person NZSEE reconnaissance team arrived in Taiwan on 7 October, 16 days after the earthquake, and departed 7 days later on Thursday 14 October. The majority of this time was spent in the affected area, based in the city of Taichung.

The report covers the effects of the earthquake on the ground lifelines, buildings, bridges, other structures and the community. The emergency management response is outlined, along with the response of the earthquake engineering community. Lessons for New Zealand are presented and discussed.

\section{THE PHYSICAL CONTEXT OF TAIWAN}

\subsection{Tectonic and Geologic Context}

Taiwan is situated at the boundary between the Philippine Sea plate and the Eurasian plate (Figure 2.1; Teng, 1990; Seno et al., 1993). To the east and northeast of Taiwan, the Philippine Sea plate is subducting beneath the Eurasian plate at the Ryukyu trench, and to the south of Taiwan, the Eurasian plate is subducting beneath the Philippine Sea plate at the Manila trench (Figure 2.2a).

Taiwan is an active mountain belt formed by the collision between the Luzon Arc and the Asian continent (Figure 2.2) The collisional context has produced a central ridge which forms the backbone of the island and is the main water divide between east and west. The context has also produced a series of folds and thrust faults that divide the country into several geologic provinces (Ho, 1988) that trend northnortheast (Figure 2.3a). These provinces are called (from west to east): the Penghu Island Group, the Coastal Plain, the Western Foothills, the Central Range and the Coastal Range. The Central and Coastal Ranges are separated by the longitudinal valley. The Penghu Island Group is covered with Pleistocene basalts; the Coastal Plain consists of Quaternary alluvial deposits; the Western Foothills consist of marine sediments from Late Oligocene to early Pleistocene age; the Central Range consists of metamorphosed Cenozoic and pre-Tertiary sediments and the Coastal Range consists of Neogene volcanic material and deep-sea sediments (Yu et al 1997). The Western Foothills and Central Range were part 
of the Chinese continental shelf before being deformed by the Luzon Arc collision, while the Coastal Range is the northern extension of the Luzon Arc (Teng, 1990). Figure 2.3b illustrates how these provinces are bounded by thrust faults verging to the east that have elevated the mountains by stacking the province to the east of the fault on the province to the west of the fault at each boundary. The faults bounding these provinces trend NNE-SSW south of latitude $24.4^{\circ} \mathrm{N}$ but turn to ENE-WSW due to the interaction between the two subduction zones to the north of latitude $24.4^{\circ}$ (Lu, 1994 and 1998).

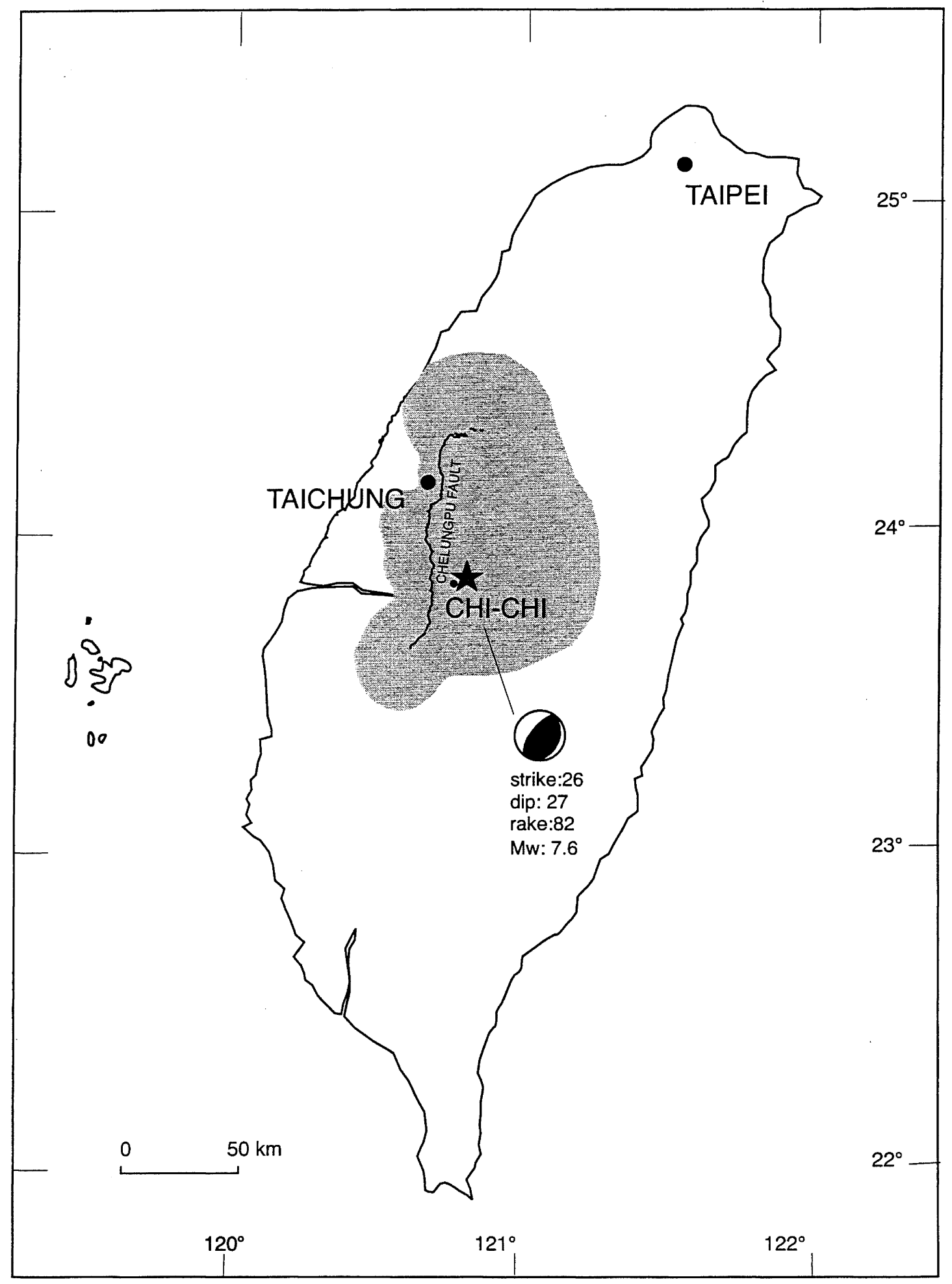

Figure 1.1: $\quad$ Map of Taiwan showing damaged region (shading denotes PGA $>0.25 g$ ), fault rupture and epicentre (data provided by National Taiwan University and the Central Geological Survey of Taiwan) 
The Chi-Chi earthquake occurred on a fault at the boundary between the Western Foothills and the Coastal Plain. The geological formations of the area affected by the earthquake shaking are late Pliocene mudstone, sandstone and limestone, Pleistocene gravel and sand and Holocene gravel and sand (Figure 2.3).

Relative plate motion across the Taiwan plate boundary is 70 $\mathrm{mm} /$ year as shown in the Nuvel solution (De Mets, 1990 and Seno et al, 1993) and from GPS data (Yu et al., 1997). Yu et al. (1997) presents the result of a recent GPS study across the whole of Taiwan (Figure 14 of Yu et al., 1997). Large velocities occur in the eastern part of the country (several centimetres difference in velocity between the Central Range and the Coastal Range). Velocity differences of the order of a few millimetres per year occur across faults in the area of Chi-Chi earthquake.
The Taiwan region is an area of abundant seismicity as to be expected at a plate boundary with very high relative motion. Figure $2.2 \mathrm{~b}$ shows that the seismicity is concentrated mainly along the east coast and offshore of Taiwan. The seismicity in the southeast is connected with the Manila trench and in the northeast and east to the Ryukyu trench. This eastern zone of seismicity consists of shallow to deep earthquakes (up to $200 \mathrm{~km}$ depth). In the central and western part of the country, seismicity is lower and concentrated in the upper 50 $\mathrm{km}$.

Several large $20^{\text {th }}$ century earthquakes have occurred in western Taiwan (Figure 2.4). Some of these are known to have occurred on faults in the western foothills and produced surface rupture (Table 2.1).

\begin{tabular}{lccccccc}
\hline \multicolumn{6}{l}{ Table 2.1: Large historical earthquakes in Taiwan (Bonilla, 1977) close to the Chi-Chi earthquake area } \\
\hline Date & Magnitude & $\begin{array}{c}\text { Surface } \\
\text { Rupture length } \\
(\mathrm{km})\end{array}$ & $\begin{array}{c}\text { Displacement } \\
(\mathrm{m})\end{array}$ & Fault type & Deaths & $\begin{array}{c}\text { Houses } \\
\text { destroyed }\end{array}$ & Fault \\
1906 & 7.1 & 13 & 2.7 & oblique-slip & 1,258 & 6,000 & Meishan \\
1935 & 7 & 27 & $1-3$ & oblique- & 3,000 & 17,000 & $\begin{array}{c}\text { Chihhu and } \\
\text { Tunztichio } \\
\text { slip/reverse } \\
1946\end{array}$ \\
\hline
\end{tabular}



Figure 2.1: $\quad$ Tectonic setting of Taiwan (modified from Seno et al 1993). 


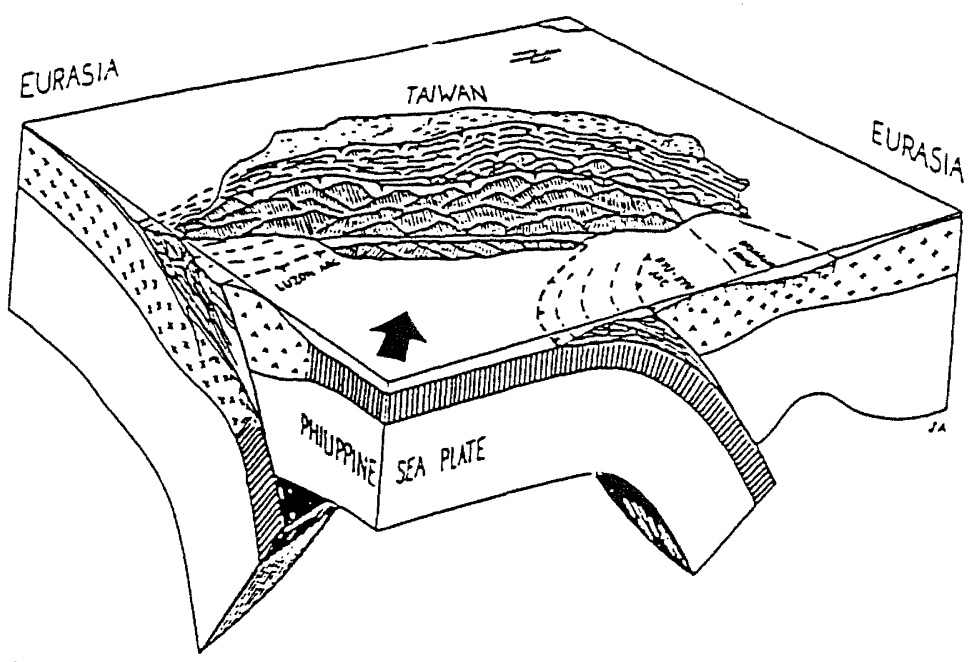

a

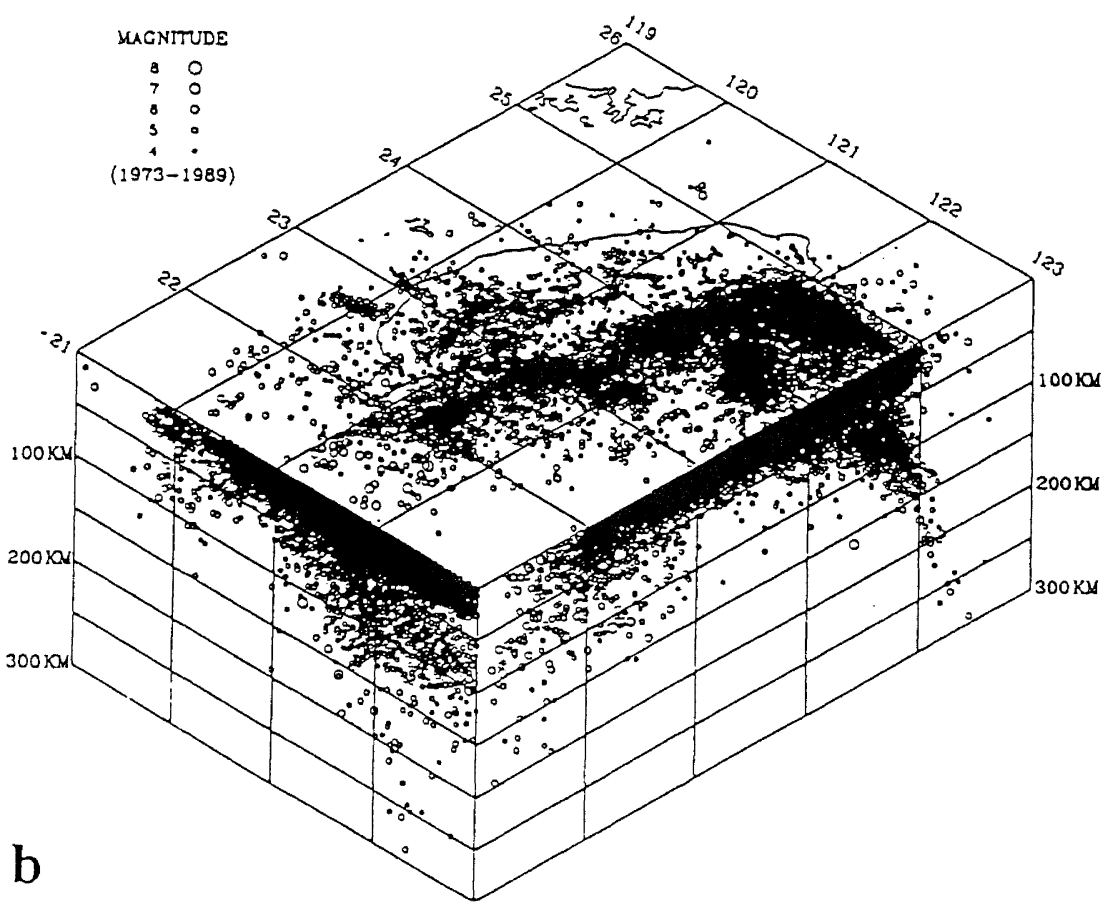

Figure 2.2: $\quad 3-D$ structure of the Taiwan collision zone (a) Lithospheric structure in and around Taiwan from Angelier (1986), main thrusts as thick lines, with triangles on the upthrust side; in sections: ocean crust hatched, continental crust with pattern of crosses, island-arc crust with pattern of overturned ' $v$ ' and lithospheric mantle left white. (b) Earthquake distribution, from Yeh et al. (1991): map of epicentres and projections of hypocentres in $E$-W and $N-S$ sections, for the most reliably located earthquakes by the Taiwan Telemetered Seismographic Network (1973-1989) (Figure taken from Hu et al. 1996) 


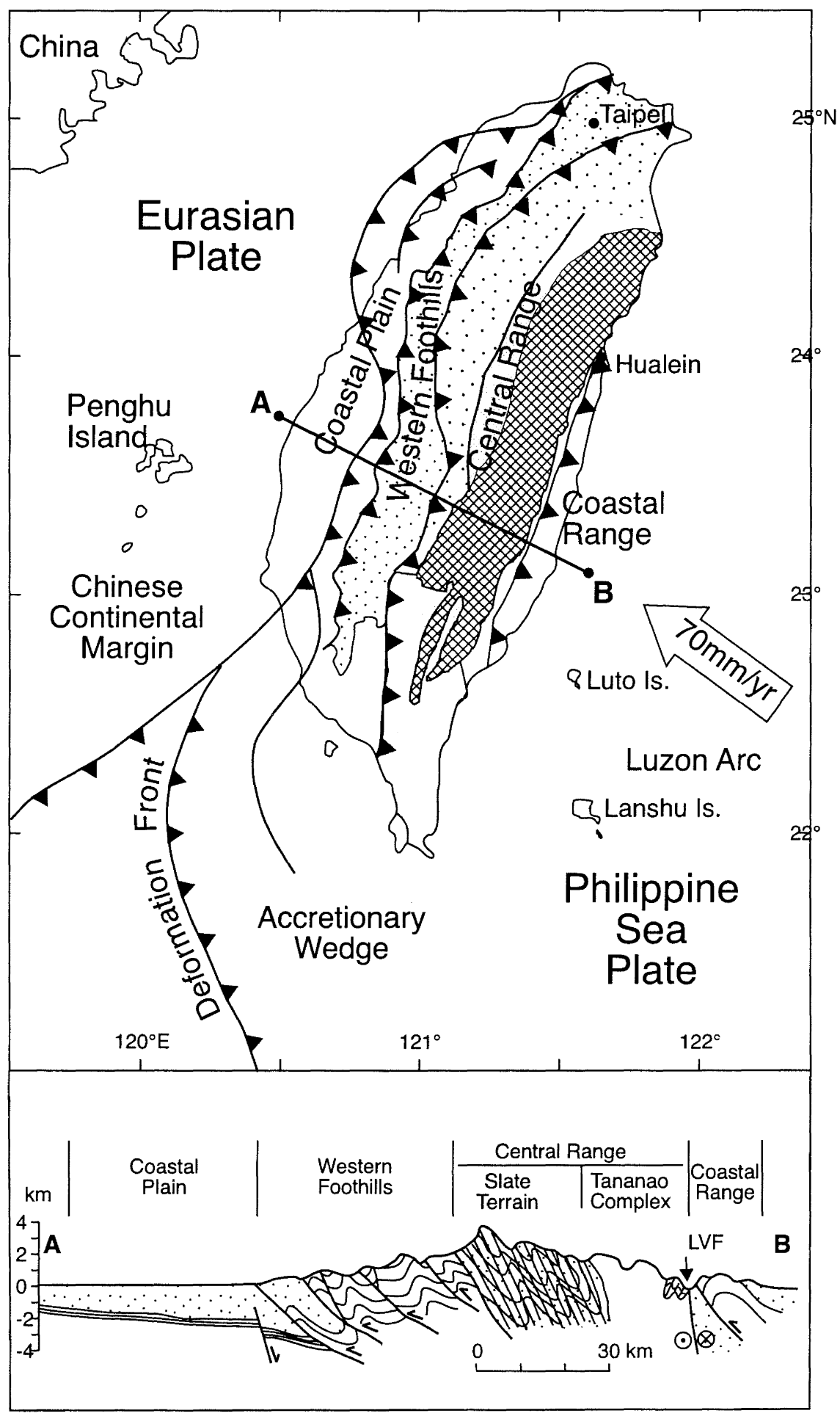

Figure 2.3: $\quad$ (a) Geologic provinces of Taiwan and (b) schematic cross-section of Taiwan (modified from Teng, 1997). 


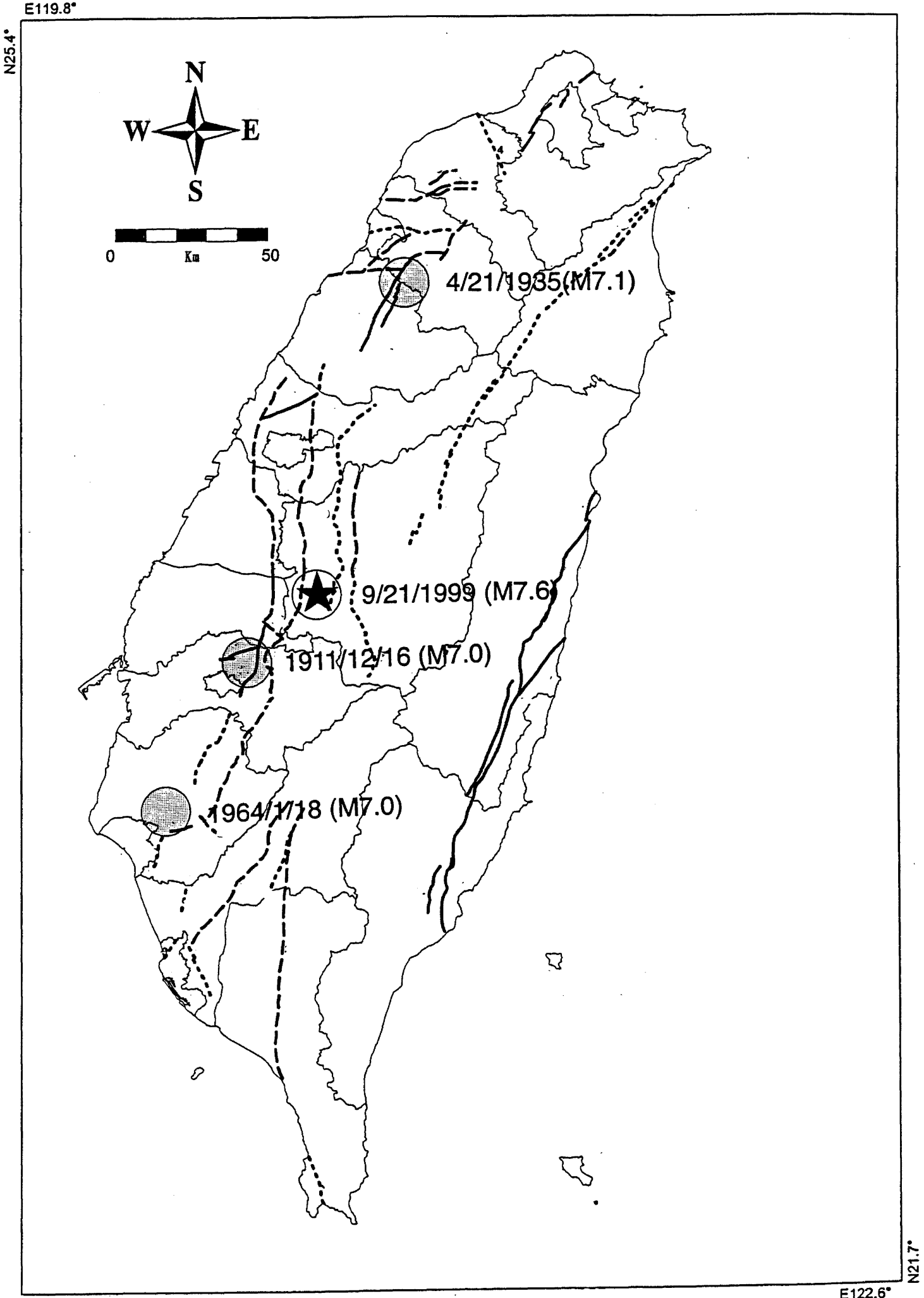

Figure 2.4: $\quad$ Historical earthquakes close to the Chelungpu fault. (http:// www2.rcep.dpri.kyotou.ac.jp/ sato/taiwan/recent.html). 


\section{$2.2 \quad$ Active Faults}

Active faults (Figure 2.5) have long been recognised in Taiwan (Bonilla, 1977) and there have been several examples of surface rupture (Table 2.1). Active faults have been classified based on their activity, as follows:

- Category I : faults that have ruptured in the last 10,000 years

- Category II: faults that have ruptured in the last 10,000 years to 125,000 years

- Category III: faults that have ruptured in the last 125,000 to $1,000,000$ years.

The principal active faults of Taiwan have a reverse, strikeslip, or oblique slip. The Chi-Chi earthquake was associated with rupture of the Chelungpu fault (Figure 2.6) and produced surface faulting at the western boundary of the Western Foothills geologic province between the surface rupturing events of 1906 and 1935. The Chelungpu fault had been classified as Category II.

\section{$2.4 \quad$ References}

Bonilla, M.G.: 1977. Summary of Quaternary faulting and elevation changes in Taiwan. Memoir of the Geological Society of China, n.2, 43-55.

DeMets, C.; Gordon, R.G.; Argus, D.F.; Stein, S. 1990. Current plate motions. Geophysical Journal International 101: 425-478.

Ho, C.S. 1988: An Introduction to the Geology of Taiwan. Explanatory text of the Geological Map of Taiwan. Central Geological Survey. Ministry of Economic Affairs, Taiwan, ROC.

Hu Jyr-Ching, Angelier, J., Lee, J. C., Chu, H-T., Byrne, D.: Kinematics of convergence, deformation and stress distribution in the Taiwan collision area; 2-D finite element numerical modelling. Tectonophysics, vol $255,243-268$

Lu, C.Y., Jeng, F.S., Chang, K.J. and Jian, W.T. 1998: Impact of Basement High on The Structure and Kinematics of The Western Taiwan Thrust Wedge: Insights From Sandbox Models. Terrestrial, Atmospheric and Oceanic Sciences, vol 9, n. 3, 533550.

Lu, C.Y.: 1994 Neotectonics in the Foreland Thrust Belt of Taiwan. Petroleum Geology of Taiwan, n. 9 1-26.

Philip, H., Rogozhin, E., Cisternas, A., Bousquet, J.C., Borisov, B., Karakhanian, A. 1992. The Armenian earthquake of 1988 December 7: faulting and folding, neotectonics and paleoseismicity. Geophysical Journal International, 110, 141-158.

Seno, T. Stein, S., Gripp, A.E.: 1993. A Model for the Motion of the Philippine Sea Plate consistent with NUVEL-1 and the Geological Data. Journal of geophysical research, vol 98, n. B10, 17,941-17,948.
Teng, L. S. 1990: Geotectonic evolution of late Cenozoic arccontinent collision in Taiwan. Tectonophysics, 183, $57-76$.

Yu, S.B., Chen, H.Y., Kuo, L.C. 1997: Velocity field of GPS stations in the Taiwan area. Tectonophysics, 274, 41 59

\section{THE EARTHQUAKE AND FAULT RUPTURE}

\subsection{Introduction}

The Chi-Chi earthquake occurred on 21 September 1999 at $1: 47$ am local time. The earthquake was of magnitude $\mathrm{M}_{\mathrm{w}}=$ $7.6\left(\mathrm{M}_{\mathrm{L}}=7.3\right)$, with the epicentre located at latitude $23.85^{\circ}$ and longitude $120.81^{\circ}$ at a depth of $7 \mathrm{~km}$ (magnitude from Harvard University and location from Central Weather Bureau of Taiwan). Its epicentre is close to the town of ChiChi (Figure 3.1). The focal mechanism calculated by the Institute of Applied Geology (National Central University) indicates reverse with minor left lateral motion on a $\mathrm{N} 26^{\circ} \mathrm{E}$ striking, $27^{\circ} \mathrm{E}$ dipping plane with a slip direction (rake) of 82 on the fault plane (i.e. to the north-northwest, Figure 3.1).

Surface rupture occurred on the Chelungpu Fault and it extended for $83 \mathrm{~km}$ with a $\mathrm{N}-\mathrm{S}$ trend that turned into a ENE to E-W trend at its northern end. Surface rupture has been mapped by the Central Geological Survey (1:25,000 scale) and by the three national Universities (National Central, National Taiwan and National Cheng $\mathrm{Chu}$ ), at a 1:5,000 scale. The fault traces show mainly a reverse with some left lateral displacements that range from $0.60 \mathrm{~m}$ of almost purely dip-slip in the south (near Tungtou to $1 \mathrm{~m}$ horizontal and 1.5 $\mathrm{m}$ vertical at Mingchien to $8 \mathrm{~m}$ of vertical displacement at Shihkang (Figure 3.1)

The morphology of the surface rupture varies along the fault trace. Dense urban development in much of the area obscures the natural morphology of the fault scarp in some cases, and in other cases part of the scarp had already been removed by the time this visit was undertaken. The surface morphology of the Chelungpu fault surface rupture had many similarities with surface trace morphologies observed in other historical reverse fault events (e.g. 7 December 1988 Spitak earthquake, Armenia, Philip et al. 1992). Scarp morphologies of Types A, C, D, E and F of Philip et al. 1992, (Figure 3.2) were recognised along the Chelungpu fault. A Type A morphology was observed at Shihkang where the scarp ruptures the bedrock and forms a $7 \mathrm{~m}$ high waterfall in the Tachia River (Figure 3.3). The fault scarp close to the Yijiang Bridge, Tsaotun (Figure 3.4) is similar to Type C. The fault scarp at Mingchien, north of the Chosui river (Figure 3.5) is similar to Type F. The tension cracks on the sports field at Tsaotun (Figure 3.6) are very similar to the normal faults on the hanging wall of morphology Type $D$. 


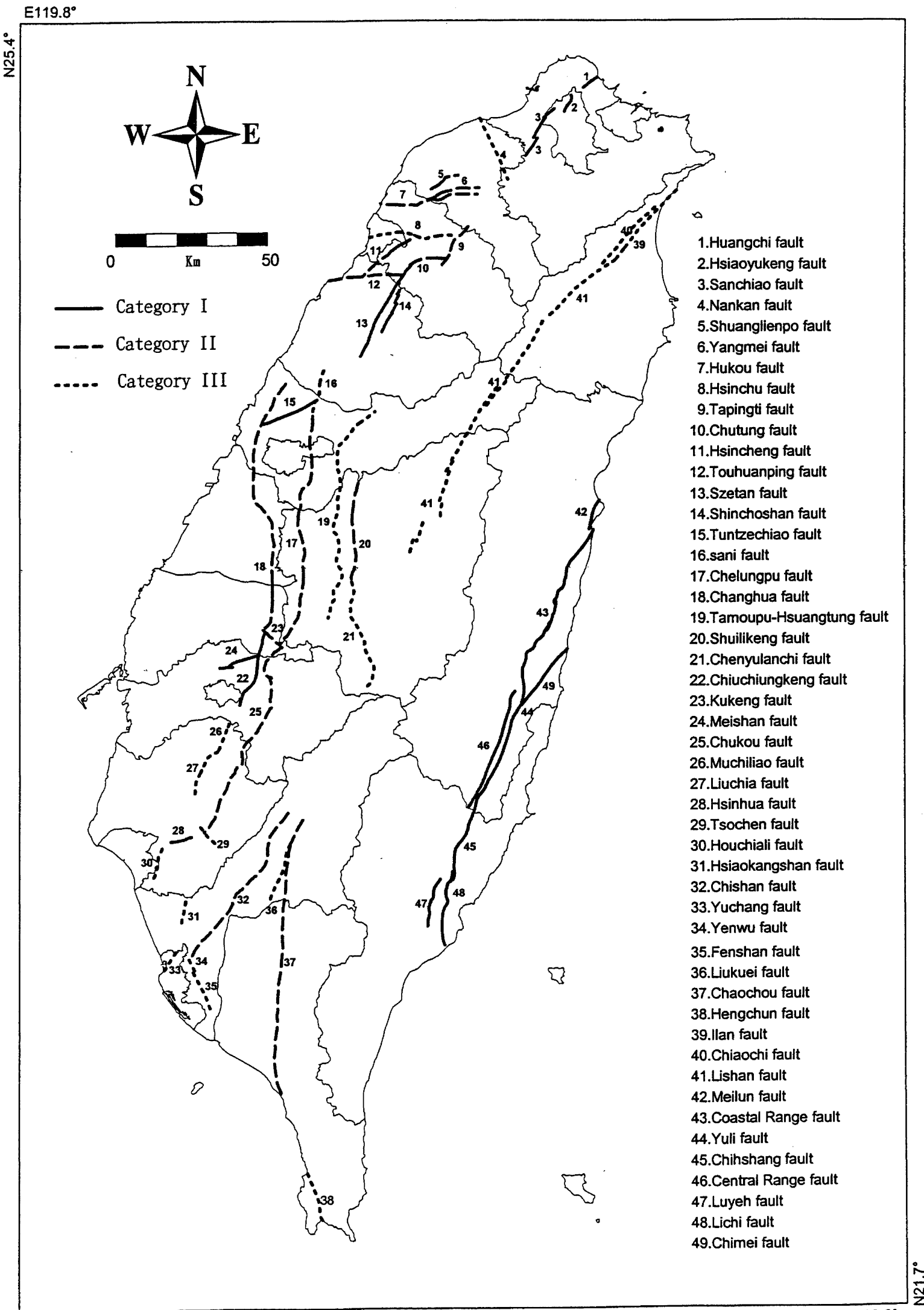

E122. $6^{\circ}$

Figure 2.5: $\quad$ Active faults in Taiwan (provided by the Institute of Applied Geophysics of the National Central University of Taiwan). 


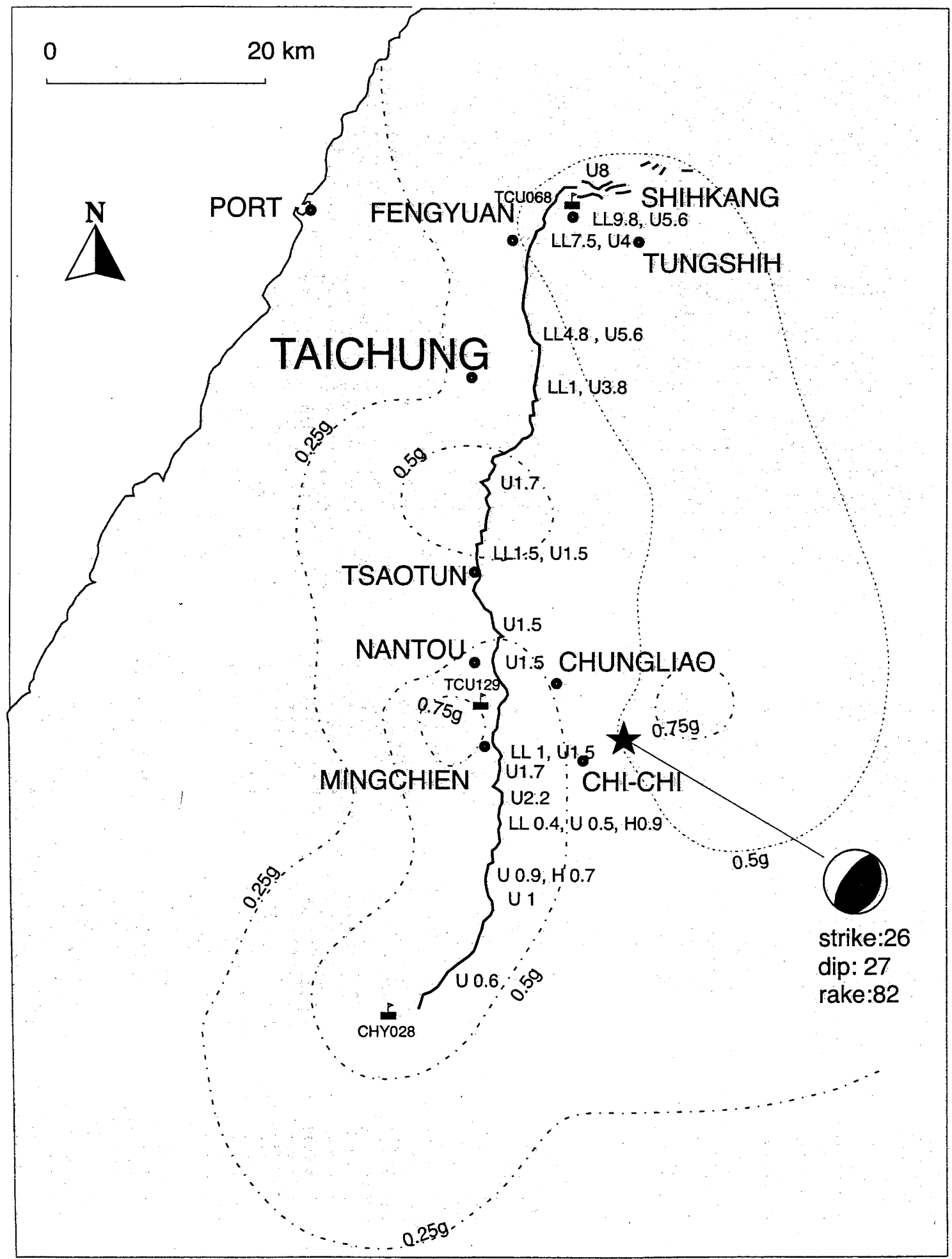

Figure 3.1: 1999 Chelungpu fault surface rupture (solid black line); fault displacement (U, uplift; H, horizontal; LL, left lateral; in metres); peak ground acceleration (dashed lines are pga contours and epicentre location (star), aftershocks and strong motion data (provided by the Institute of Applied Geophysics of the National Central University of Taiwan). 


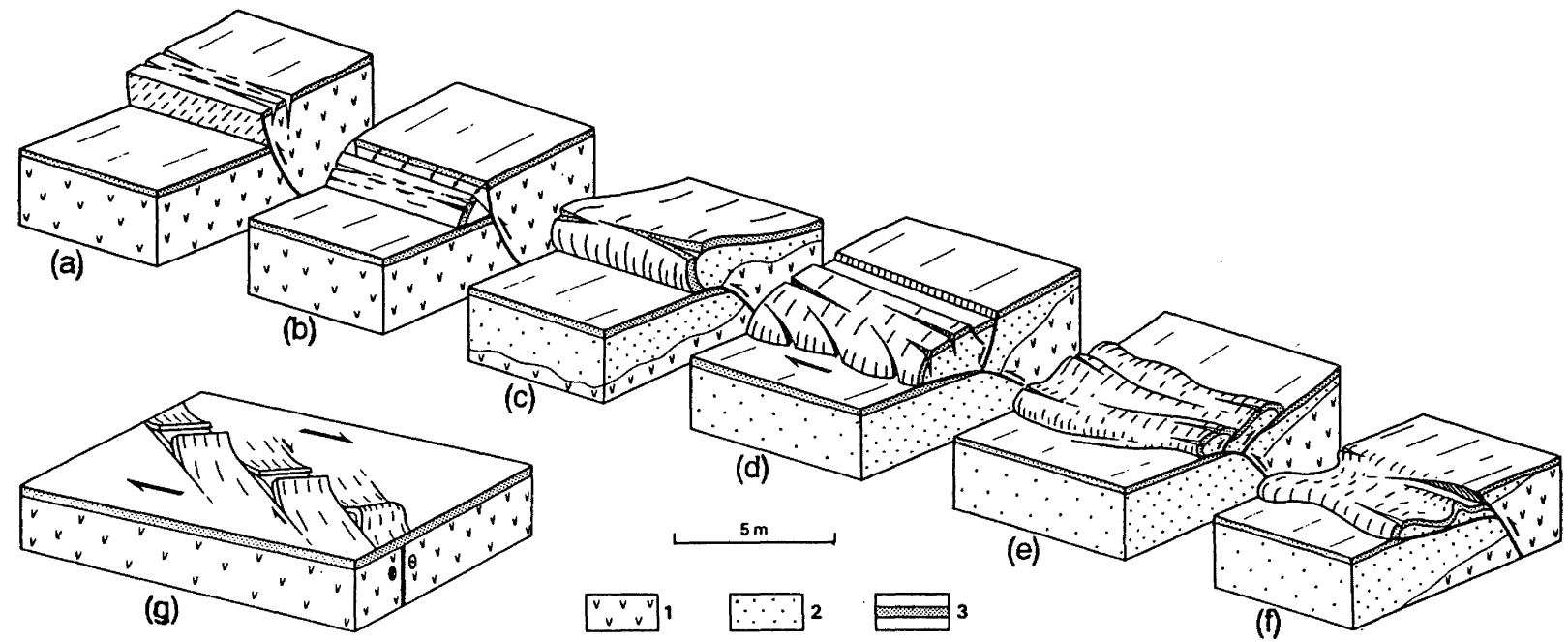

Figure 3.2: $\quad$ Fault-scarp morphology along the Spitak fault, 7 December 1988 El Asnam earthquake, Armenia (from Philip et al. 1992).

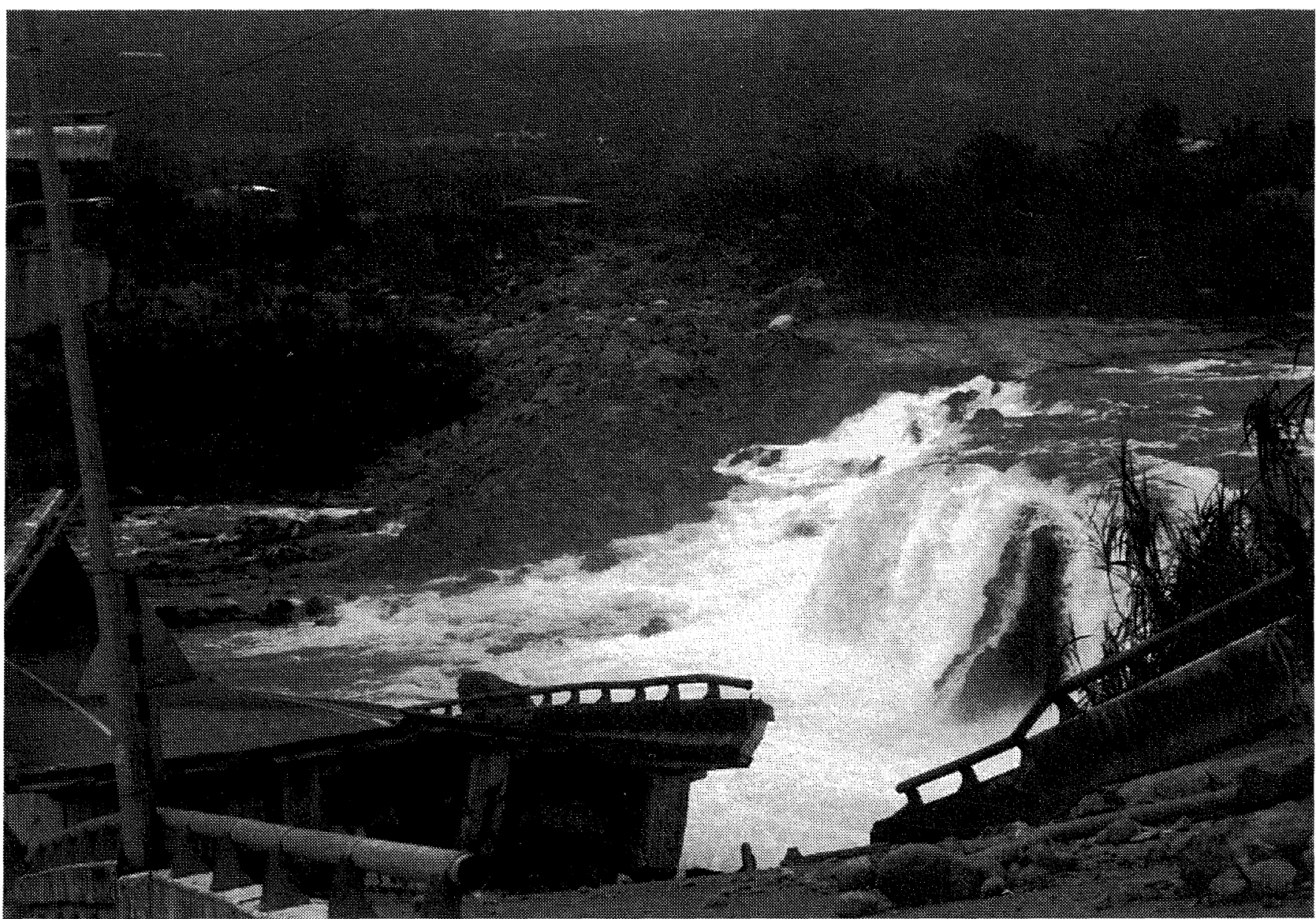

Figure 3.3: $\quad$ New waterfall formed due to the Chelungpu fault surface rupture, Tachia River. Fault scarp height is $7 \mathrm{~m}$. 


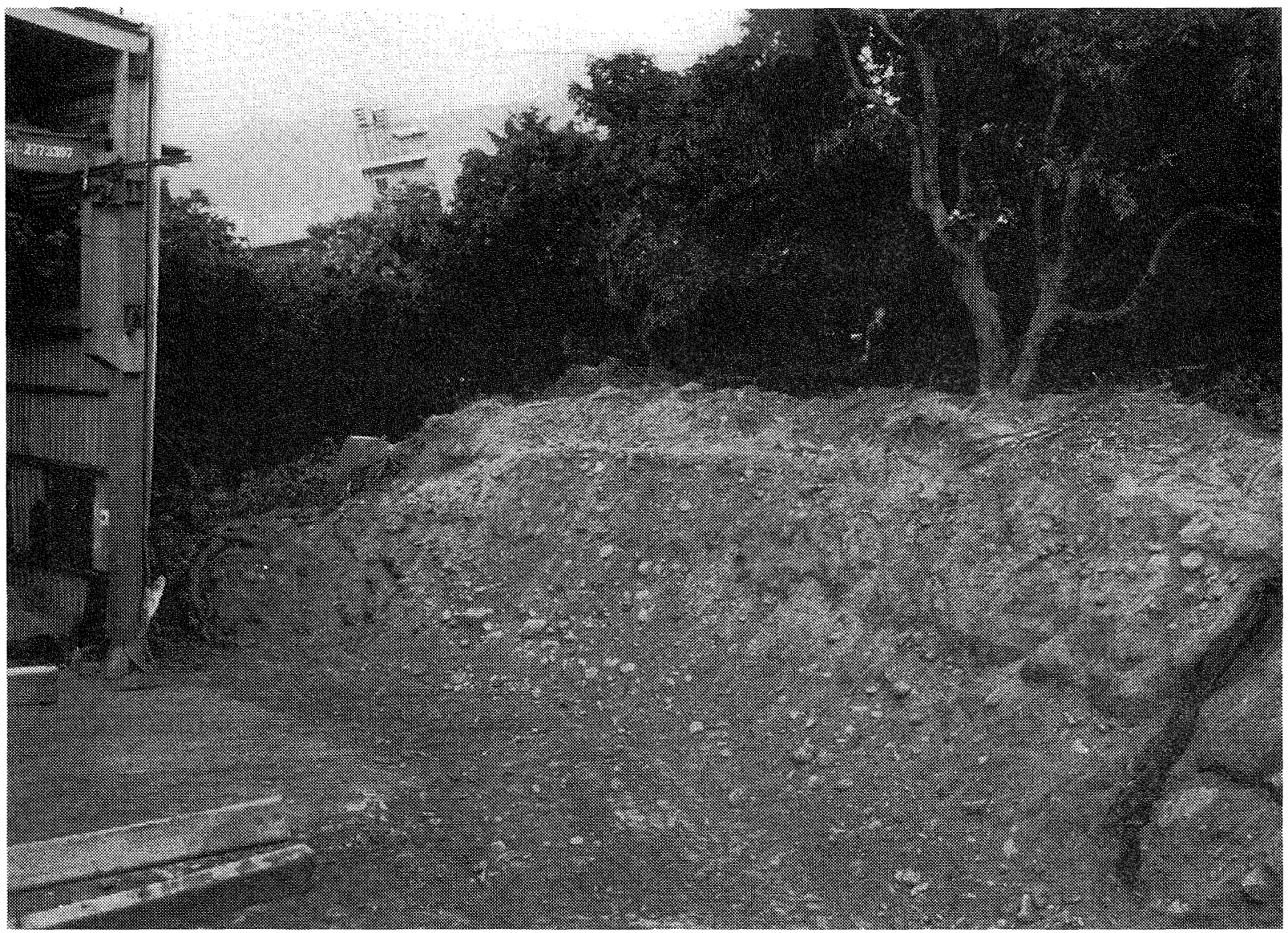

Figure 3.4:

Fault scarp at Yijiang Bridge, Tsaotun. Note drag fold.



Figure 3.5: $\quad$ Fault scarp at Mingchien. 


\section{2}

\section{Strong-motion Records}

Taiwan established a nation-wide network of modern digital strong-motion recorders in 1996. It is operated by the Seismological Center of the Taiwan Central Weather Bureau (CWB) (Wu et al., 1997). The network consists of about 700 digital accelerographs in free field sites, all of which record data in trigger mode, and 56 arrays in building and bridges. Data from 61 of the free-field sites are continuously telemetered to the CWB headquarters in Taipei. Each structural array has up to 60 acceleration channels, and one 3component accelerometer on the ground outside the structure whenever possible. All of the digital accelerographs have telephone modems for remote access and about half of them are capable of producing a continuous digital data stream for easy telemetry. CWB also maintains a realtime digitally telemetered seismic network of 80, 3-component, short period stations.

The strong-motion network is a very impressive network for a small island. In comparison, New Zealand, which has an area 7 times that of Taiwan, has a strong-motion network with only 110 digital accelerographs and 170 analog accelerographs. Apart from the largely inaccessible Central Mountain Range (up to nearly $4,000 \mathrm{~m}$ ) where there are very few instruments, the Taiwanese strong-motion network is the densest network of digital strong-motion instruments in the world, with the station spacing of the free-field accelerographs being only about $3 \mathrm{~km}$ in metropolitan areas.

The Chi-Chi earthquake and its major aftershocks produced a comprehensive set of near-field strong-motion records. At least 12 strong-motion records were obtained from within 10 $\mathrm{km}$ of the fault rupture for the main shock, and perhaps a similar number for each of the eleven aftershocks with local magnitude greater than 6.0. Two of the aftershocks were similar in size to the 1994 Northridge main shock of $\mathrm{M}_{\mathrm{w}}=$ 6.7 .

The largest horizontal peak ground acceleration (PGA) was $1.01 \mathrm{~g}$, at an epicentral distance of about $10 \mathrm{~km}$ (station TCU084). It was accompanied by a vertical PGA of $0.32 \mathrm{~g}$. The largest vertical PGA of $0.53 \mathrm{~g}$ was recorded at a station near the northern end of the fault surface rupture (station TCU068), accompanied by a horizontal PGA of $0.51 \mathrm{~g}$ (Figure 3.1). The recorded PGAs are compared with two attenuation models, one by Abrahamson (similar to that by Abrahamson and Silva 1997) and one from an unknown Taiwanese author for the NS and EW components respectively. This comparison shows that the EW components (strike-normal) from the near-field records (within about $10 \mathrm{~km}$ ) are on average larger than the NS components (strike-parallel). This is consistent with previous findings (Somerville et al. 1997).

Figures 3.7 - 3.9 show the acceleration time histories recorded at 3 stations: CHY028 at the southern end of the fault surface rupture, TCU129 at the lower middle part close to the epicentre, and TCU068 at the northern end of the fault surface rupture trace, as shown in Figure 3.1. The fault rupture initiated at the epicentre close to Station TCU129 at a depth of $11 \mathrm{~km}$ and from there propagated both north and south. The records from the three stations are interesting because they demonstrate fault directivity effects.

The record from station CHY028 has a relatively short period of duration for strong shaking, for example, much less than $10 \mathrm{~s}$ for acceleration peak values larger than $0.15 \mathrm{~g}$. The strong shaking is possibly associated with the southernmost part of the fault rupture, with the seismic waves associated with the middle and the northern parts of the fault being attenuated considerably after travelling more than $30 \mathrm{~km}$. A preliminary fault rupture process can be found from http:Iwww.eic.eri.u-tokyo.ac.jp/yuji/tai/tai.html.

The duration of ground shaking over $0.15 \mathrm{~g}$ of more than $25 \mathrm{~s}$ recorded at station TCU129 near the lower middle part of the fault surface rupture is noticeably longer than those of the records from the other two stations. Accelerations over $0.4 \mathrm{~g}$ are however nearly all short period spikes. The long duration of moderate shaking is possibly due in part to backward directivity effects (Somerville et al, 1997) from the northpropagating part of the rupture.

Two notable features of the TCU068 record (obtained at the northern end of the fault surface rupture) are its relatively simple waveforms and the very long period of the strongest ground motions for all 3 components compared with the other two records. Appropriate integration of this record results in a very simple long-period velocity pulse with a peak ground velocity of about $2.8 \mathrm{~m} / \mathrm{s}$ and a permanent ground displacement of the order of $6 \mathrm{~m}$ (presentation by Institute of Earth Sciences, Academia Sinica, Taipei, October, 1999). Long period motions and large velocity pulses are common features of the records obtained from the near-field stations at the northern end of the fault surface rupture, and presumably result from forward directivity effects (Somerville et al. 1997).

The seismic load-zoning map for Taiwan is shown in Figure 3.10 (taken from the Taiwan seismic design code). Much of the most strongly shaken and most heavily damaged areas of the Chi-Chi earthquake were within the Zone-2 region. Figure 3.11 shows the elastic design spectrum for Zones-1 A and 2 for the Taiwanese equivalent of the New Zealand "ground class B", and the design spectrum of NZS4203 for a zone factor of 1.2 (the highest value for NZ) for ground class B. The Taiwanese Zone-2 design spectrum is much smaller than that of NZS4203 with a zone factor of 1.2. For period up to $1.8 \mathrm{~s}$ the Zone-1A design spectrum for Taiwan is also smaller than that of NZS4203 for the northern part of the South Island and the southern part and the eastern coast of the North Island. However, caution needs to be exercised in interpreting design spectra from different codes, because the lower design spectrum in the Taiwan code may not necessarily result in a lower value of seismic load applied to a structure after many other parameters are applied.

Figures $3.12-3.14$ show the $5 \%$ damped response spectra for the records shown in Figures $3.7-3.9$ and the design spectrum of Zone- 2 in the Taiwanese design code. As a comparison, the $5 \%$ response spectrum of the Sylmar record (NS component) from the 1994 Northridge earthquake $\left(\mathrm{M}_{\mathrm{w}}=\right.$ 6.7) at a source distance of $7.6 \mathrm{~km}$ is also shown in Figures $3.12-3.14$. A general feature is that the spectra from the Taiwanese records are much higher than the design spectrum for the area at nearly all periods and this has been attributed as part of the reason for the signiticant structural damage (Loh et al., 1999). Another feature is that the spectra from the Taiwanese records up to $2.0 \mathrm{~s}$ spectral period are generally comparable with or smaller than that of the NS component of the Sylmar record even though the Sylmar record is from a much smaller event. This is also true for many other near-source records from the Chi-Chi earthquake. 


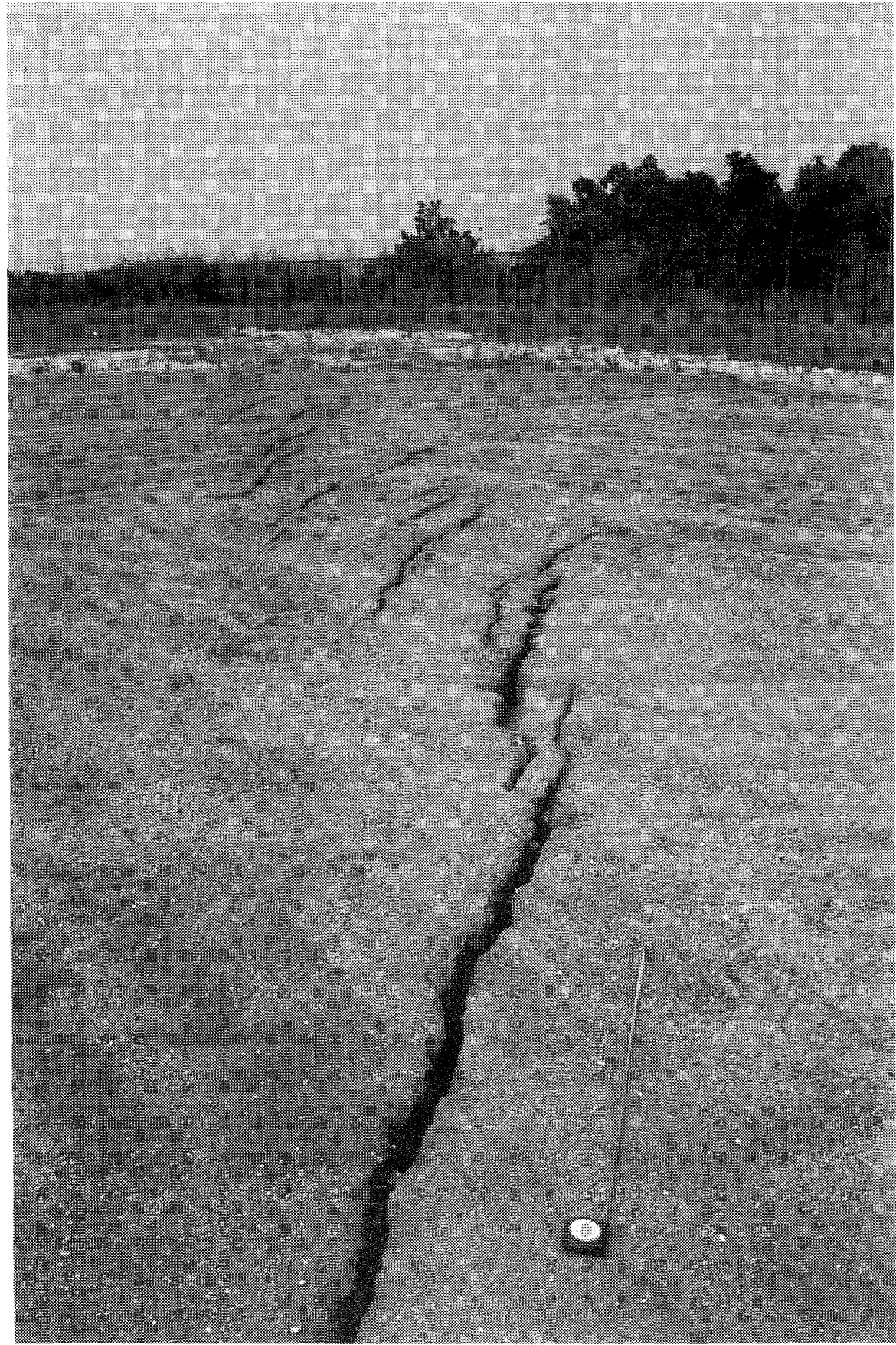

Figure 3.6: $\quad$ Tension cracks on the hanging wall of the Chelungpu fault at Tsaotun. 

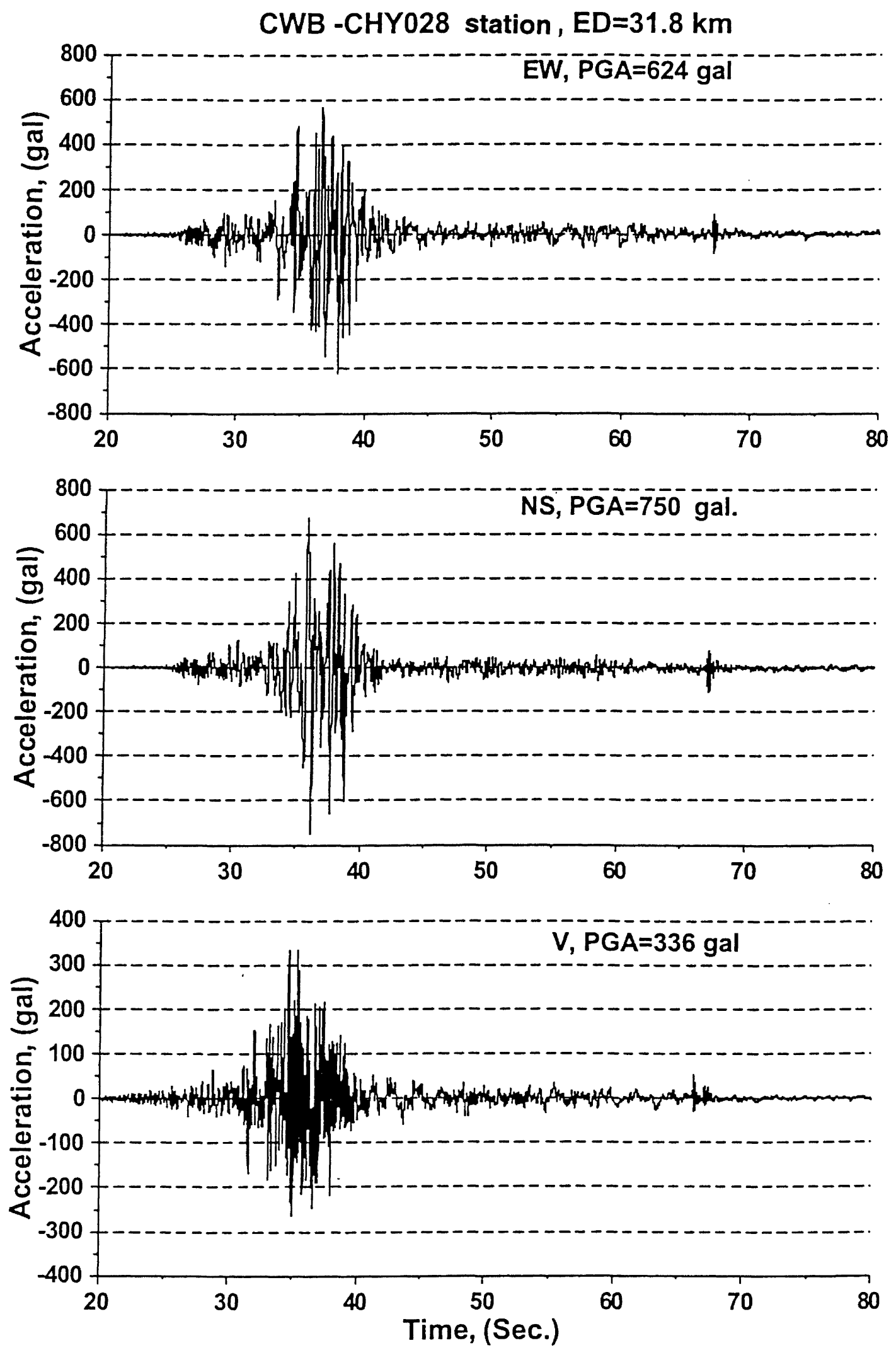

Figure 3.7: $\quad$ Acceleration time history for the record obtained at station CHY028, at the southern end of the surface fault rupture. 

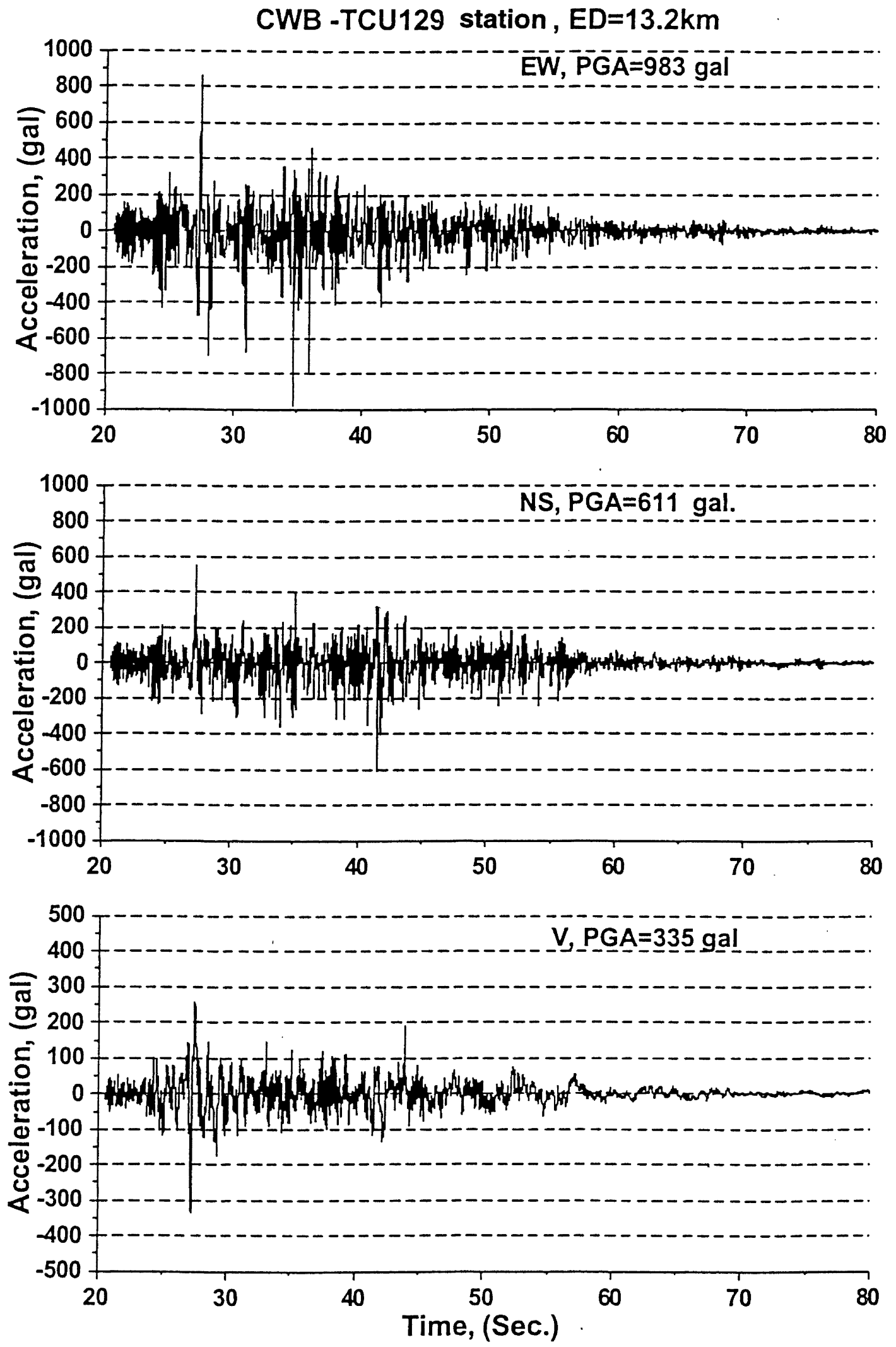

Figure 3.8: $\quad$ Acceleration time history for the record obtained at station TCU129, at the lower middle part of the surface fault rupture. 

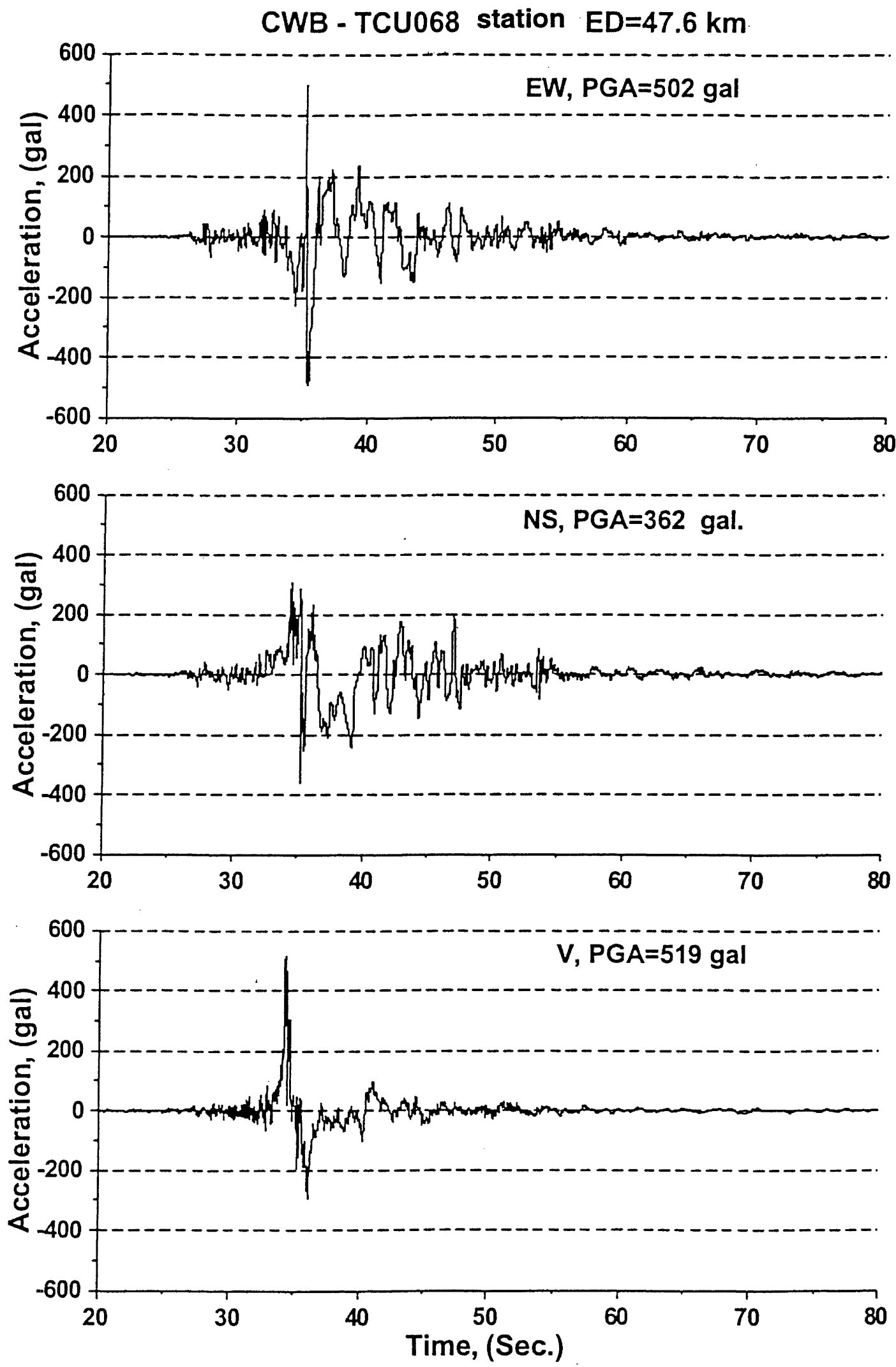

Figure 3.9: $\quad$ Acceleration time history for the record obtained at station TCU068, at the northern end of the surface fault rupture. 


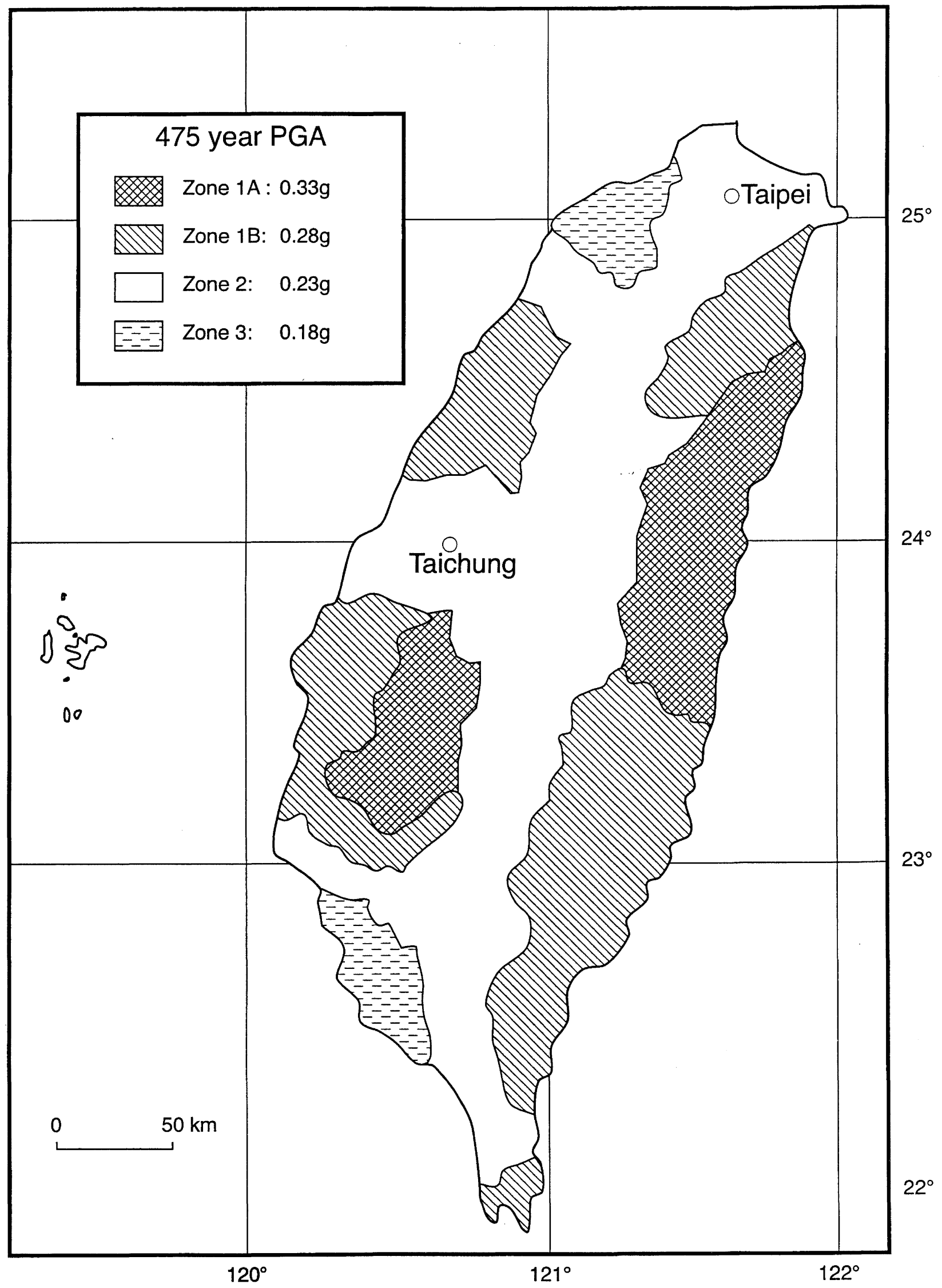

Figure 3.10: $\quad$ Zoning map for the design spectrum for the 1997 Taiwan design code. The white area is Zone 2, which includes most of the severely damaged areas. 


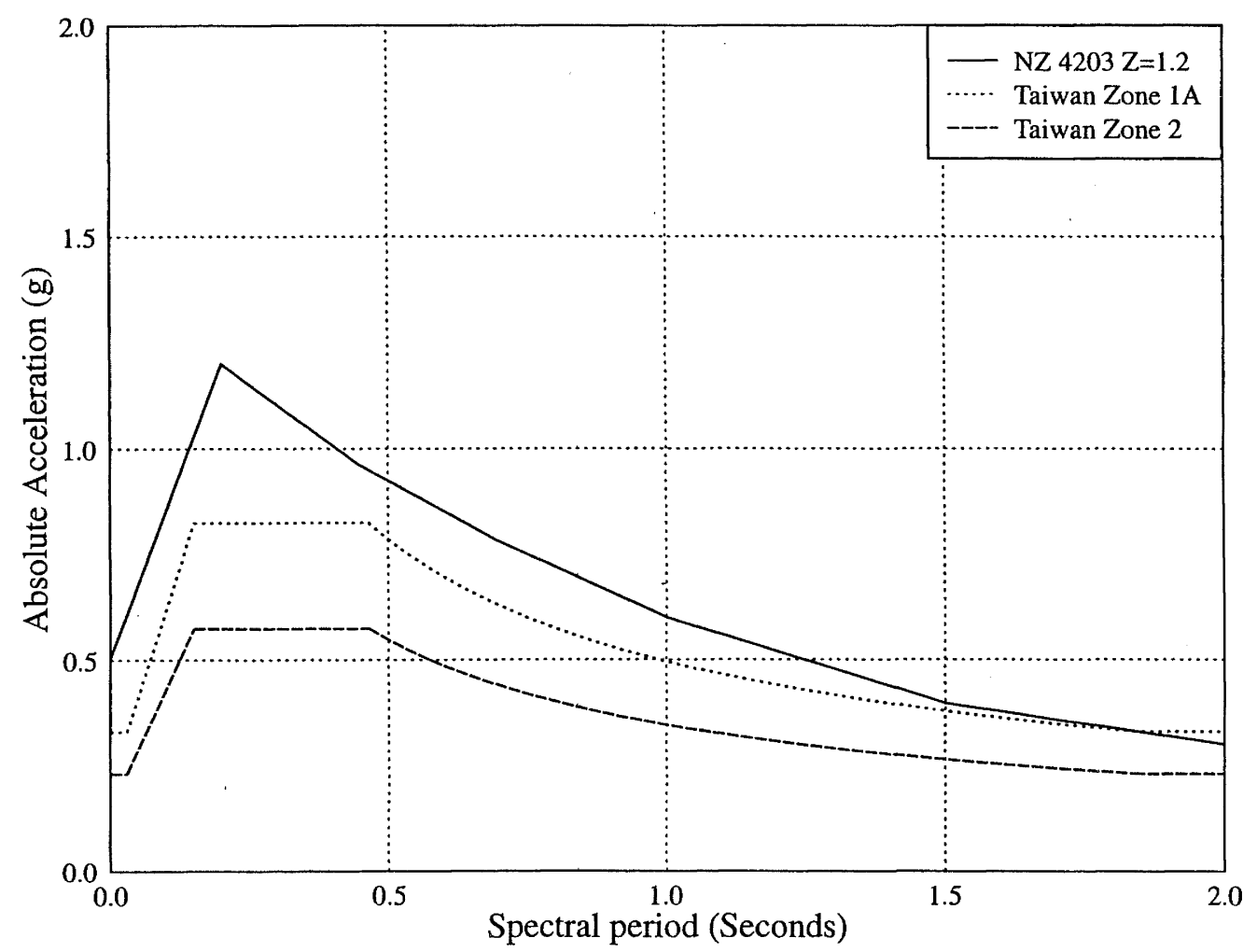

Figure 3.11: $\quad$ Comparison of design spectrum for Zone 1A and Zone 2 in Taiwan with that for New Zealand with a zone factor of 1.2.

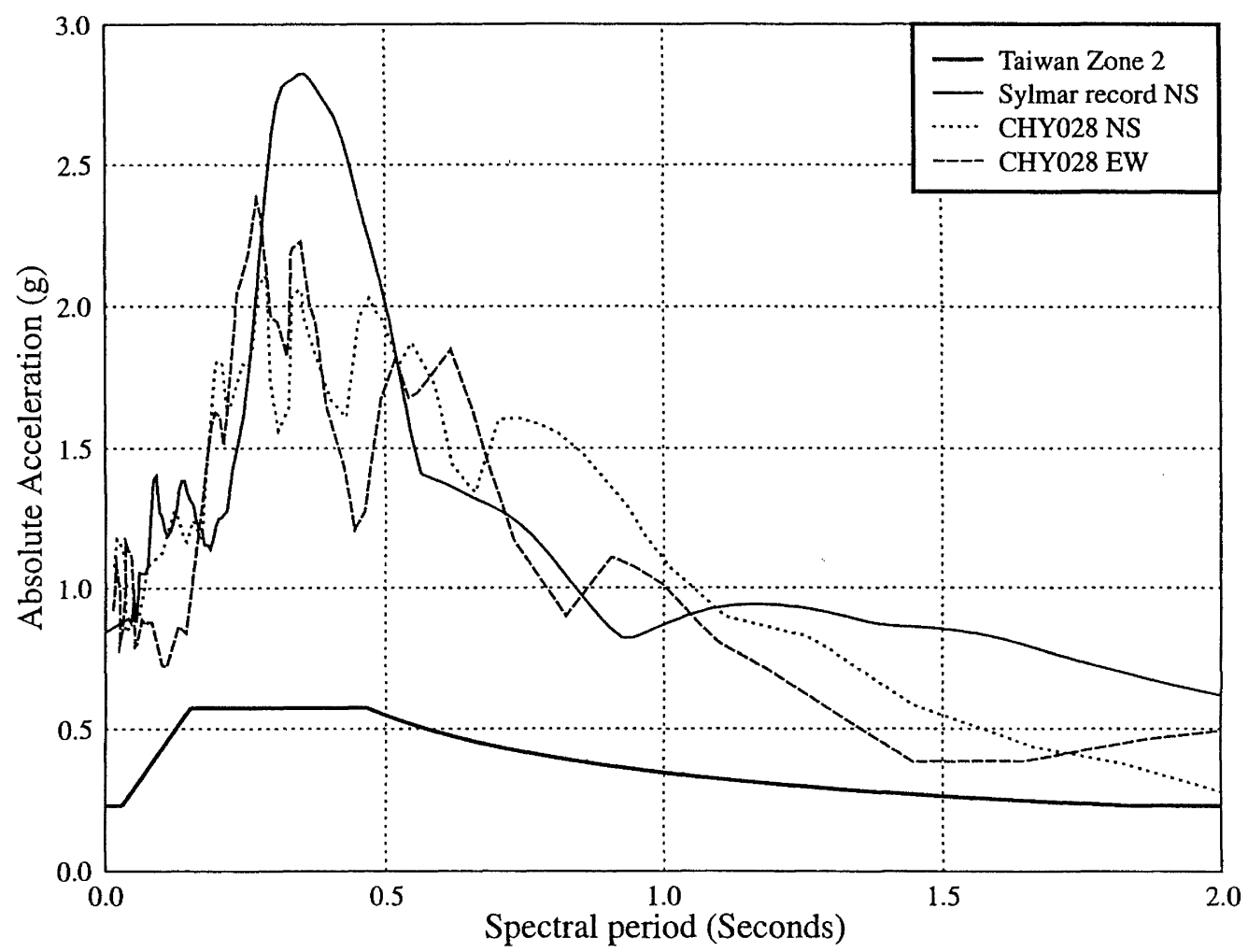

Figure 3.12: $\quad$ Comparison of 5\% damped spectra for the CHY028 record with that of the Sylmar record from the 1994 Northridge earthquake and the Zone 2 design spectrum. 


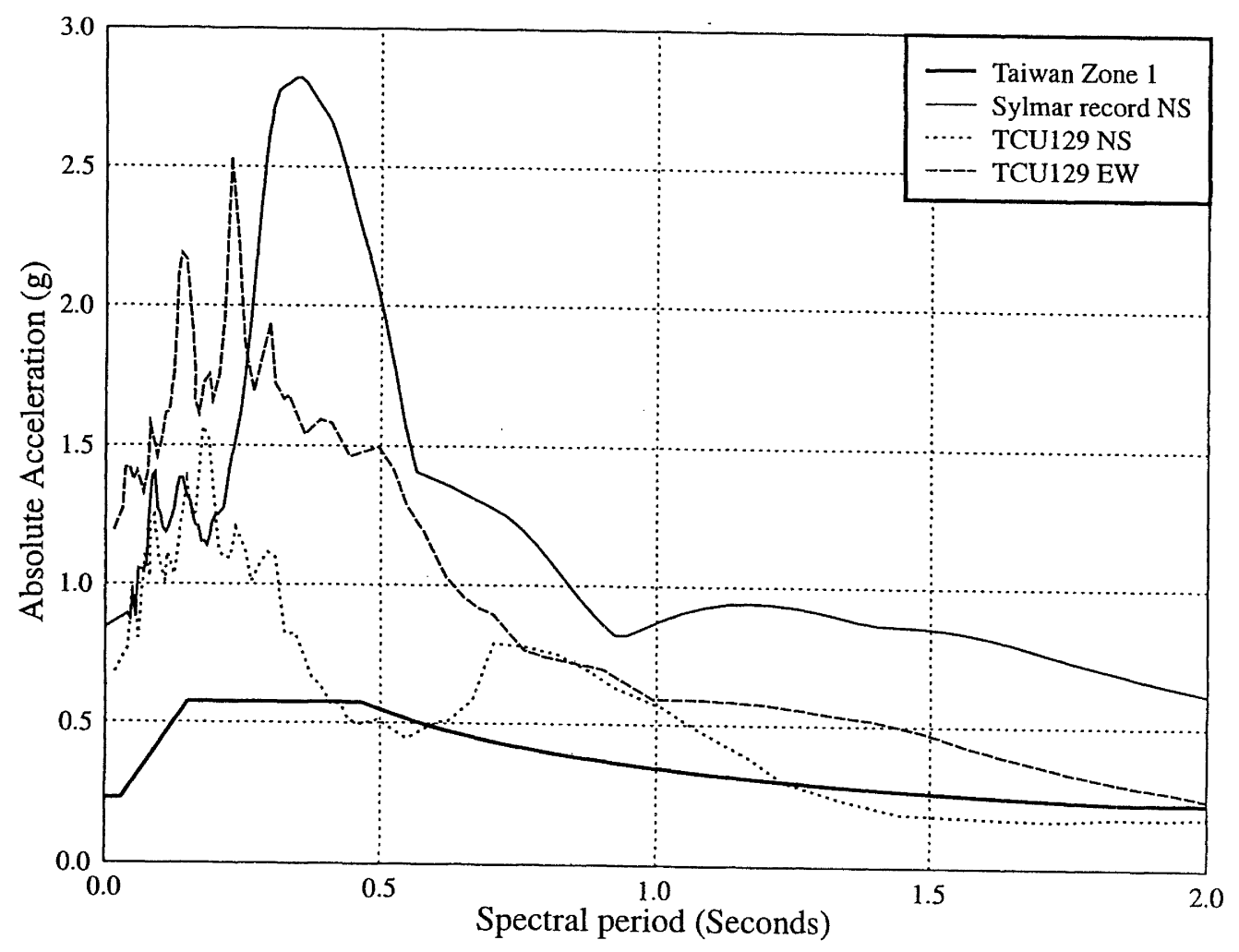

Figure 3.13: $\quad$ Comparison of 5\% damped spectra for the TCU129 record with that of the Sylmar record from the 1994 Northridge earthquake and the Zone 2 design spectrum.

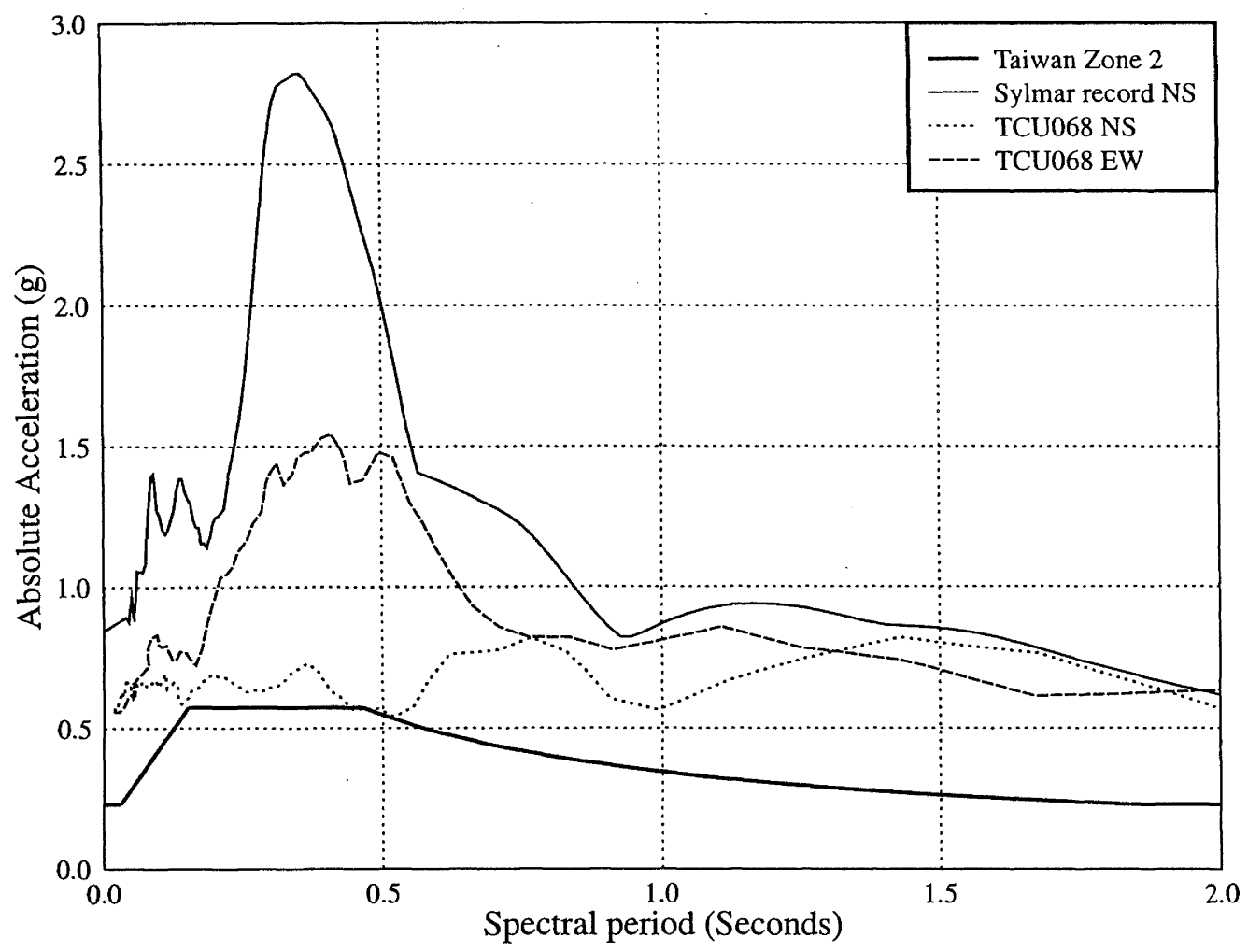

Figure 3.14: $\quad$ Comparison of 5\% damped spectra for the TCU068 record with that of the Sylmar record from the 1994 Northridge earthquake and the Zone 2 design spectrum. 
At spectral periods beyond $2.0 \mathrm{~s}$, we would expect very large spectral values from many of the near-source records from Taiwan, judging from the long period motions in the acceleration time history plots (the digital forms of which were not available at the time of writing this report).

At the southern end of the fault surface rupture (Station CHY028), the response spectra for both components are generally similar and are comparable in amplitude with that of the Sylmar record. The mean values of the spectra at periods up to $1.0 \mathrm{~s}$ are 2.5-3 times the design spectrum.

At the lower middle part of the fault surface rupture (Station TCU129), the spectrum of the EW component is larger than that of the Sylmar record at short periods up to about $0.3 \mathrm{~s}$. For the other periods up to $2.0 \mathrm{~s}$, the spectra of both components are significantly smaller than the Sylmar spectrum. For most periods, the spectrum for the EW component is much larger than that for the NS component, possibly caused by strike-normal effect (Somerville et al., 1997).

At the northern end of the fault surface rupture, the NS component of the record from Station TCU068 has an almost flat spectrum between 0 and $2.0 \mathrm{~s}$ periods. At periods less than 1.0 seconds, the spectra from this site are much smaller than that of the Sylmar record and become similar to the Sylmar spectrum at periods from 1.0 to $2.0 \mathrm{~s}$. The permanent horizontal displacement was of the order of $7 \mathrm{~m}$ in the EW direction and $5 \mathrm{~m}$ in the NS direction at this site. These very large permanent displacements suggest that the spectra at long periods beyond $2.0 \mathrm{~s}$ could be very large. By contrast, the permanent displacements at the other two stations were much smaller. At periods in the range $0.2-1.0 \mathrm{~s}$, the spectrum for the EW component is larger than that for the NS component. The code design spectrum is again much smaller than the record spectra at most periods.

The areas adjacent to Stations TCU129 and TCU068 have been reported as heavily damaged areas.

Detailed information on site conditions at the above strongmotion sites is not yet available, hence it is presently not possible to say whether or not some of the features of the acceleration time histories and response spectra may at least partially have been due to site effects.

It has also been reported that ground motions obtained at stations from the hanging wall of the fault are generally larger than those from the foot wall (NCREE presentations, Taipei), which is consistent with previous findings in attenuation modelling of near-source ground motions (Abrahamson and Silva, 1997). Loh and Tsai (1999) also reported that the amount of building damage on the hanging wall was generally greater than that on the foot wall.

\subsection{Ground Response}

\section{Landslides}

The earthquake triggered landslides which caused damage to roads and bridges and destroyed homes. Local geologists reported over 2,000 landslides were triggered by the earthquake. Landslides generally occurred on steep slopes in areas with PGA greater than $0.4 \mathrm{~g}$. No landslides were reported where the PGA was less than $0.2 \mathrm{~g}$.
Large areas in the mountains were denuded of vegetation by shallow slips with one feature covering 15 sq. $\mathrm{km}$. Local geologists also reported the formation of the Tsaolin landslide dam. The feature was $32 \mathrm{~km}$ from the epicentre and $5.7 \mathrm{~km}$ from the fault trace. The feature occurred on a dip slope in shale and was reported to be $200 \mathrm{~m}$ thick, covering 6.3 sq. $\mathrm{km}$. Earthquakes and heavy rain have triggered previous landslides at this location. An earlier landslide dam failed in 1942 killing 154 people. Foster and Campbell (2000) contains a more detailed description of this landslide area. At the time of the reconnaissance, a lake had formed behind the landslide. The formation of the lake has the potential to cause a major new hazard for downstream people and facilities.

The reconnaissance team assessed damage to roads by logging landslides on a $5 \mathrm{~km}$ section of rural road from the coastal plain into the western foothills. Slips partially blocking the road were observed every $500 \mathrm{~m}$ and three of these were considered large enough to have caused a temporary road closure. The reconnaissance team visited a mountain village where landsliding had destroyed several houses. The landslide were in elevated quaternary terraces on slopes which were $30-35^{\circ}$ (refer Figure 3.15).

\section{Liquefaction}

Liquefaction damage was observed during the reconnaissance visit to the city of Nantou, situated about $10 \mathrm{~km} \mathrm{NW}$ of the epicentre and $2 \mathrm{~km}$ from the fault trace. The PGA at this location is estimated to have been $0.3 \mathrm{~g}$. Buildings or sealed roads and footpaths cover most of the land in Nantou. The area was visited 19 days after the earthquake but sand ejecta was still obvious in many streets and in some cases was 'splattered' up the walls of the buildings (refer Figures 3.16 and 3.17).

A liquefaction-induced settlement of up to $1 \mathrm{~m}$ was observed in a multi-storey apartment building, and in traditional 3 storey 'up to heaven' buildings settlements of $300 \mathrm{~mm}$ were observed. Local geotechnical engineers reported similar liquefaction damage in the city of Yaunlin some $50 \mathrm{~km}$ from the epicentre. They also reported liquefaction damage in the lower reaches of the Choshui River Valley and at Taichung Harbour northwest of Taichung. Damage to the port is outlined in Section 7.2.

Liquefaction damage was also observed at several bridge abutments. Typically, damage included 150-200 $\mathrm{m}$ of settlement at approach fills and the formation of 'tomos' behind the abutment (refer Figure 3.18).

The Chi-Chi earthquake is the first time liquefaction has been observed in Taiwan. Extensive follow up investigations and research are planned and should lead to advances in the understanding of liquefaction-induced damage. A liquefaction hazard map for the Taipei basin is currently being prepared. It is planned to extend this work to cover the rest of Taiwan.

\section{Ground Deformation}

Ground deformation was the most dramatic cause of damage in the earthquake. This was a consequence of the nature of the fault and because much of the $83 \mathrm{~km}$ long fault trace passed through a built-up area. Figure 3.2 shows a typical 
cross-section through a reverse fault. Ground deformation was concentrated on the hanging wall side of the fault and this is the reason why damage was concentrated in this zone. The large vertical displacements which occurred on the fault caused catastrophic damage to building bridges and dams. It is impractical to design structures to survive the degree of ground deformation observed in this event. The impact of ground deformation on buildings is shown in Figures 3.19 and 3.20. The general shape and extent of deformation on the hanging wall of the fault shows in the road surface and in the roof-line of buildings. Two dramatic examples of ground deformation damage occurred near Shih-kang where the vertical displacement of the fault was 7 to $8 \mathrm{~m}$. Both a dam (refer Figures 7.1 and 7.2) and highway bridge (refer Figure 3.21 ) were severely damaged. The fault trace has created a waterfall in the river and caused a $7 \mathrm{~m}$ offset in the bridge. The damage to the dam is described in Section 7.1.

\section{Soft Site and Basin Effects}

The city of Taipei is $120 \mathrm{~km}$ north of the northern extent of the fault rupture and is sited in a soft basin. The PGA in the city was generally $0.05 \mathrm{~g}$ but in some locations a PGA of $0.15 \mathrm{~g}$ was recorded. This is attributed to basin edge effects, a phenomenon which occurs when the basin geometry results in a concentration of energy. Several buildings were damaged and some destroyed, and there was loss of life in some locations where basin edge effects caused high accelerations.

\section{$3.4 \quad$ References}

Wu, Y.M., T.C. Shin, C.C. Chen, Y.B. Tsai, W.H.K. Lee and T.L. Teng (1997), "Taiwan rapid earthquake information release system". Seism. Res. Letters, Vol. 68, pp. 931-943.

"Seismic Design Code for Buildings and Commentary" (1997), Ministry of Interior, R.O.C., Taiwan.

NZS4203:1992, "Code of Practice for General Structural Design and Design Loadings for Buildings".

Somerville, P.G., N.F. Smith, R.W. Graves and N.A. Abrahamson (1997), "Modification of Empirical strong-motion attenuation relations to include the amplitude and duration effects of rupture directivity”. Seism. Res. Letters, Vol. 68, No.1, pp. 199-222.

Loh, C.H. et al. (1999), "Preliminary report on Chi-chi earthquake". National Centre for Earthquake Engineering, Taipei, Taiwan (in Chinese).

Abrahamson, N., and W. Silva (1997) "Empirical response spectra attenuation relations for shallow crustal earthquakes". Seism. Res. Letters, Vol. 68, No.1, 94117.

Loh, C.H. and K.C. Tsai (1999), "Building damage survey report". NCREE report series for 921 Chi-Chi earthquake, 17 November 1999 (in Chinese).

Foster, P. and Campbell, G. (2000) NZSOLD Reconnaissance Report Taiwan Dams - March 2000. (Draft in Preparation).

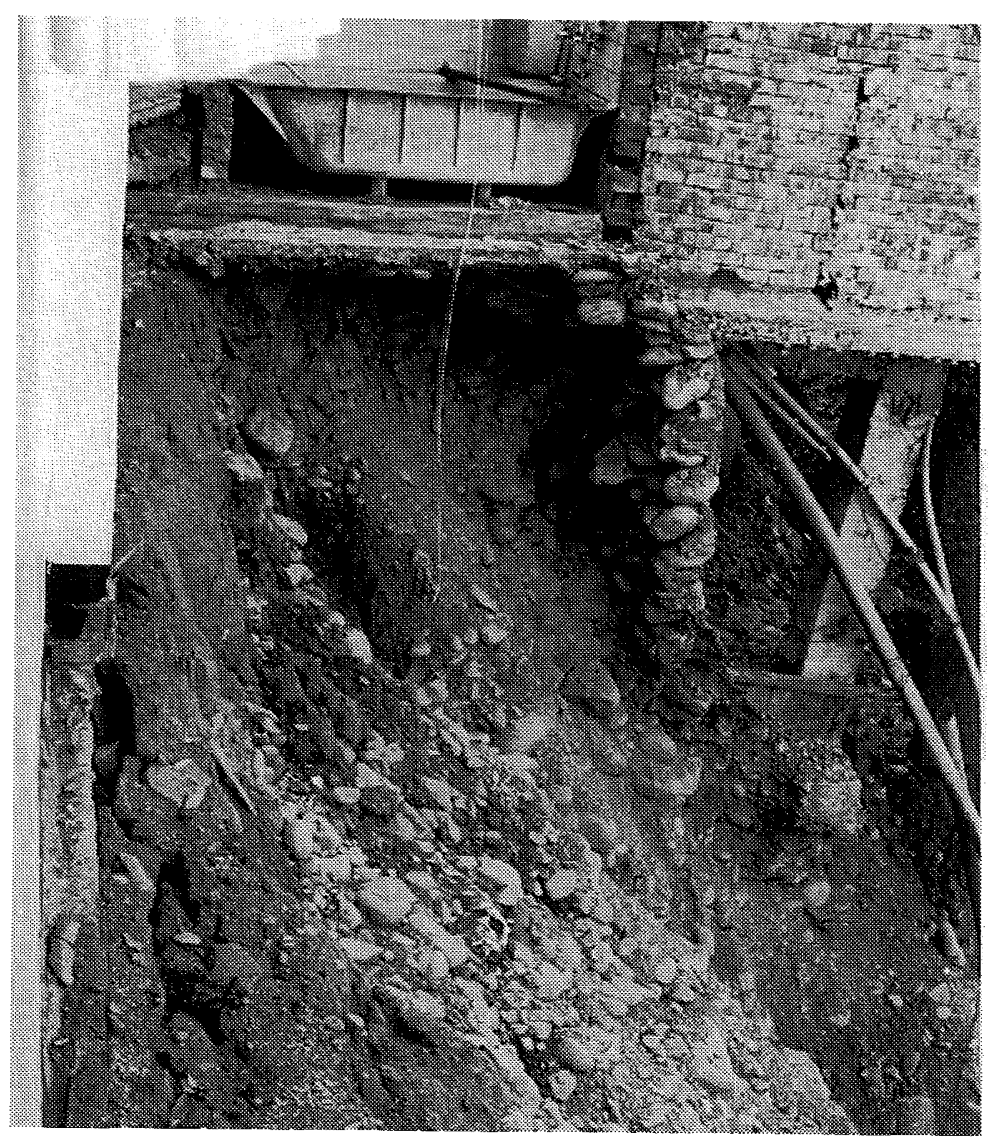

Figure 3.15: $\quad$ Landslide in an elevated quaternary terrace, Chongsing Village. 


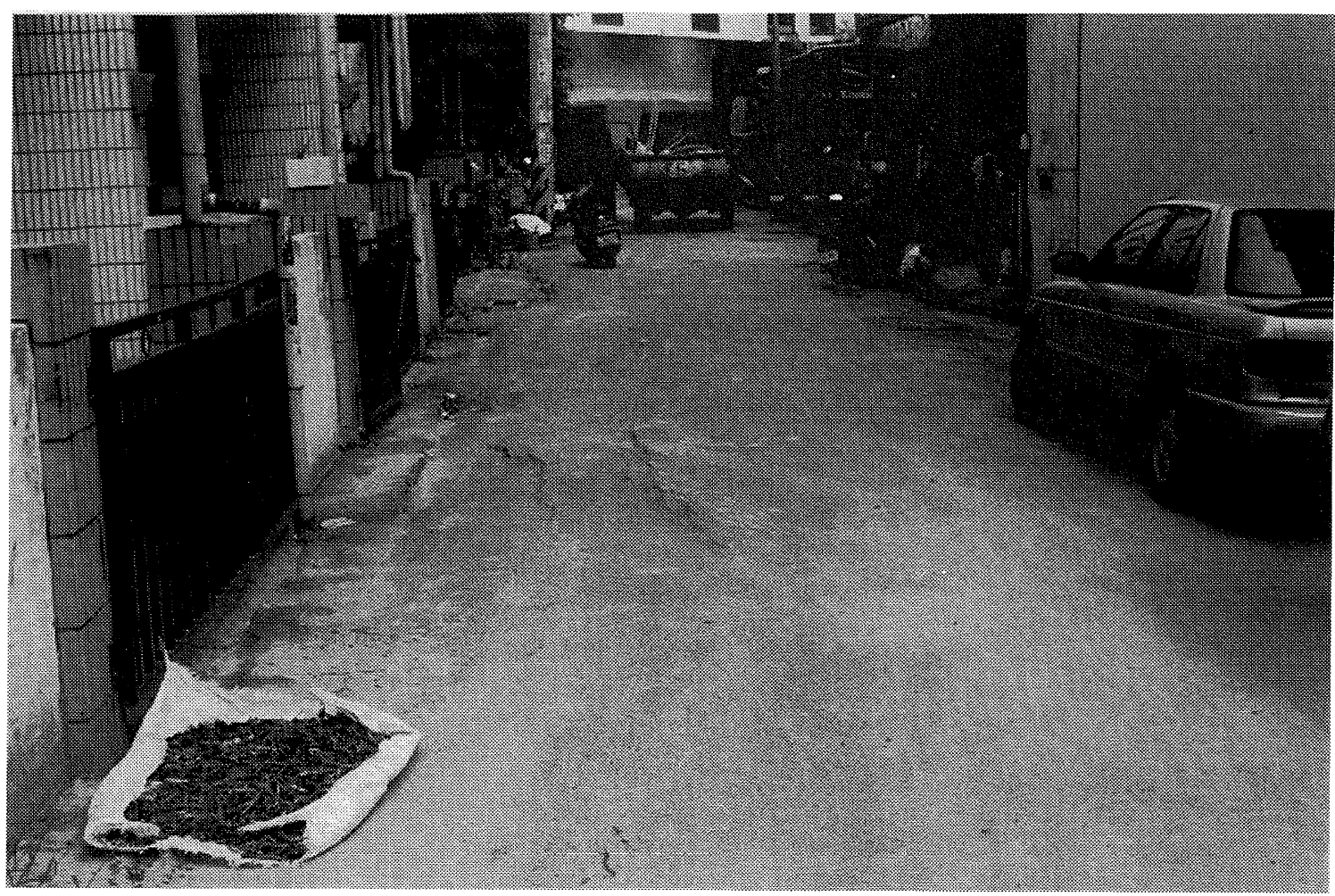

Figure 3.16: $\quad$ Sand ejected from liquefaction features coats the road two weeks after the event, Nantou.

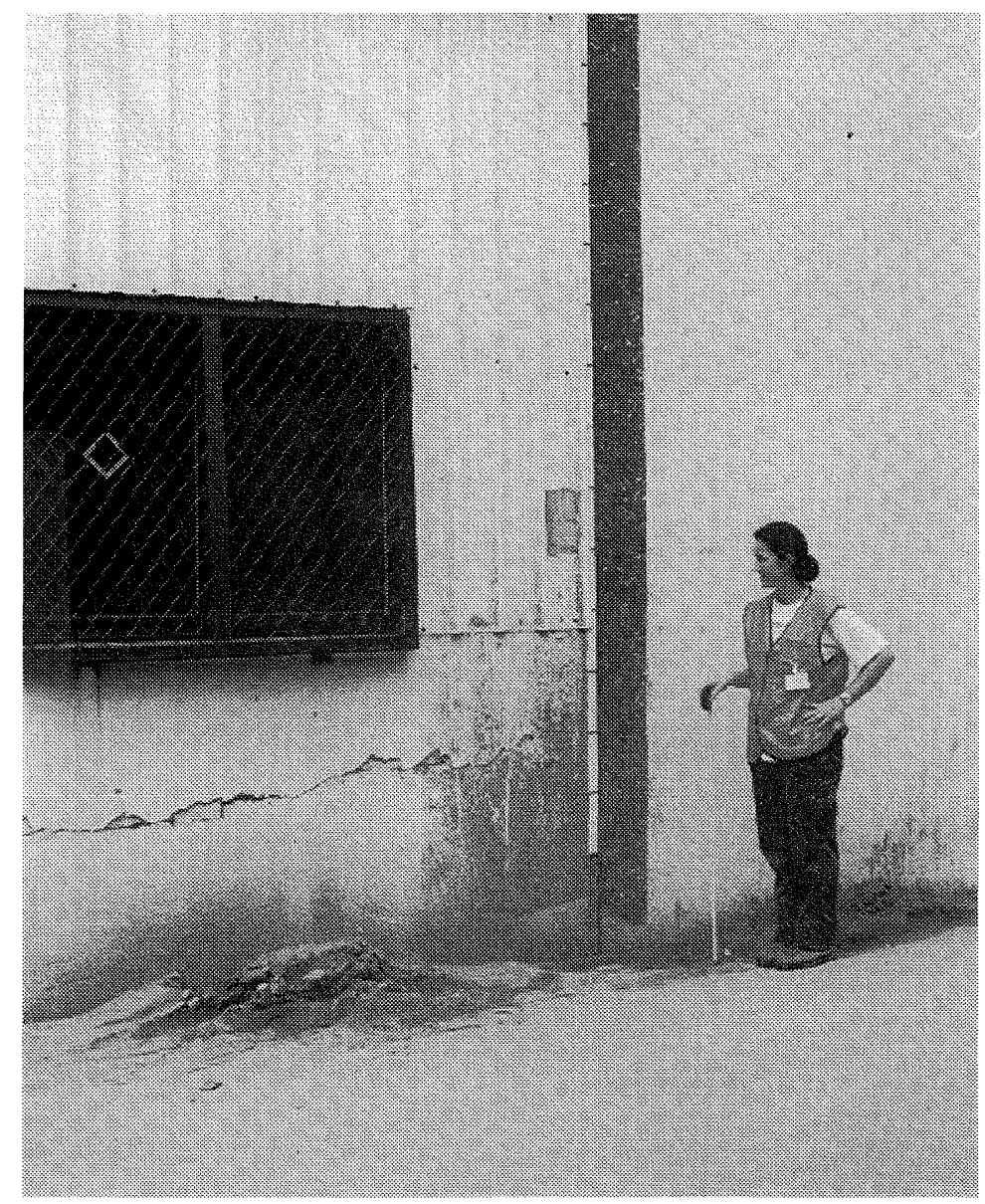

Figure 3.17: $\quad$ Sand ejecta from a sand boil splattered to height of $3.5 \mathrm{~m}$, Nantou. 




Figure 3.18: $\quad$ A typical liquefaction feature behind a bridge abutment.

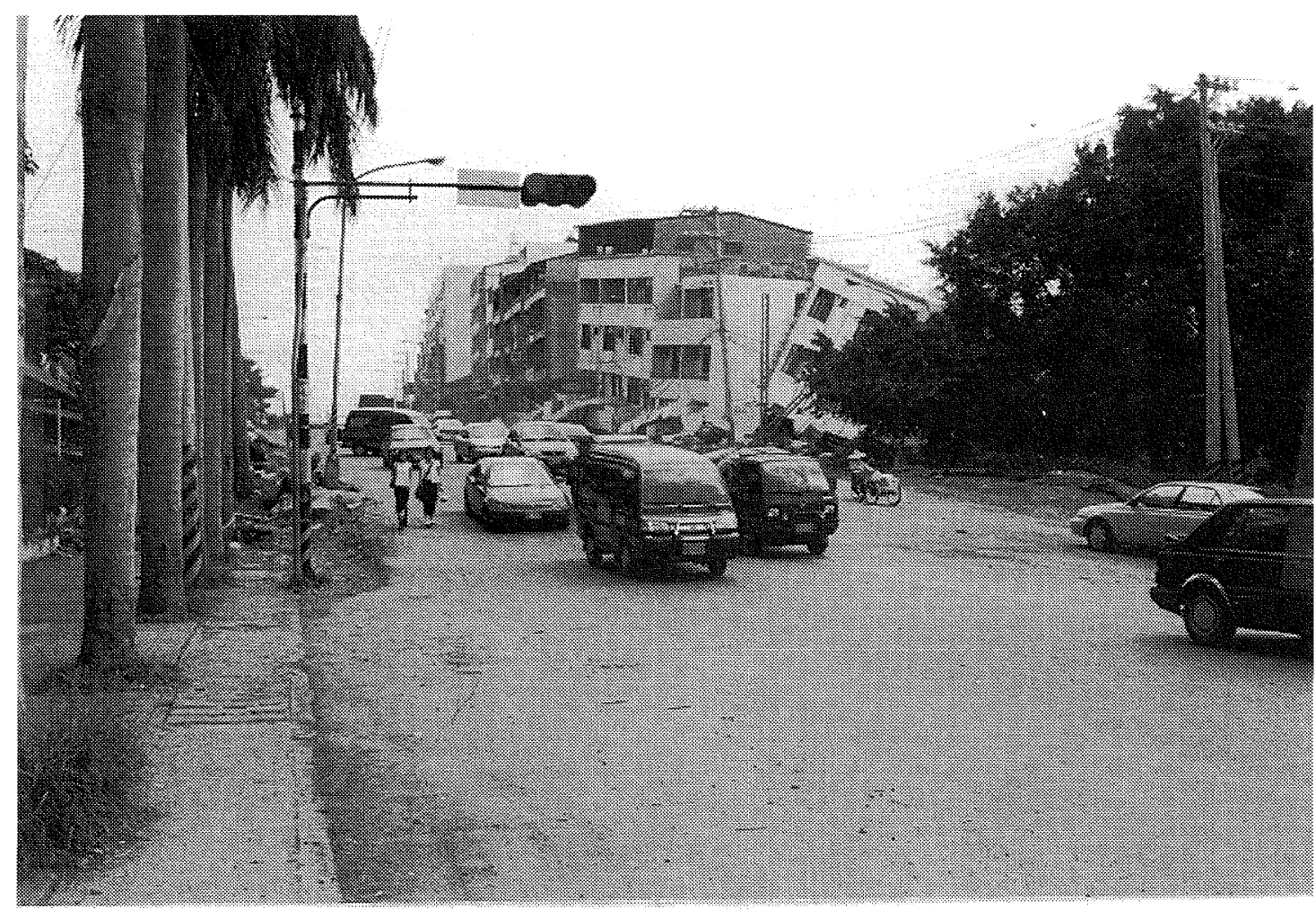

Figure 3.19: $\quad$ The fault scarp near Tsaotun. The scarp deformation shows clearly in the road and in the building damage. 


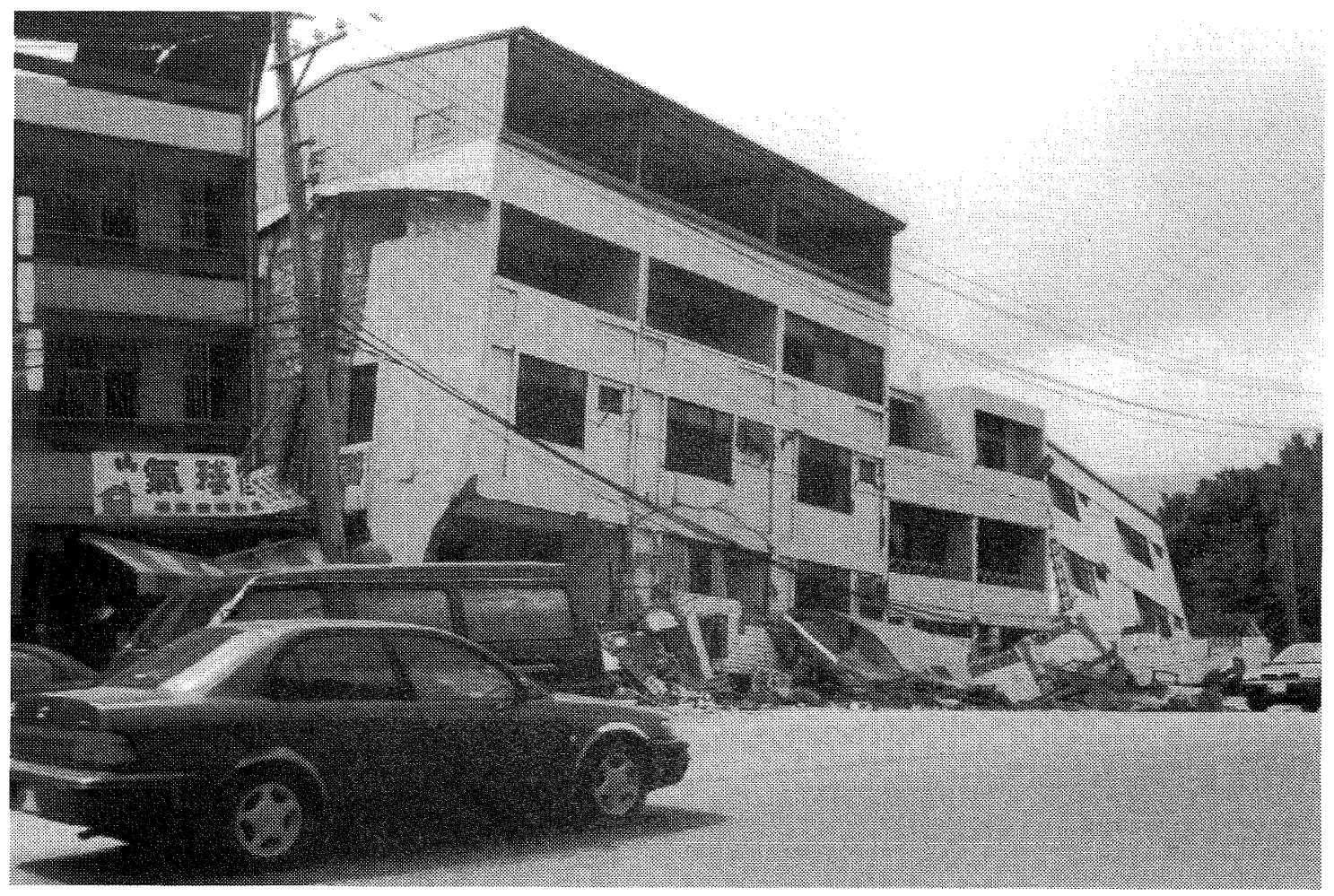

Figure 3.20: $\quad$ The fault scarp near Tsaotun. The scarp location and shape is reflected in the building damage.

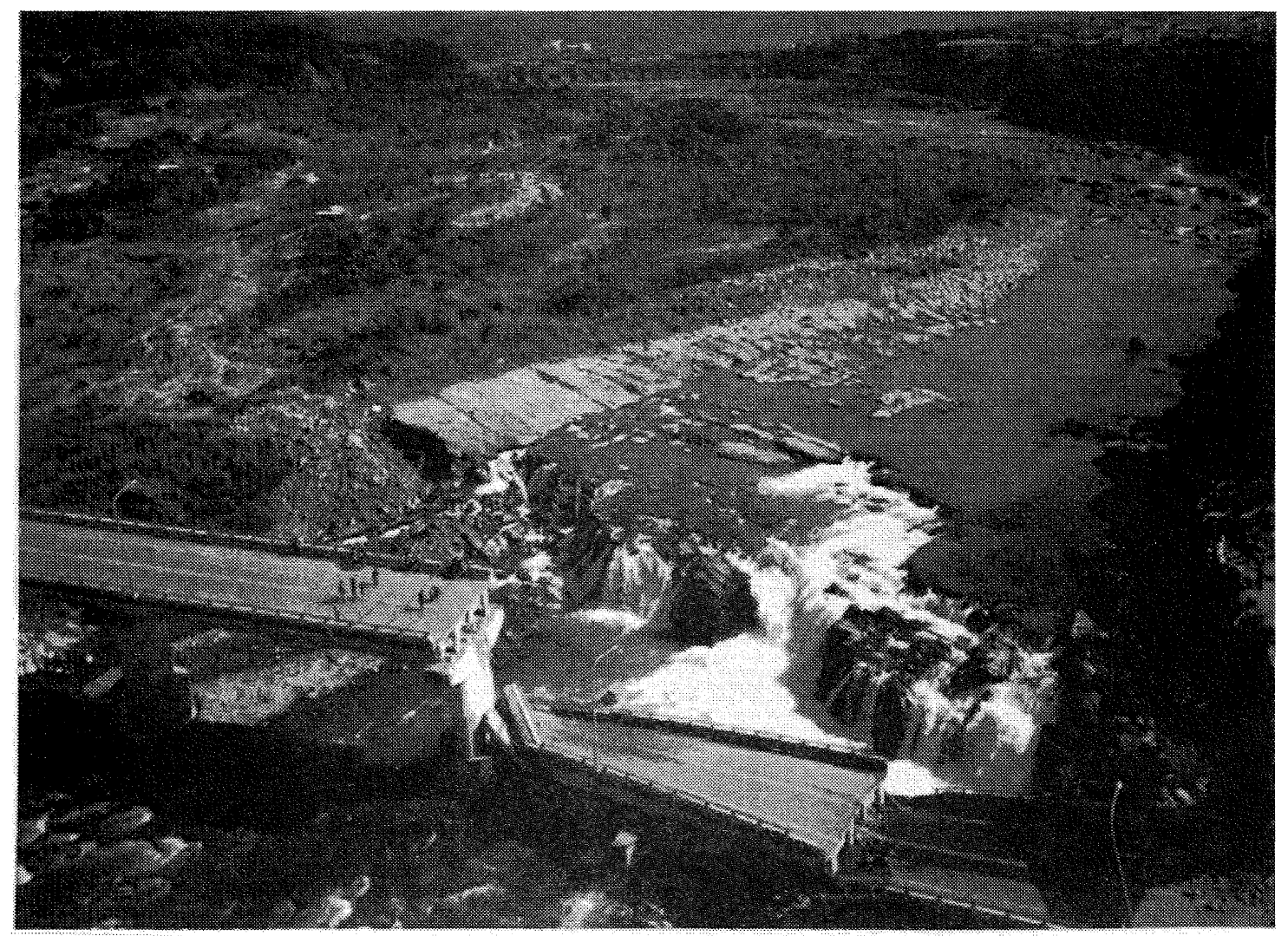

Figure 3.21: $\quad$ Fault rupture passes through the bridge and dam (background) near Shihkang. 


\section{LIFELINES}

\subsection{Introduction}

The Chi-Chi earthquake caused significant damage and disruption to key utility services such as electricity, telecommunications and water supply. While this experience essentially matched that from recent major earthquakes elsewhere, there was a notable lack of impact to reticulated gas services.

This section of the report outlines the performance of utility services and key transportation networks. The seismic response of bridges and port facilities is handled separately in Sections 6 and 7.2 respectively.

The information reported comes principally from observations and brief meetings with national utility operators.

\subsection{Electricity}

All aspects of electricity generation, transmission and distribution were affected by the Chi-Chi earthquake. Within the worst effected epicentral region, customers were typically without power for the first two days, with intermittent supplies available from 3 to 7 days after the event. There were also problems in the northern part of Taiwan due to major problems at the national switchyard, Chungliaou (10 $\mathrm{km}$ from the epicentre) and the loss of a major $345 \mathrm{kV}$ transmission tower. Electricity supply was rationed on a rotating basis (i.e. rolling brownouts) during the first week.

Electricity is generated and supplied exclusively by the Taiwan Power Company (Taipower). The information summarised in this section is based on a meeting with Taipower Transmission Unit Managers, which was held on Thursday 14 October (23 days after the earthquake). Information relating to community impacts is also taken from people we spoke to and newspaper articles.

Taipower was established in May 1946, and currently has assets totalling NZ\$175 billion. It is essentially a state owned enterprise with $94 \%$ Government ownership and $6 \%$ public ownership of stock. The total installed capacity to December 1998 was 26,680 MW with a recorded peak load reaching $23,830 \mathrm{MW}$ in July 1998 (approximately twice that recorded in 1988).

There are 69 generating plants as follows:

- 3 Nuclear plants producing 5,144 MW

- $\quad 27$ Thermal plants producing 17,114 MW

- 39 Hydro plants producing 4,422 MW
Taiwan's electricity industry is currently in the midst of a "liberalisation" phase. Two recent phases of "open bidding" for power generation has resulted in the selection of 11 independent power producers with a total capacity of 10,300 MW (included in the above figures)

Energy sales in 1998 totalled 128 billion KWH, divided by sector as follows:

$$
\begin{array}{ll}
\text { - } & \text { industrial } 65 \% \\
\text { - } & \text { domestic } 26 \% \\
\text { - } & \text { commercial 9\% }
\end{array}
$$

\section{Network Description}

The key routes of the Taipower electricity network are indicated in Figure 4.1. Features of this network include:

- $\quad$ nuclear power stations at the northern and southern tips of the island

- thermal power plants at the northern tip and western side of the island

- $\quad$ hydro plants in the centre of the island.

The Taipower network comprises $345 \mathrm{kV}$ main transmission lines, $161 \mathrm{kV}$ regional distribution lines and $69 \mathrm{kV}$ local distribution lines. Their network has 12,813 and 244,872 circuit kilometres of transmission and distribution lines respectively.

There are 3 key sub-stations in the north (Longtan), the south (LongQi) and the centre (Chungliaou) of the island. Chungliaou was only 10 kilometres from the epicentre and was significantly affected by the earthquake. There was also apparently appreciable damage at the Taichung thermal power plant

Buildings and equipment were designed for $0.2 \mathrm{~g}$ and $0.3 \mathrm{~g}$ respectively, with a factor of safety of 2 being mentioned. Taipower staff therefore regarded the equivalent original design capacity as being $0.4 \mathrm{~g}$ and $0.6 \mathrm{~g}$ respectively, noting the implication of working stress design.

The design of transmission towers is governed by typhoon wind philosophies which vary according to location on the island. The transmission towers that failed had a design wind speed of $61.9 \mathrm{~m} / \mathrm{s}$.

\section{Collapse/Deformation of Transmission Towers}

Table 4.1 below summarises the extent of damage recorded to transmission towers for each of the 345,161 and $69 \mathrm{kV}$ networks.

\section{Table 4.1: Transmission Towers Affected}

\begin{tabular}{l|c|c|c} 
& $\mathbf{3 4 5} \mathbf{~ k V}$ & $\mathbf{1 6 1} \mathbf{k V}$ & $\mathbf{6 9 k V}$ \\
\hline Toppled & 1 & 9 & 3 \\
\hline Leaning & 9 & 4 & 16 \\
\hline Structural member damage & 55 & 9 & 3 \\
\hline Foundation settlement. & 271 & 157 & 60 \\
\hline$\%$ affected in Nantou \& Taichung Counties & $28 \%$ & $20 \%$ & $18 \%$
\end{tabular}




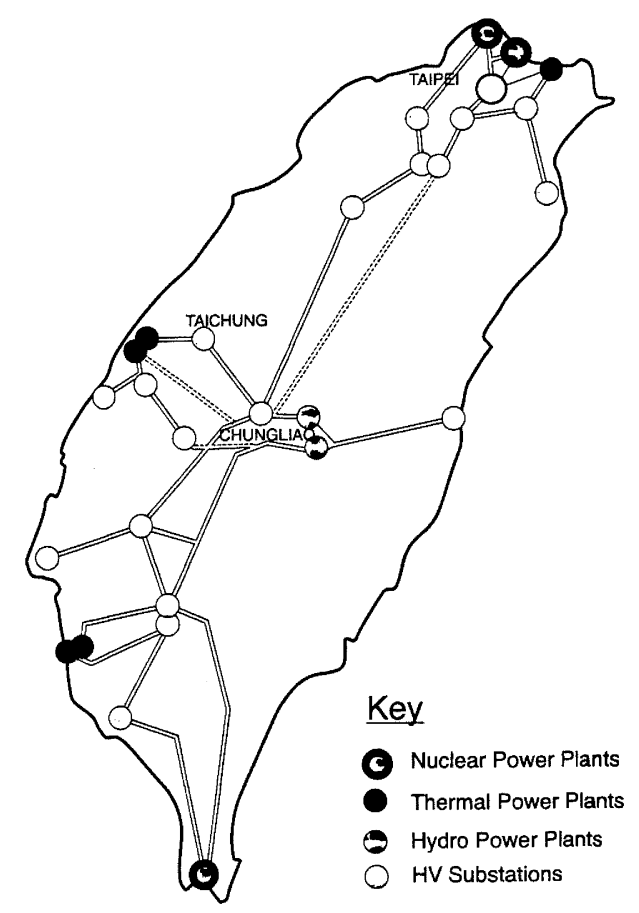

Figure 4.1: $\quad$ Overview of Taiwan's Electricity Network (disrupted main routes shown dotted).

It is understood that most of the failures of the 345 and 161 $\mathrm{kV}$ towers related to landslides which directly affected the tower foundations. In the case of the one $345 \mathrm{kV}$ tower, constructed approximately 25 years ago, the tower toppled due to an earthquake-induced landslide which took away support to two of the four legs of the tower. This tower, which was $19 \mathrm{~km}$ north of Chungliaou, provided support to the major 4,000 MW line north, and its loss had significant operational implications. Figures 4.2 and 4.3 illustrate the process of erecting temporary towers to restore this line. Two temporary towers of 45 and 94 tonnes respectively were erected to replace the toppled 42 tonne tower.

These towers took a total of five days to erect in the field. However access was a major obstacle due to the extent of landsliding in the affected area. The army had to "blow up" a number of landslides before the erection process could commence, and it was not until 13 days after the earthquake that the temporary towers were completed.

Figures 4.4 and 4.5 shows the displacement of a $69 \mathrm{kV}$ pylon at the fault scarp near Mingchien. This pylon is situated immediately on the hanging wall (up thrust) side of the fault trace. It is interesting to note the displacement of the tower to the left, given that it is a near right angle comer with the power cables going from the right of the picture around the pylon and into the page. This form of concrete base foundation, although common, was limited to the smaller 69 $\mathrm{kV}$ pylons.

It is understood that one of the $345 \mathrm{kV}$ pylons had a 4 caisson base and did rotate due to liquefaction on one side.

\section{Chungliaou Switchyard}

Chungliaou is within $10 \mathrm{~km}$ of the epicentre and experienced an assessed intensity of MMI IX. Strong motion instruments at the Chungliaou switchyard recorded the following accelerations:

$$
\begin{array}{ll}
\text { East - West } & 0.97 \mathrm{~g} \\
\text { North - South } & 0.40 \mathrm{~g} \\
\text { Vertical } & 0.15 \mathrm{~g}
\end{array}
$$

As well as this level of shaking, the side of the switchyard which was constructed in fill material settled and displaced laterally. This significantly affected the north bus - that part of the yard which controls the northern transmission route. Figure 4.6 shows that nature of the ground deformation and examples of porcelain damage. One third of all insulators at the Chungliaou switchyard were damaged in the earthquake. This switchyard had only one type of insulator, Class A (13 $\mathrm{kN}$, manufactured by NGK).

Approximately 20 sets of circuit breakers (out of a total of 40 at Chungliaou) are understood to have some form of damage. Only one type of circuit breaker was used at Chungliaou, namely a gas type (SF6).

In terms of damage to equipment, sufficient spare parts were able to be sourced from within Taiwan to enable adequate temporary repairs to be in place. All of the spares were however used up, and there is up to a six month wait for the delivery of permanent replacement elements.

At the time of our visit, the estimate of damage to the switchyard, transmission lines and associated elements was NZ\$120 million. This figure is understood not to include the earthquake damage experienced by three generating plants (Ma An, Qing Shan and DeJi). 




Figure 4.2: $\quad$ Assembling the elements for one of the temporary $345 \mathrm{kV}$ Towers.

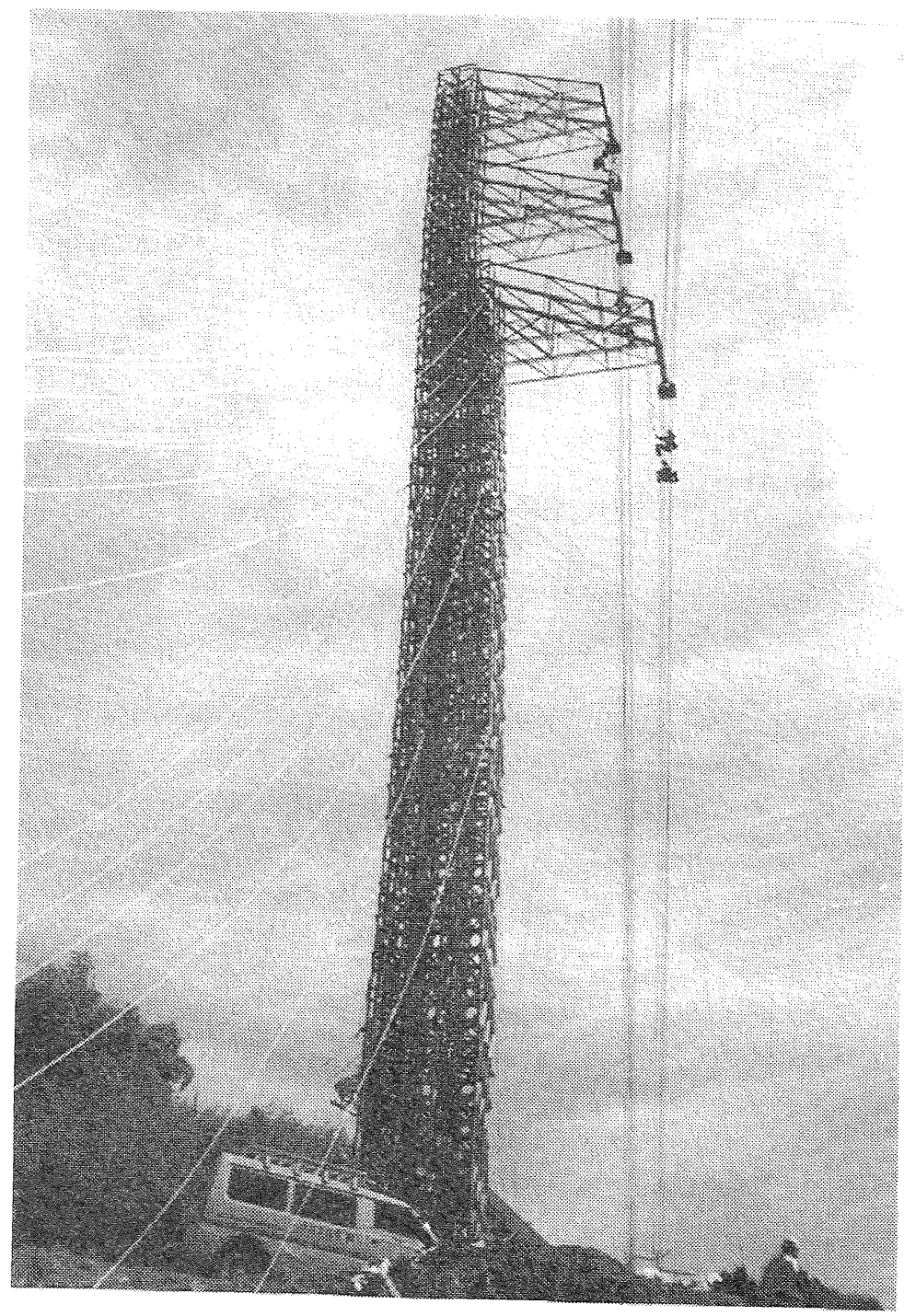

Figure 4.3: Temporary $345 \mathrm{kV}$ Tower in Place. 


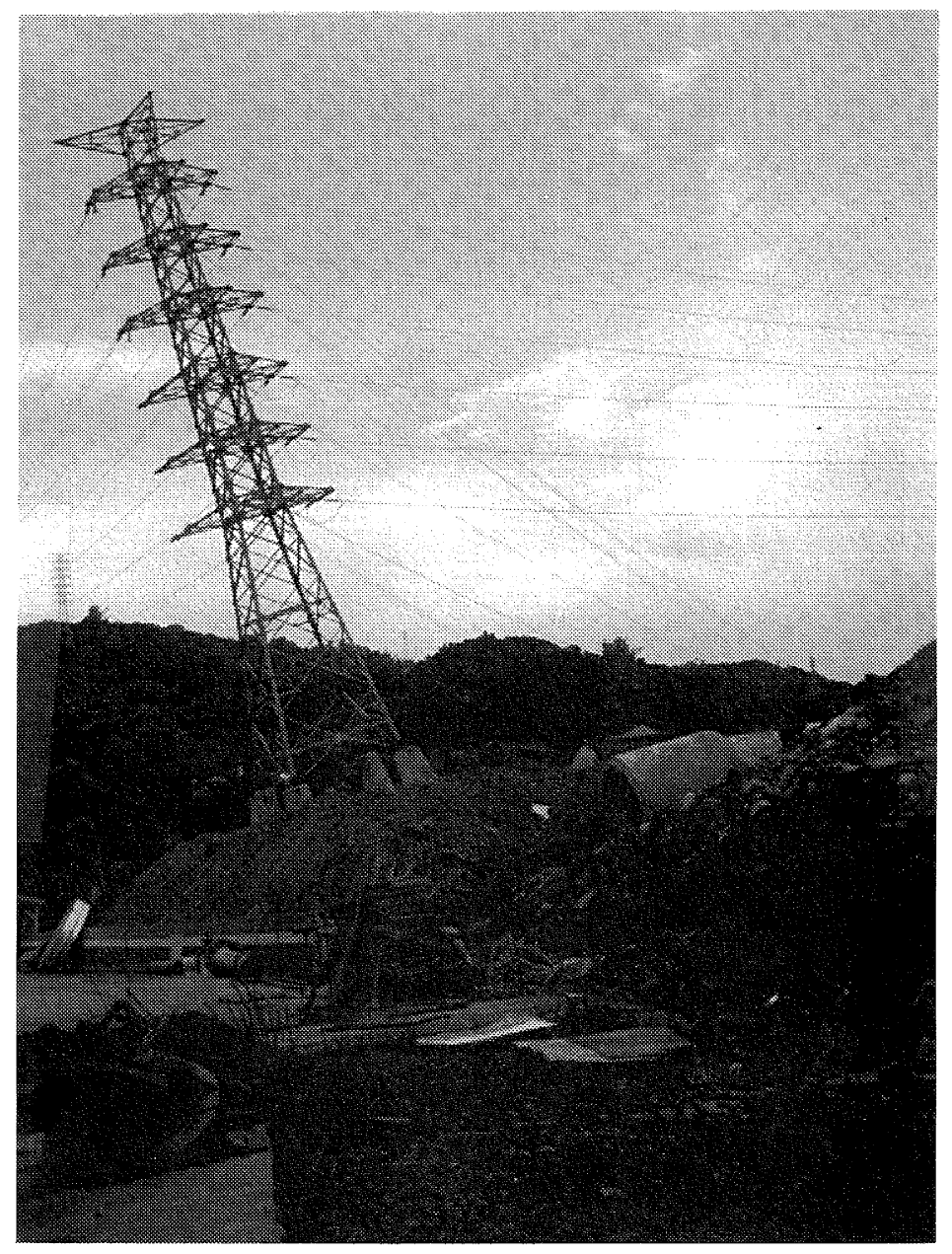

Figure 4.4: $\quad$ Deformation of $69 k$ V Pylon Due to $2 m$ Uplift near Mingchien.



Figure 4.5: $\quad$ Typical Foundation Detail for $69 \mathrm{kV}$ Pylons. 


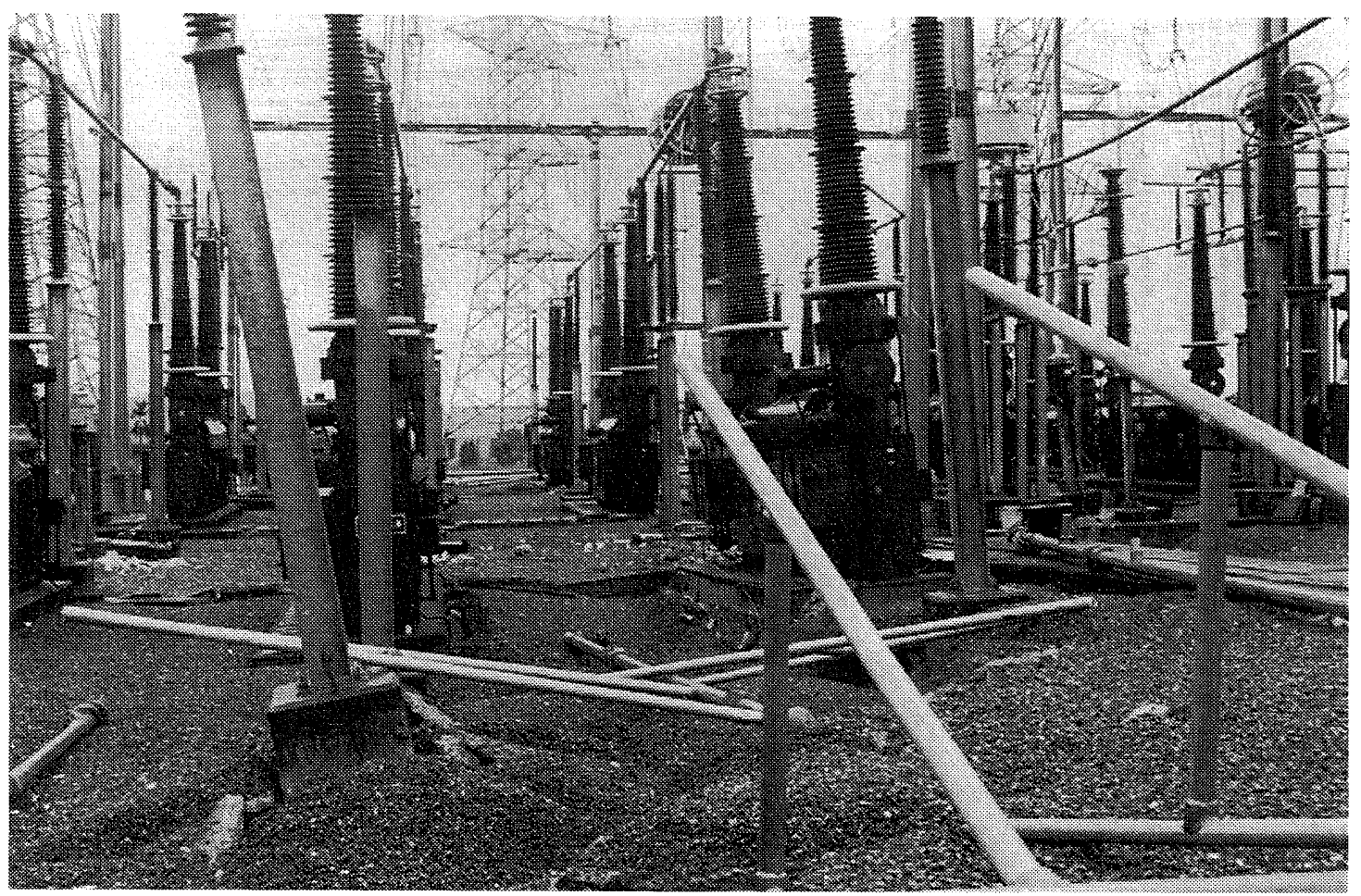

Figure 4.6: Chungliaou Switchyard-Ground deformation and insulator damage.

\section{Chungliaou Control Room}

The control room at Chungliaou switchyard is of robust two storey concrete construction with a high proportion of solid walls. It suffered only minor damage in one location where sub-grade cable tunnels entered the building. A number of control cabinets toppled due to lack of top seismic restraint (refer Section 5.8). The toppling of these control cabinets took a number of hours to reinstate, and in isolation would have caused considerable operational difficulties. However due to the scale of damage in the switchyard and due to the loss of major transmission towers, this did not have a significant operational impact.

\section{The Response}

Given the scale of the impacts, the Taipower response process appeared to have been effective. It was not possible to ascertain the extent to which their response process followed a predetermined plan.

As well as swinging a massive repair process into action, Taipower had to implement a major power rationing plan for the northern half of Taiwan. This involved up to $6 \frac{1}{2}$ hour outages for most customers each day ( 5 of these in the daytime) with the different times relating to zones as indicated on individual power bills. This rationing was introduced within 3 days of the earthquake, and affected 3.6 million households. It is understood that the major industrial parks were exempt from this rationing. As part of this strategy, full power was made available to the principal damage zone (this decision alone became a political issue).
It is understood that full restoration island wide occurred on the $10^{\text {th }}$ October ( 20 days after the earthquake). At this point however, the temporary cabling was understood to be struggling under the load imposed by air conditioning units in the major northern city of Taipei.

We understand that there were no issues such as fires resulting from early reconnection of power supplies in moderately and severely damaged areas.

\section{Other Comments}

The obvious lack of redundancy in the electricity network had been recognised by network planners in the early to mid1990's. A major project (The New Central Transmission Line Project) had been documented during this time. However construction has yet to commence due to protests by land owners and others about having their properties taken for power supply purposes - the project was originally scheduled to be completed by 1996 . Using the postearthquake emergency decree issued by the government, key construction projects such as this were accorded top priority status and so construction was due to commence in February 2000. This implies that the protests now have no status.

\subsection{Telecommunications}

The telecommunications service to 198,700 subscribers in central Taiwan was affected. This represents $8 \%$ of the total number of subscribers in this region. Outside plant and power supply equipment suffered heavy damage. Although 
one switching system was significantly damaged, few transmission facilities were damaged.

The estimate for repairing physical damage due to the earthquake was NZ $\$ 80$ million as at February 2000.

The state-run Chunghwa Telecom Company manages the National Telecommunications Network in Taiwan. It is the sole supplier of landline connections. There are a number of different mobile phone service providers in addition to Chunghwa Telecom.

It is understood that the design standards used in Taiwan are the same as apply in Japan, which are in turn believed to closely parallel those in the United States.

\section{The Nature of Damage}

A summary of damage to outside plant according to element type is as follows:

- Underground tunnels - no damage

- $\quad$ Pipes through which cables run - damage occurred over a length of 93 $\mathrm{km}$

- Underground cables

- damage occurred over a length of $256 \mathrm{~km}$

- breakage occurred at 20 bridges (settlement of abutments)

- Manholes

- 2,320 were damaged

- Telephone poles

- 422 fallen

- Overhead cable (between street pole and subscriber) damage occurred over a length of 15 $\mathrm{km}$

The following items of inside plant were affected:

- $\quad$ Battery units at 47 sites moved and/or sustained damage

- Diesel engines shifted position at 16 sites with the fuel pipe and water pipes being broken at 14 sites. Three mobile diesel generators were dispatched to three sites.

- Building damage occurred at three sites (cooling tower sustained damage at three sites)

- Base stations for the mobile network were rendered out of service at 1,500 sites (out of a total of 10,000 in Taiwan)

The five-storey central exchange office at Nantou County was seriously damaged by the earthquake. This exchange building (constructed in 1974) consists of one tandem switching system providing service for 300,000 subscribers and one local switching system of 39,000 lines. As such it is a transmission hub for this county. Two days after the earthquake, two switching systems were installed in a nearby building to restore telecommunication service (completed by 30 September, with the related transmission equipment and subscriber line connections being completed on 5 October)

Relatively little damage to either the building or equipment within was observed at the exchange building inspected by a member of the team at Chungliaou, despite the high accelerations experienced by this area.

The 6,000 subscribers in the small mountainous town of Lishan received service via $5 E$ Remote Switching Modules (RSM). The fibre connecting the Host and the RSM's was cut by the earthquake, and was not able to be repaired due to severe damage to the road. A microwave relay station between the same point was also out of service because of power outage. Their solution to this problem was to install a 5E Host at Lishan on September 29. This was completed with telephone service being restored on 5 October.

An international optic fibre, part of the Asian Pacific Optical Network, was also damaged, disrupting more than 7,000 circuits to Hong Kong, Japan, Korea and the US. Foreign telecommunications companies allowed use of some of their back up circuits.

\section{The Response Process}

The Chunghwa Telecom response plans were based on typhoon events, and as such were well practiced.

Figure 4.7 indicates the service restoration progress summary for affected subscribers in the central Taiwan area, highlighting that:

- $5 \%$ of the subscribers who had lost service were reconnected by the end of the first day

- Half of the affected subscribers had their service restored within two days of the earthquake

- $90 \%$ of the affected subscribers had service restored within four days of the earthquake

- $99 \%$ of the affected subscribers had service restored by 17 days after the earthquake.

In the wake of a sudden influx of phone traffic resulting from the quake, Chunghwa Telecom instituted controls on long distance calls.

By 14 October, approximately 1,500 subscribers had yet to be reconnected. This generally related to either damage to the subscribers' property or lack of access due to severely damaged roads.

The above rate of restoration was achieved using 1,253 people. The central region of Chunghwa Telecom was assisted by 100 workers from the northern region plus 100 workers from the southern region. These people were understood to all be employees of Chunghwa Telecom, and not contractors.

It had not been common practice to hold significant replacement or spare stock. Immediately after the earthquake, Chunghwa Telecom called for help from their manufacturing suppliers, and this resulted in the range of resources being redirected from other construction sites. They considered this to be somewhat fortunate. 


\section{Chunghwa Telecom: Response}

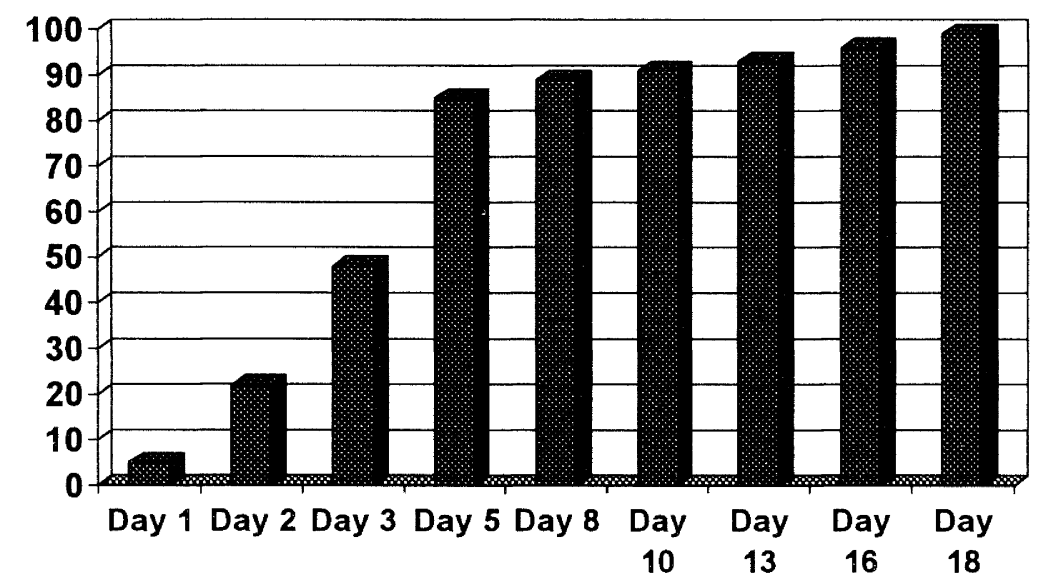

Figure 4.7: Restoration rate for affected Chunghwa Telecom subscribers.

In terms of mobile communications, the restoration of normal service was achieved as follows:

- At the end of day one, $10 \%$ of calls via Chunghwa Telecom mobile were completed, with $15 \%$ from other carriers being completed

- $\quad$ By the end of day three $40 \%$ of calls were being completed

- $\quad$ By the end of day seven $60-70 \%$ of calls were being completed (understood to be normal)

Two other mobile service providers indicated that $80 \%$ of their bay stations were up and running within four days of the earthquake.

As a result of the earthquake, Chunghwa Telecom have realised they need more radio facilities. Also, they only had access to one helicopter for reconnaissance and delivery of supplies. While they requested general and specific assistance from the Army, this took considerable time given the demands on those resources.

Chunghwa Telecom provided the following free telecommunication services in the earthquake stricken area for the use of the rescue teams and the general public:

- Free telephone services: 2,452 lines

- Mobile phones:

500 sets

- Satellite telephone services: 24 sets

- Leased data lines:

27 lines

- Internet access service:

34 accounts.

\subsection{Water and Wastewater}

Only a small amount of information on the performance of water and wastewater systems was able to be obtained whilst in Taiwan. This was principally due to the considerable number of cities and municipalities affected by the earthquake and the different water and wastewater networks and organisational structures involved. A brief interview was however held with a senior regional official of the Taiwan Water Supply Corporation. No information regarding the performance of sewage and stormwater systems was able to be obtained.

Taiwan Water Supply Corporation is responsible for supplying water throughout Taiwan, with the exception of Taipei. The regional division in Taichung supplies water to both Taichung City and all of the surrounding areas, cities and townships. It is organised separately from Taichung City and Taichung County Government.

The Taichung County water supply network involves a number of major catchment dams through to individual property connections. Two of the principal elements that were located in close proximity to the northern end of the fault trace were the Shih-kang Dam and the Fengyuan Water Treatment Plant. Approximately 50\% of the region's water supply comes from the Shih-kang Dam, which due to an 8 metre vertical displacement at one end was rendered virtually inoperable after the event (refer Figures 7.1 and 7.2).

It is understood that all of the water from the Shih-kang Dam was treated at the Fengyuan Plant. The fault rupture passed through this plant. Settling basins, storage reservoirs and associated piping at the plant were damaged. Photographs briefly viewed showed considerable damage to heavy elements such as precast concrete trough beams in clarifier units. Baffles were displaced due to sloshing. Four steel 
pipelines with diameters of 400 to $2000 \mathrm{~mm}$ which traversed the fault in the vicinity of the plant ruptured. Of considerable interest is the failure of a section of roof over a reservoir at the treatment plant. This large reservoir is rectangular in plan, and is understood to be partially below ground. The roof is a flat slab structure supported on intermediate columns, and as Figure 4.8 indicates, it failed in the end sections.

In the absence of any apparent outward movement of the walls, it is likely that this slab failed due to wave action causing a punching shear mode. Recorded vertical accelerations in this vicinity were less than $0.2 \mathrm{~g}$.

Key elements of damage and impact included the following:

- The Shih-kang Dam typically produced 1 million cubic metres of potable water per day. Another dam which provides water for irrigation purposes was pressed into service. After some deliberation, the decision was taken to repair the dam. This decision was influenced by the lack of an alternative site in the vicinity, and took account of the very low potential for loss of life downstream should a future failure occur (Foster and Campbell (2000)). Most of the 18 spillway bays can be rehabilitated, with new structure required only at the right bank where the main dislocation occurred (refer Figure 7.2).

- An added demand on storage resulted from the need to pump 1.5 million cubic metres of water per day through the system in the weeks following the earthquake due to the effect of broken water mains.

- Where a 2 metre diameter ductile iron water main crossed the fault trace, the section of main was crushed into a ball-like shape (photograph not available).

- The reticulation network experienced different types of damage including joints pulling apart, compression buckling and fracturing of steel. Unfortunately no breakdown of the network in terms of pipe sizes and materials was available.

- A number of filing cabinets and associated contents fell in the offices at the water treatment plant.

In the only information available from other water supply networks, a water treatment plant in Chi-Chi (the closest town to the epicentre) which was completed but had yet to be commissioned performed well in the earthquake.

The total damage estimate for Taiwan Water Supply Corporation was NZ\$400 million.

\section{Restoration of Service}

Characteristics of the restoration of service are as follows:

- For the first 3 days, a half of the normal volume was available with reduced pressure in Taichung City.

- A basic level of service was restored to all areas within 6 days.
During this period there was extensive reconfiguration of the network and reconnections. Water trucks provided water to the local reservoirs. Loss of power was not a problem due to the presence of standby generators.

It was interesting to note that of all the earthquake issues that recurred in the daily press both prior to and during our visit, there were very few stories (negative or otherwise) relating to water supply. In a press article on Thursday 30 September (or 9 days after the earthquake), it was noted that "water supplies in the greater Taichung area finally resumed yesterday".

\section{Emergency Water Supplies}

Emergency water was typically supplied by using stainless steel tanks refilled by tanker trucks (refer Figures 4.9 and 4.10). These tanks typically have a capacity of $2.5 \mathrm{~m}^{3}$, with the cradle and interlinked manifold arrangement shown.

It was unclear as to who was in overall charge of these arrangements, and the extent to which a prior response plan had been developed. It was however our understanding that the tanks themselves were provided by major corporates (in one location for example there was a large Nissan tent immediately adjacent).

The system appeared to be functioning satisfactorily, as we did not observe major queuing or hear about short-term supply difficulties.

\subsection{Gas}

Reticulated gas is restricted to the main cities of Taiwan, and so the exposure of these networks in the areas of fault rupture and liquefaction was limited. It is understood that these networks are operated by three separate organisations.

For those parts of the gas networks in the region of greatest damage, generally good performance of the mains and gate stations was reported. Very limited specific information was available.

No conflagrations immediately following the earthquake were reported.

\subsection{Transportation Networks}

Roading and port facilities were the principal transportation networks significantly affected by this earthquake.

Section 6.2 provides information on the effect on bridges. In the mountainous areas, sections of roads were severely impacted by extensive rock falls and drop outs. It took two weeks after the earthquake to establish that a bus with 15 mountain climbers was buried under a landslide on a remote high country road. This incident indicates the scale of impact of this event on roads in high country terrain.

The impact on facilities at Taichung port is outlined in Section 7.2 .

It is understood that there was only limited damage and disruption to airport and active rail facilities. 




Figure 4.8:

Failure of reservoir roof, Fengyuan Water Treatment Plant.

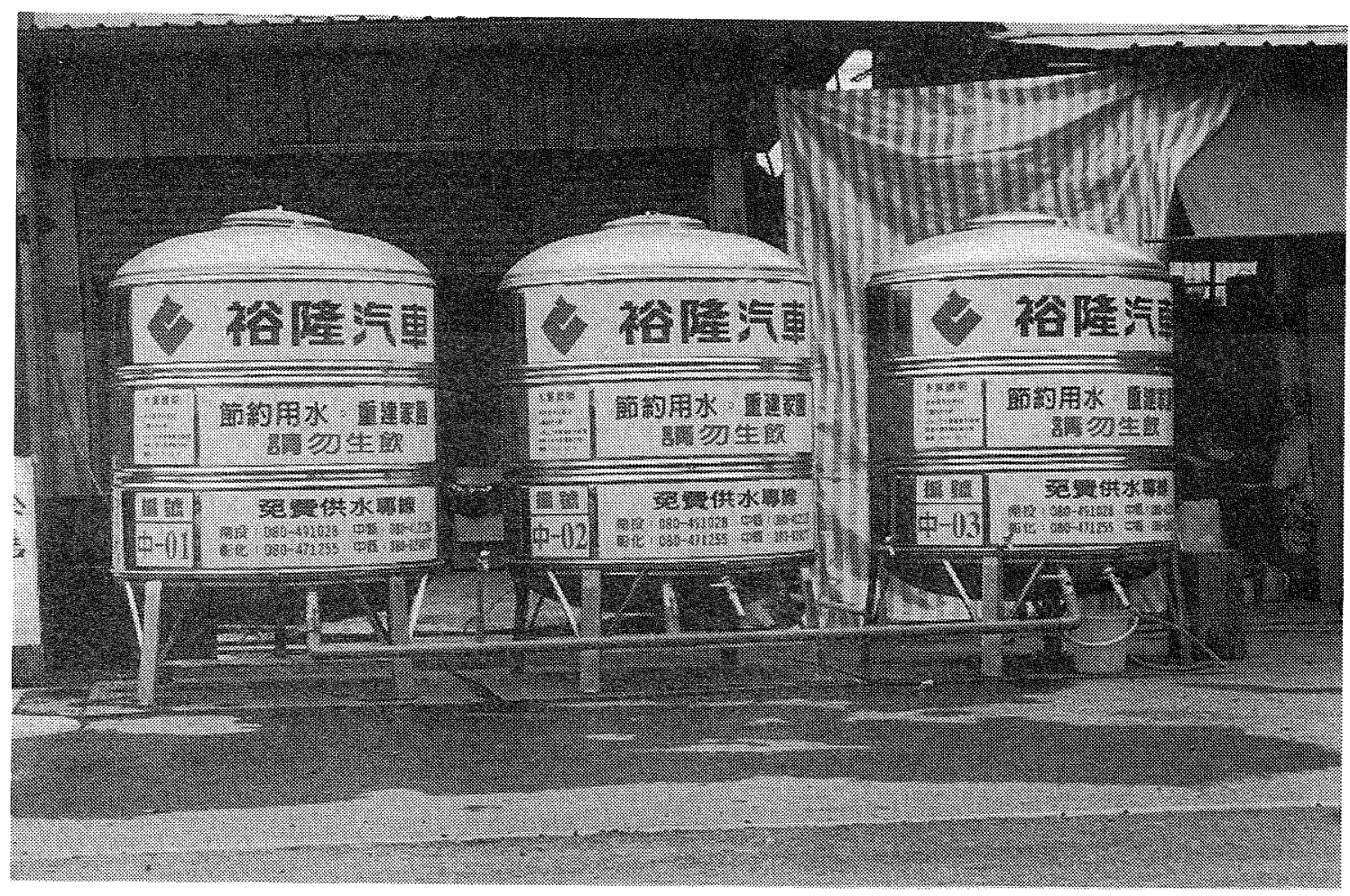

Figure 4.9: $\quad$ Common configuration of $2.5 \mathrm{~m}^{2}$ emergency water tanks. 


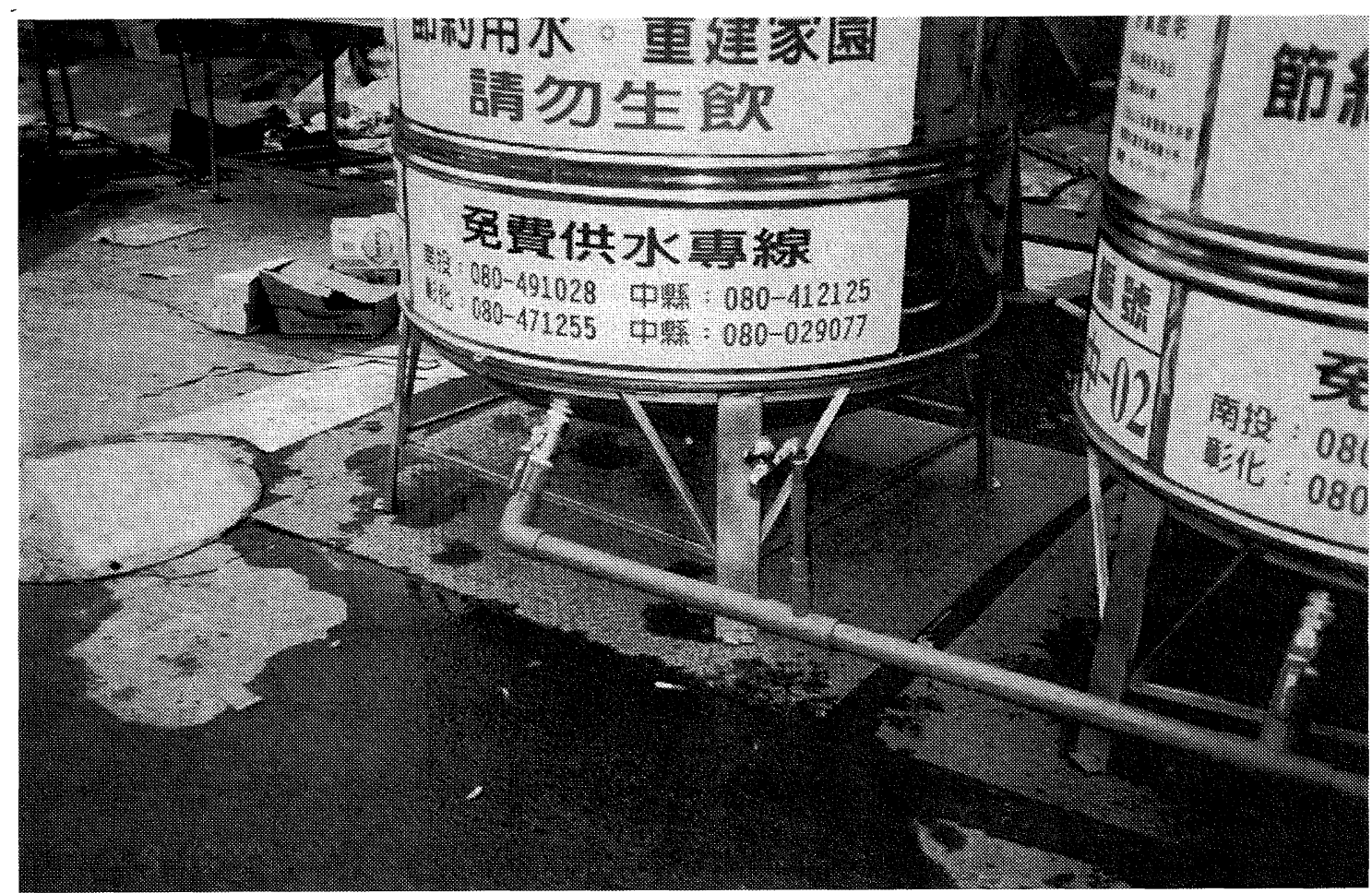

Figure 4.10: $\quad$ Manifold arrangements for emergency water tanks.

\section{Building Structures}

\subsection{The Design and Construction Process}

Engineering design of earthquake resistant structures in Taiwan, like New Zealand and most other countries, has been an evolving process. The necessity to provide ductility within structures so as to limit the forces to be resisted to an economical level is now internationally accepted, and is incorporated into the current Taiwanese design codes.

For modern building structures, the Taiwanese codes are based on the following documents:

- The United States Uniform Building Code (UBC) for design loads and philosophy. The latest Taiwan code was issued in 1997 and is based on the 1994 version of the UBC. The peak ground accelerations to be used in conjunction with the codes scalable spectra have been mapped into four separate zones as shown in Figure 3.10

- Reinforced concrete design is based on the American Concrete Institute code ACI 318

- Structural steel design is based on the AISC code

Buildings over $50 \mathrm{~m}$ in height are required to have the design peer reviewed by a team of independent experts. The team undertaking this review is drawn from the various universities and research institutes. As a consequence of this requirement a considerable number of buildings were designed to be just under the $50 \mathrm{~m}$ limit. The review is limited to the design and does not require any additional site control but designers consider that a lot of additional calculations must be furnished to the reviewers.

Designs are under the control of the Architect who is responsible for directing a team of consultants to produce design documentation and review the construction. The Architect is required by law to sign off the complete building. As in New Zealand local territorial authorities have a role in the planning and approval process before construction is allowed to proceed.

The above is a statement of the ideal. In reality most of the construction is led by developers and constructed by the developers' own construction company. This clearly puts strains on the Architects who are still required to sign off on the construction but have limited opportunities to monitor work on site. There have been several articles in the Taiwanese press relating to inadequate construction practice with several developers, contractors, architects and engineers having had their passports withdrawn and some reported to have been jailed.

Based on the current design code the cities and towns of the affected region are all in Zone 2 for which the design PGA is $0.23 \mathrm{~g}$. The acceleration contours that have been released (refer Figure 3.1) indicate all of the cities and towns within the central area of Taiwan were within the $0.25 \mathrm{~g}$ contour and that large areas were subjected to PGAs greater than $0.5 \mathrm{~g}$. Therefore many of the buildings in the affected area have been subjected to ground shaking approaching or exceeding the design code intensity.

Low-rise buildings are almost exclusively constructed from heavy materials due to the ever-present threat of typhoons. It was notable that one of the few light timber framed construction buildings viewed by the team exhibited no signs 


\subsection{Adobe and Unreinforced Masonry Construction}

Unfortunately for the occupants there were a significant number of these non-engineered buildings in the rural parts of the affected area and as would be expected they did not perform well. Since these structures tended to collapse into small pieces many of them had been completely removed by the time the reconnaissance team undertook its tour.
Figure 5.2 shows a collapsed structure of this type on the downside of the fault but near the scarp. An undamaged example of this type of building is shown in Figure 5.3 and ironically was located on the upside of the fault and within a few tens of metres of the fault scarp, usually a zone of extreme damage.

These single storey dwelling units were reported to be responsible for a significant proportion of the deaths that occurred in the earthquake.

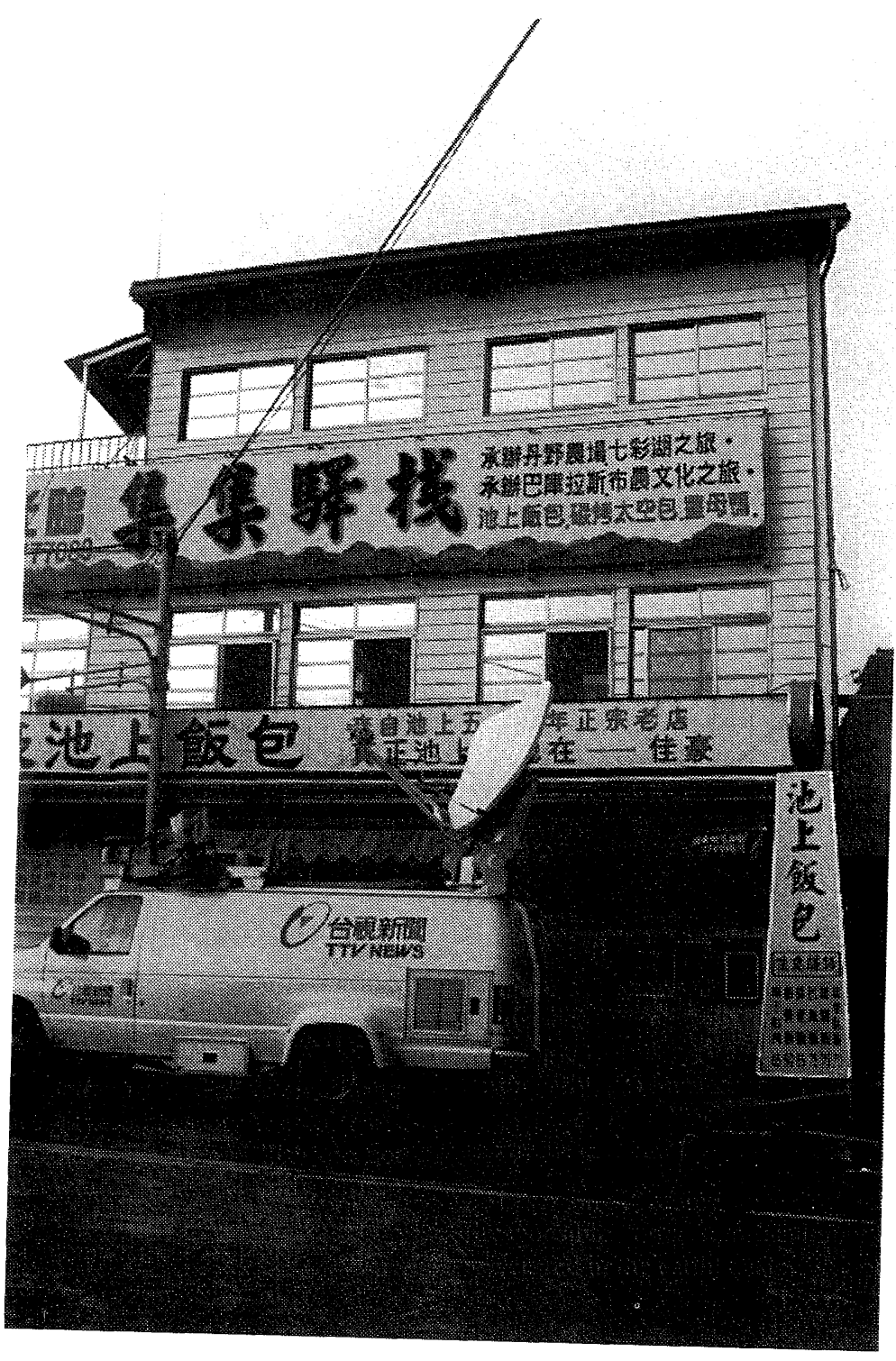

Figure 5.1: $\quad$ Undamaged light timber framed building, Chi-Chi. 


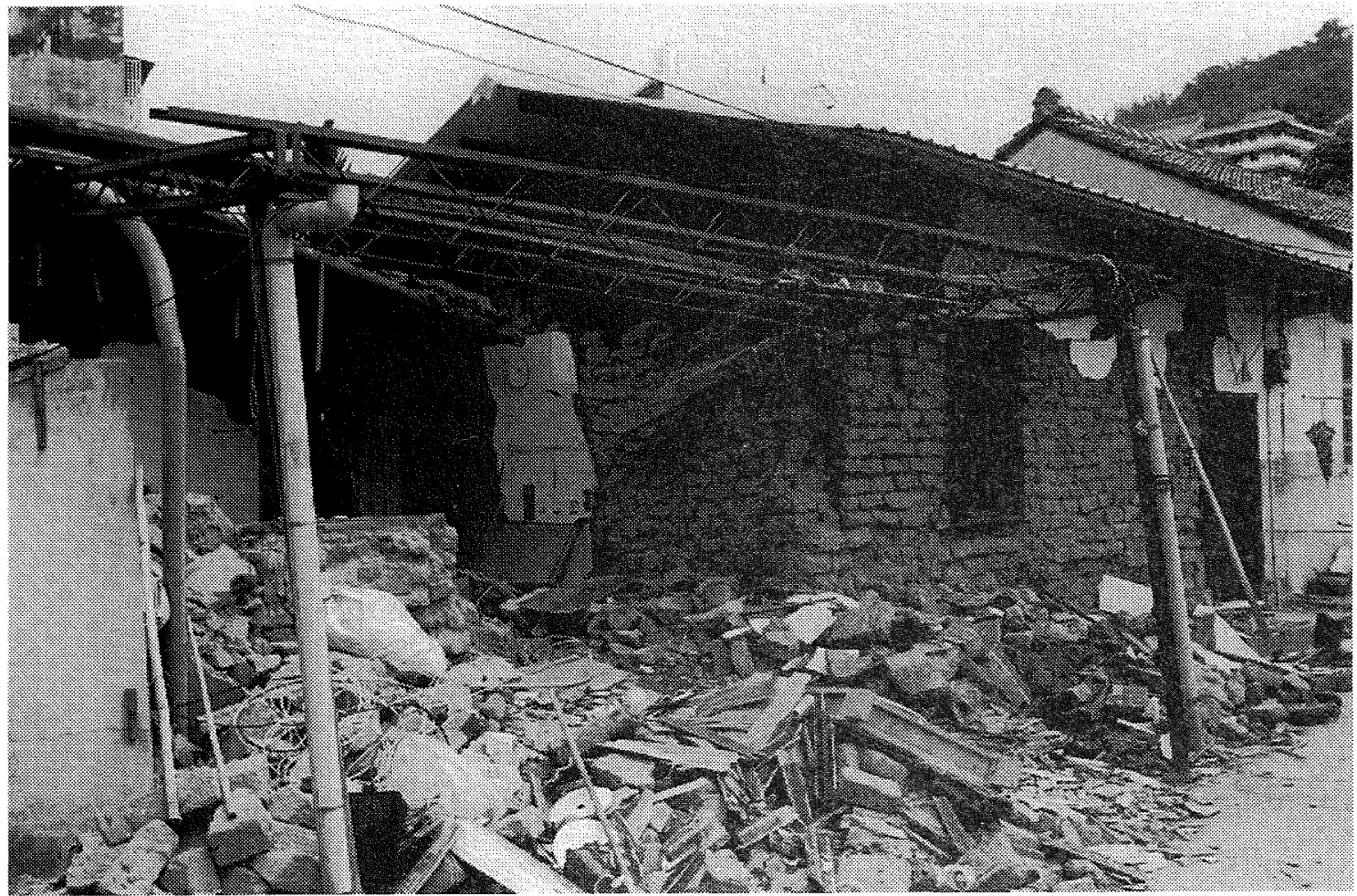

Figure 5.2: $\quad$ Collapsed adobe house, Tsaotsun.

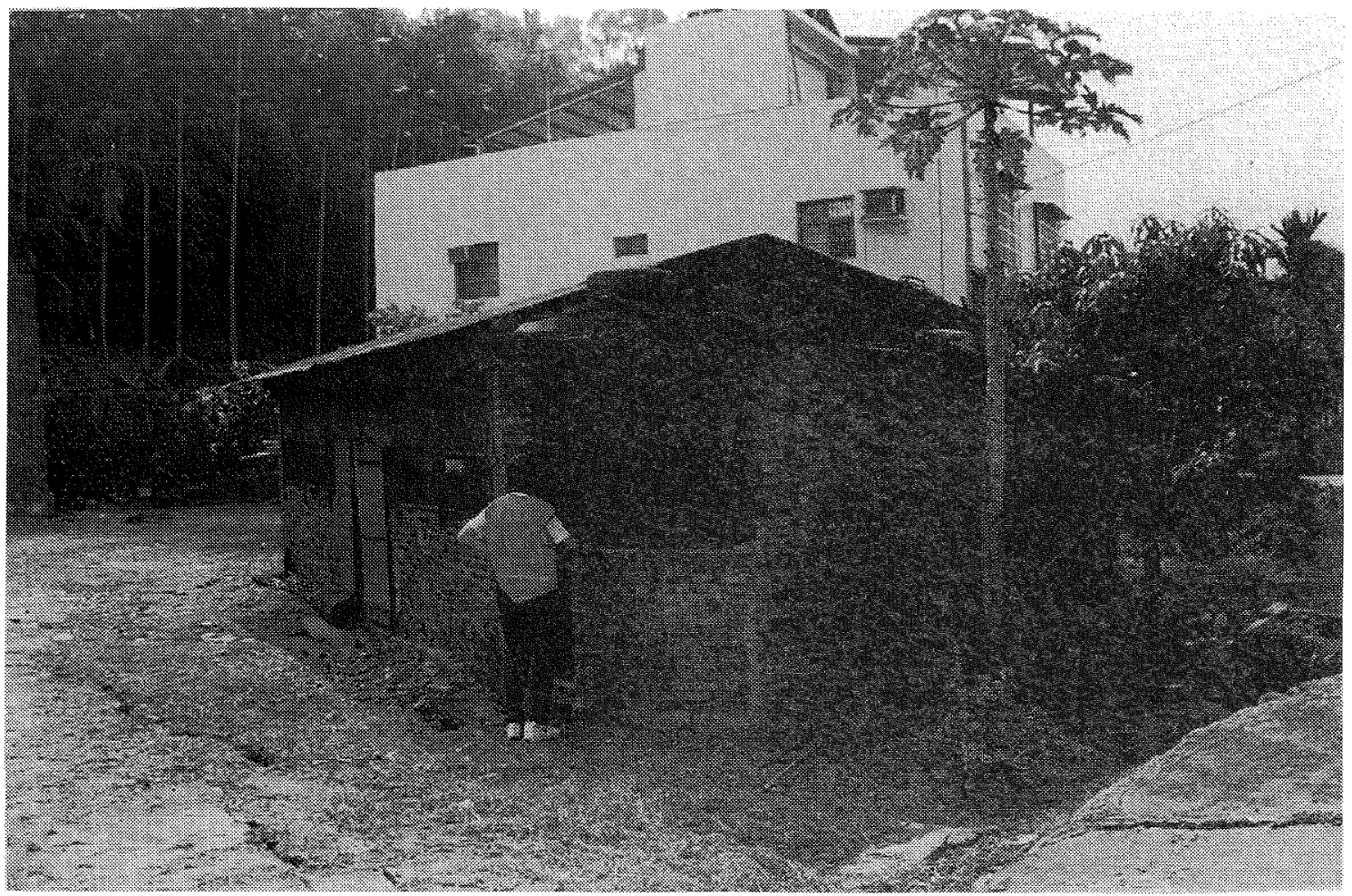

Figure 5.3: $\quad$ Undamaged unreinforced masonry dwelling, Tsaotsun. 


\section{3 'Up to Heaven' Housing}

This archetypal Taiwanese building is usually some three storeys high and is both the place of employment and residence for $2-3$ generations of a family. They are called "up to heaven" houses as the same family owns everything from the ground up.

Taiwanese planning practice is to require that buildings be set back from the street edge at street level to provide a sheltered walkway for pedestrians in all streets over $7 \mathrm{~m}$ wide, no provision is made for footpaths within the road reserve.

These buildings occupy the full site width and frequently the full depth of the site. If the site on any one side is empty then starter bars are left protruding so that the next building can join on and utilise the common wall for support. Starter bars are frequently left protruding from the column tops show that additional storeys can be added.

Figure 5.4 shows a typical collection of these buildings, and while somewhat taller than is typical, Figure 5.5 shows the inherent character of this style of building.

As can be seen from these views, in the plane of the street at ground level the front is very open to provide a view into the shop or access to the workplace. In the upper floors the partitions between rooms are unreinforced masonry or lightly reinforced insitu concrete and not separated from the structural frame. The sidewalls consist of frames infilled with the same two choices of materials.

Figure 5.6 indicates the typical structural elevations and materials used for these structures. The columns are finished with ceramic tiles and hence the underlying structural dimensions are some $50-75 \mathrm{~mm}$ smaller than the overall dimensions shown on this figure.

As could be expected from their structural form, buildings of this type are liable to form a soft storey mechanism in the event of severe seismic disturbance and did so in their thousands. Figure 5.7 shows the cars on the footpath overnight crushed by the collapse of the first storey and is typical of the many where the forces induced in the buildings mass overwhelmed the strength of the structure. It is indeed fortunate that the event occurred while people were asleep in the upper storeys and not in the zone of maximum damage and collapse.

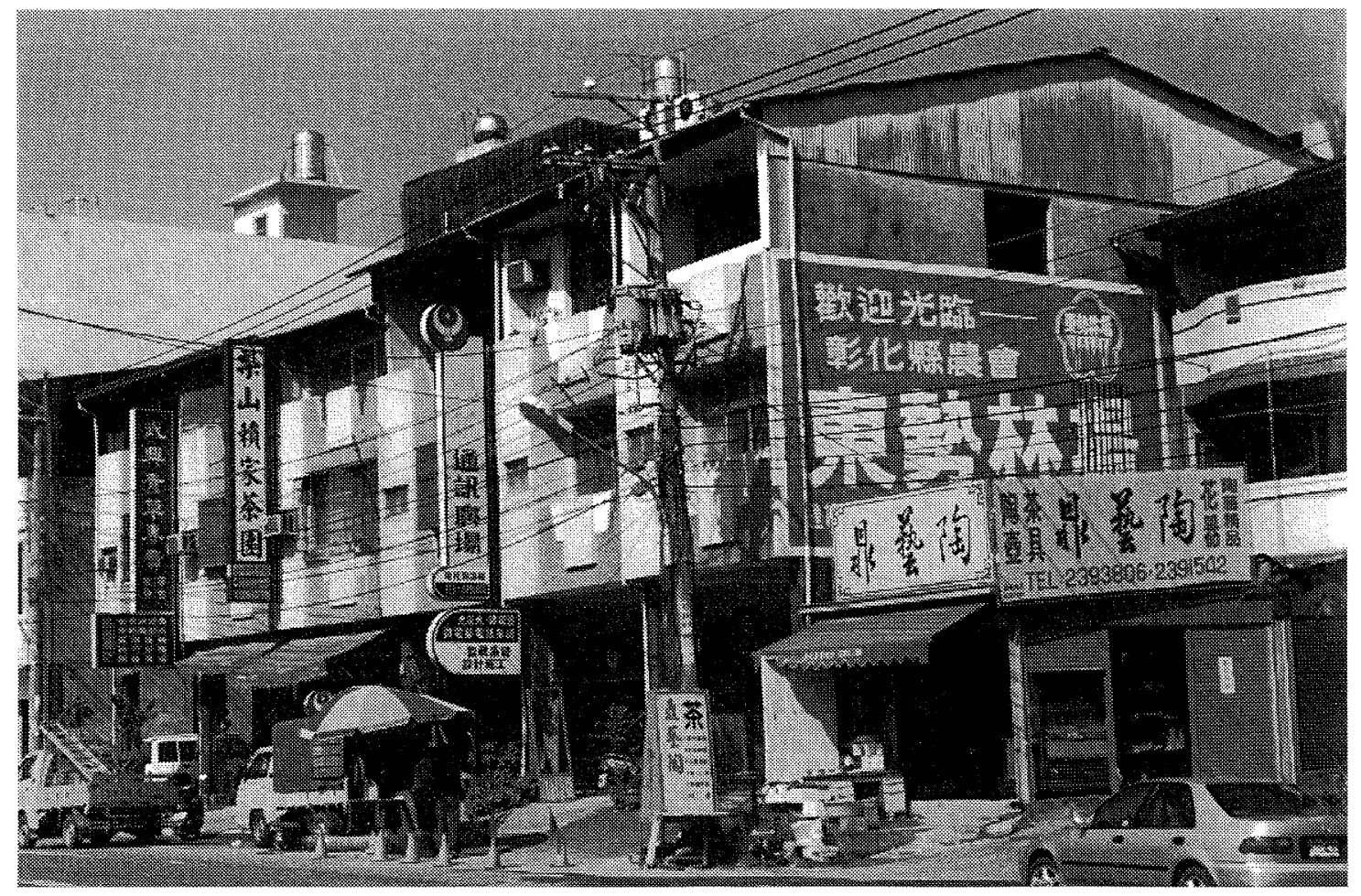

Figure 5.4: A typical streetscape consisting of a collection of "Up to Heaven Houses". 


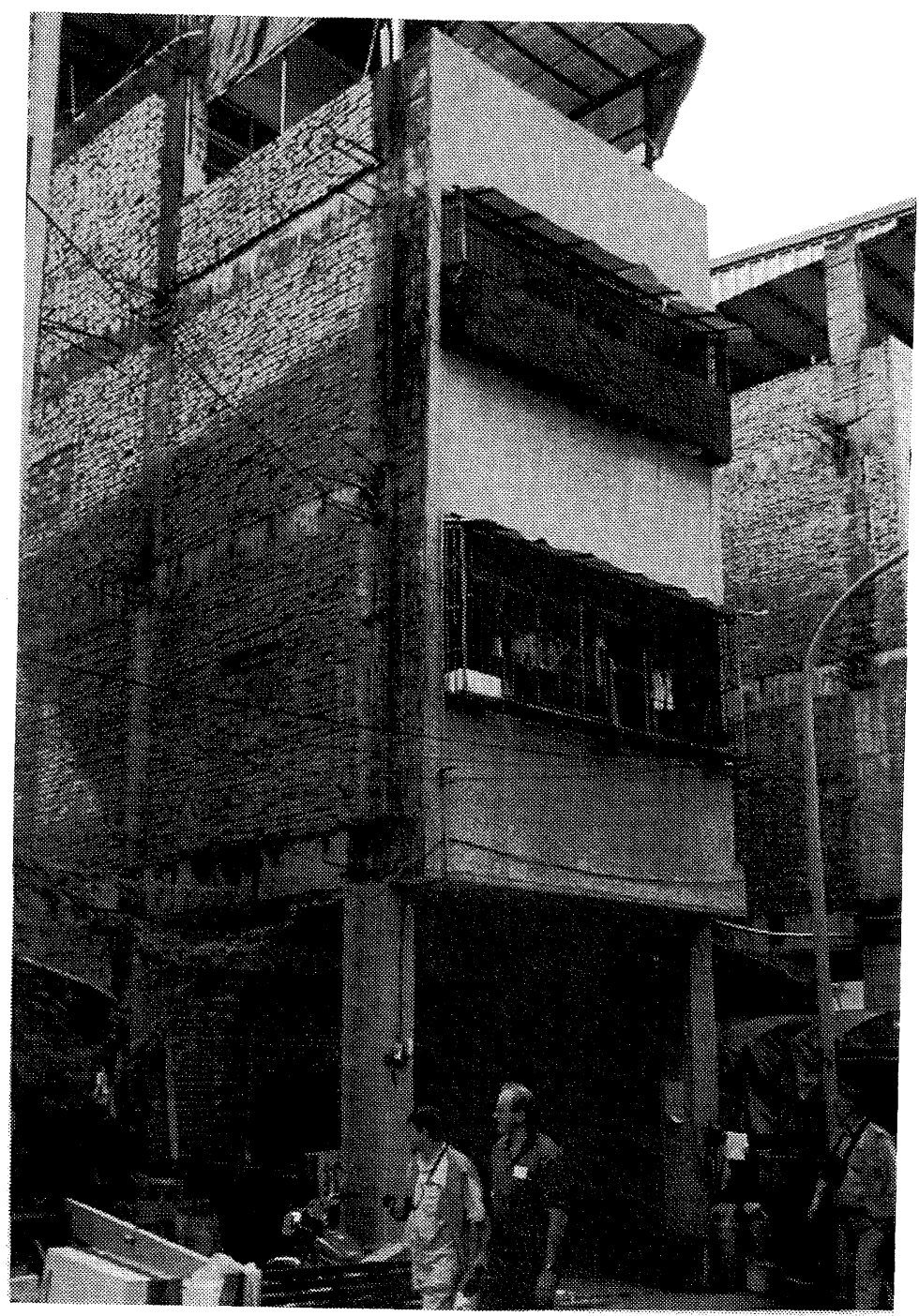

Figure 5.5: $\quad$ Tall single "Up to Heaven House", Fengyuan.

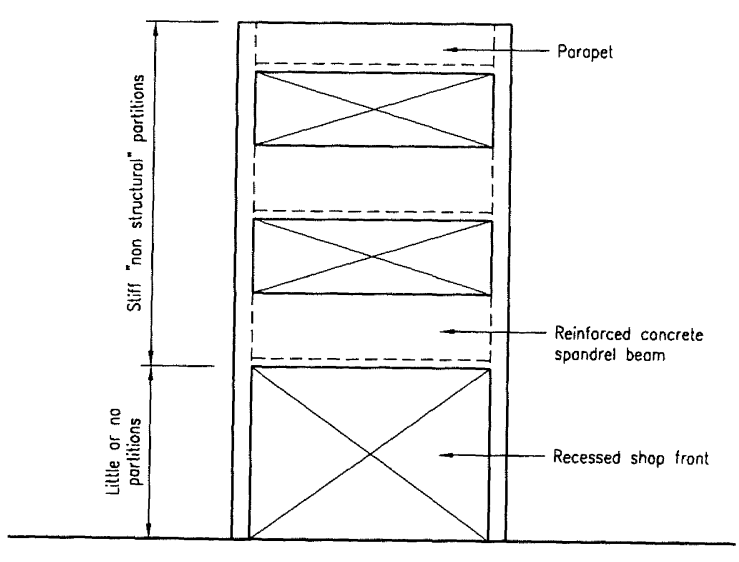

FRONT ELEVATION

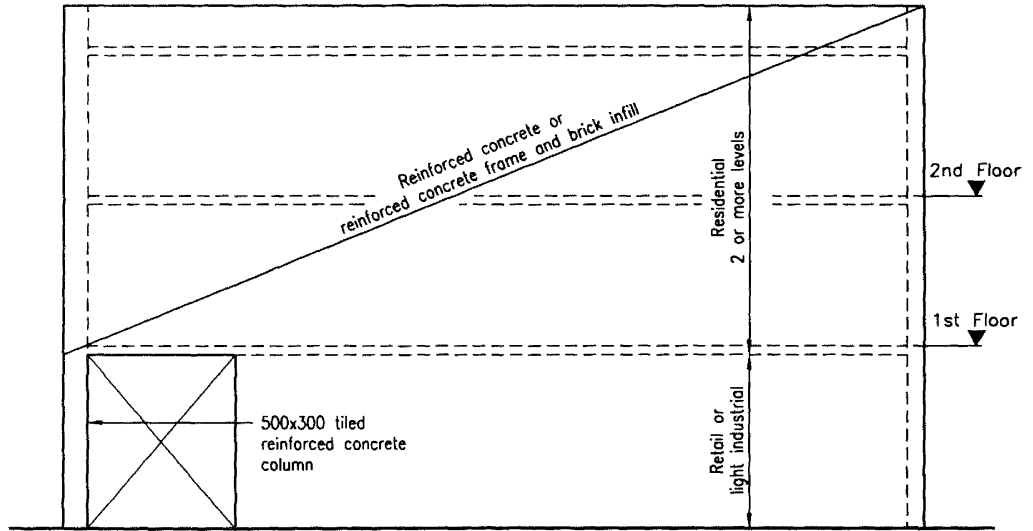

SIDE ELEVATION

Figure 5.6: Typical structural configuration of " $U p$ to Heaven House". 


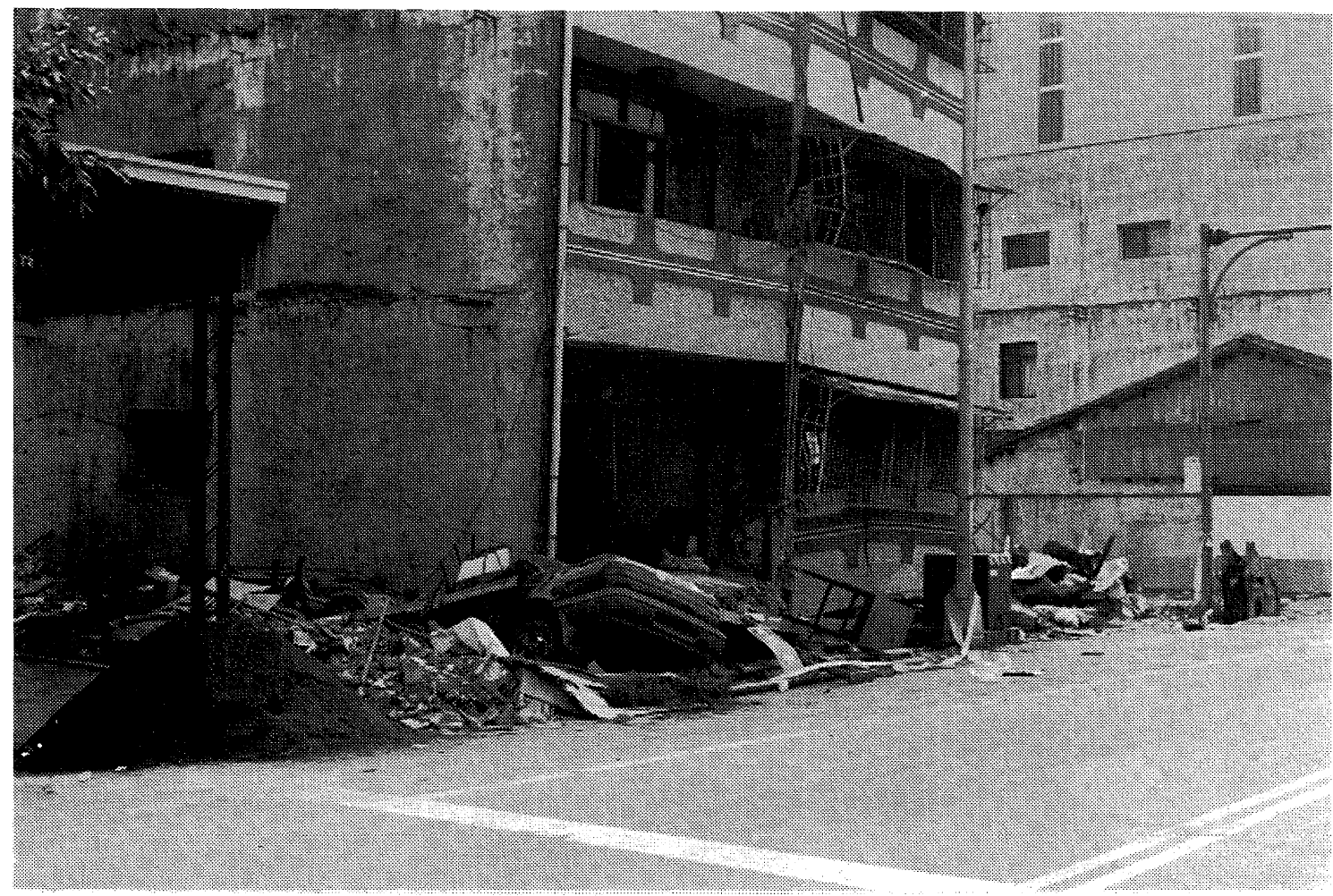

Figure 5.7: Weak storey collapse, Chi-Chi.

\subsection{Multi-storeyed Apartments and Hotels}

In the main these are reinforced concrete framed structures with significant amounts of infill panelling, masonry or lightly reinforced concrete, and like in the low-rise structures in the main these are not separated from the prime structure. In many of these structures a soft storey existed at the ground floor, either to provide for retail activities or car parking. In some of the larger developments the car parking is provided in basement areas and so that the soft storey situation was avoided.

While most of these buildings performed well, the overwhelming impression was that too many of these relativity modern buildings collapsed and at locations where there was little damage to more traditional buildings. An apartment block and a hotel in Taipei some $160 \mathrm{~km}$ from the epicentre collapsed. While Taipei is in a soft alluvial basin and thus subject to some site magnification effects, the press was reporting the failures as being primarily due to substandard construction.

Figure 5.8 shows the general streetscape in Fengyuan with a collapsed apartment building in the background. Neither the traditional buildings in the foreground or the water tanks on their roofs so any sign of distress. The extent of the collapse of this ten year old building in which some 47 people lost their lives is revealed in Figure 5.9. Located about $1 \mathrm{~km}$ from the fault trace on the downside, the extent of the collapse is understood to be attributed to the use of the ground floor for carparking and thus creating a soft storey. Other multi-storey apartment blocks in the vicinity had extensive damage to structural and non-structural elements and were in the process of being abandoned.

The traditional buildings shown in Figure 5.10 are located in Taichung city and have survived the event with little damage.
Some $50 \mathrm{~m}$ to the left of this is the building shown in Figures 5.11 and 5.12 , while some $200 \mathrm{~m}$ to the right is the so called "oil can building" as shown in Figures 5.13, 5.14 and 5.15.

Notwithstanding that the first of these buildings was "red tagged", there were a considerable number of people in the ground floor space. This building was clearly highly distressed and possibly owed its survival to the presence of the lightly reinforced concrete panel at ground level. Extensive cracking is evident over large areas of the building façade with sliding shear at first storey level causing significant cracking.

The "oil can building" was named after the presence of oil cans used to form voids in some of the architectural elements was exposed by the seismic damage. For all that the ground floor storey was lost over two thirds of this large building with the subsequent extensive damage to the upper floors it was reported that the four deaths in this building were all in the ground level retail area.

Figure 5.16 shows a view of an apartment complex in Taichung that suffered some structural damage and was to undergo repairs while still occupied by the owners. The damage to ground floor columns is shown in Figures 5.17 and 5.18. This structure showed evidence of poor strength concrete in these columns, a lack of confinement ties and joint reinforcement and inadequate cover, all in all poor construction. It was considered by local engineers that while the drawings would have called for joint reinforcement, steel fixers would have considered them too difficult to put in. It is anticipated that detailed analysis of these columns will reveal that they primarily suffered a compression failure due to the axial forces induced by overturning effects. 


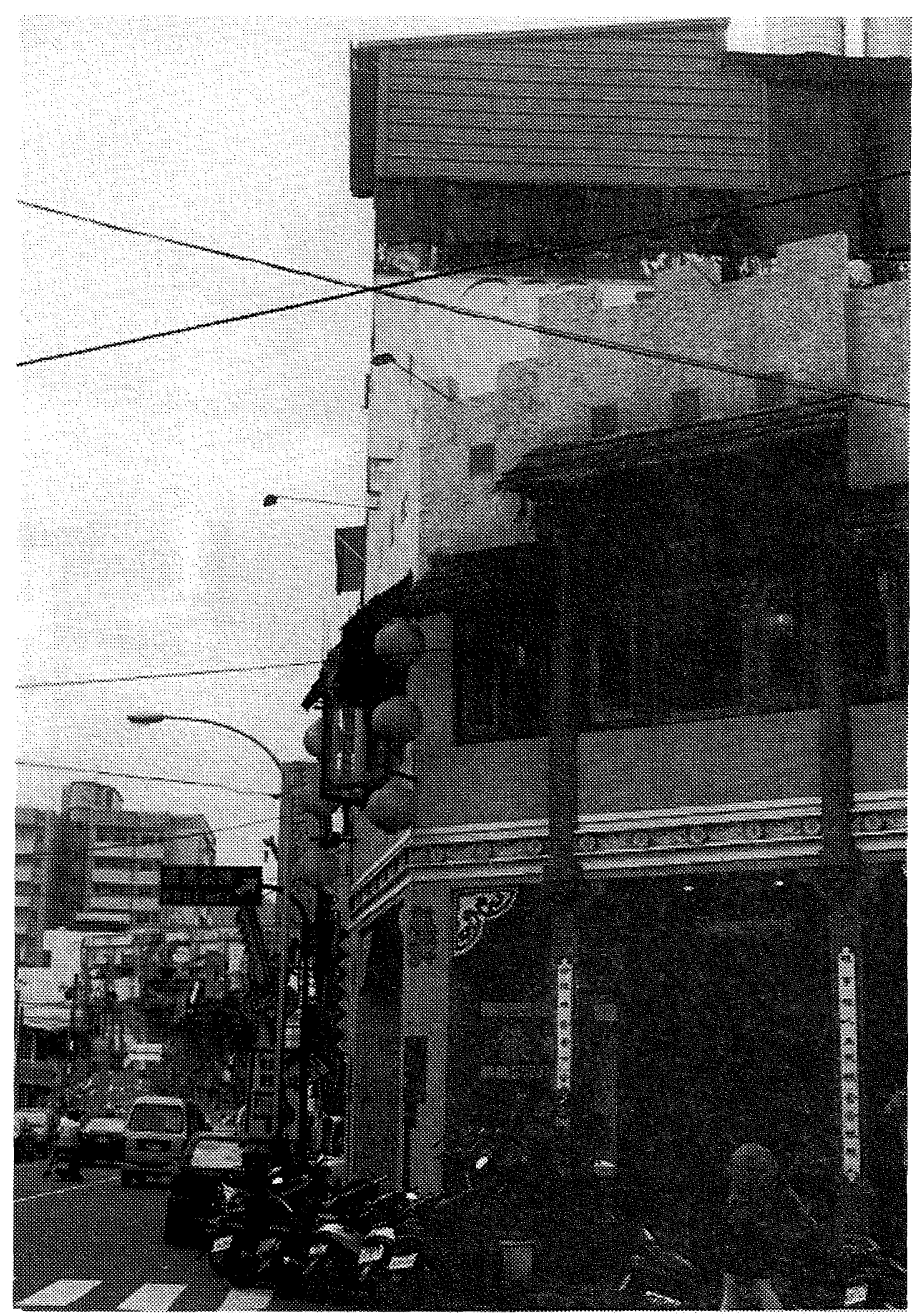

Figure 5.8: $\quad$ Fengyan Streetscape in vicinity of toppled building. Buildings generally undamaged.

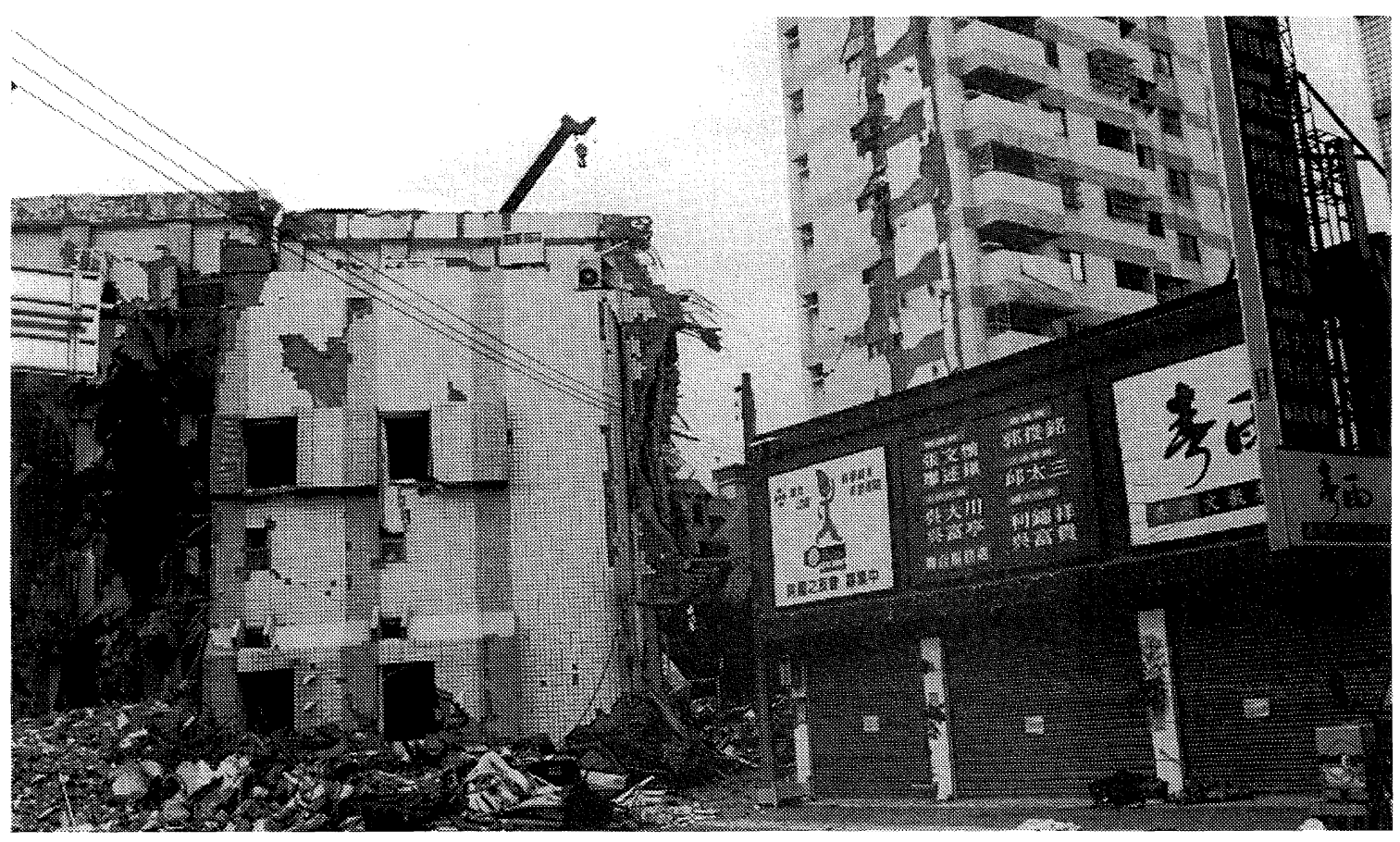

Figure 5.9:

Soft storey collapse resulting in toppled building, Fengyuan. 


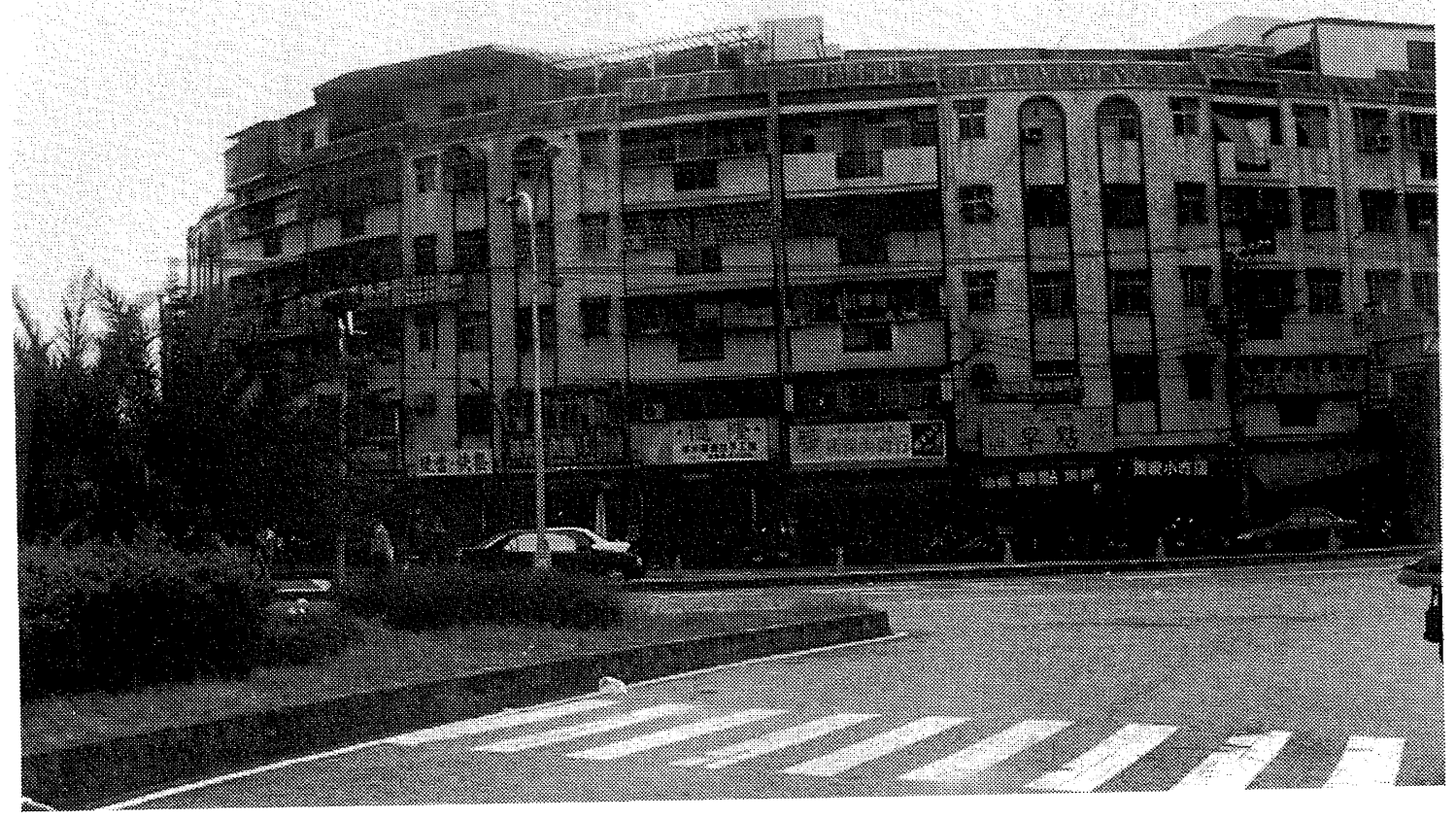

Figure 5.10: $\quad$ Traditional buildings in Taichung City.

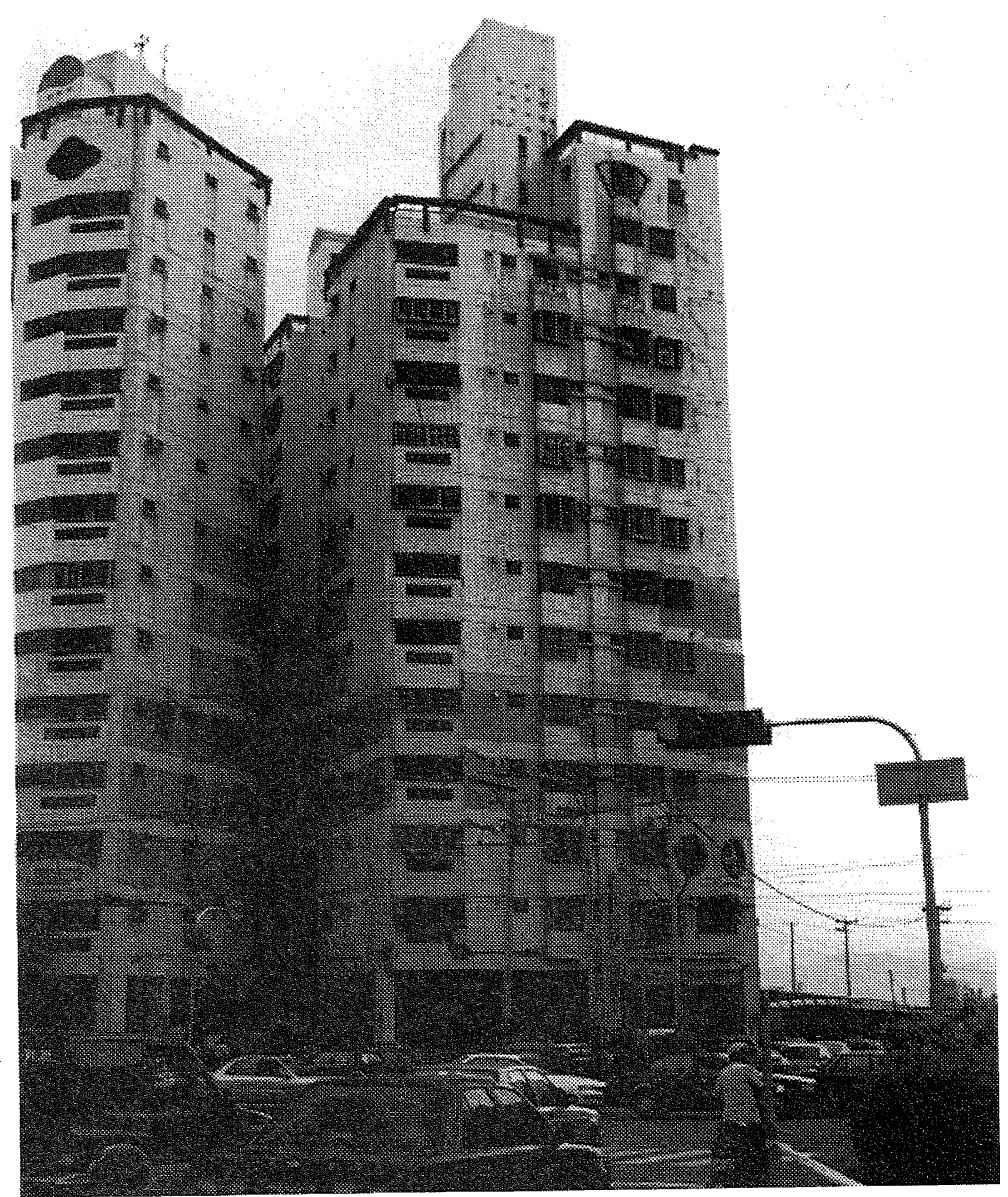

Figure 5.11: Overall view of damaged multistoreyed apartment building, Taichung. 


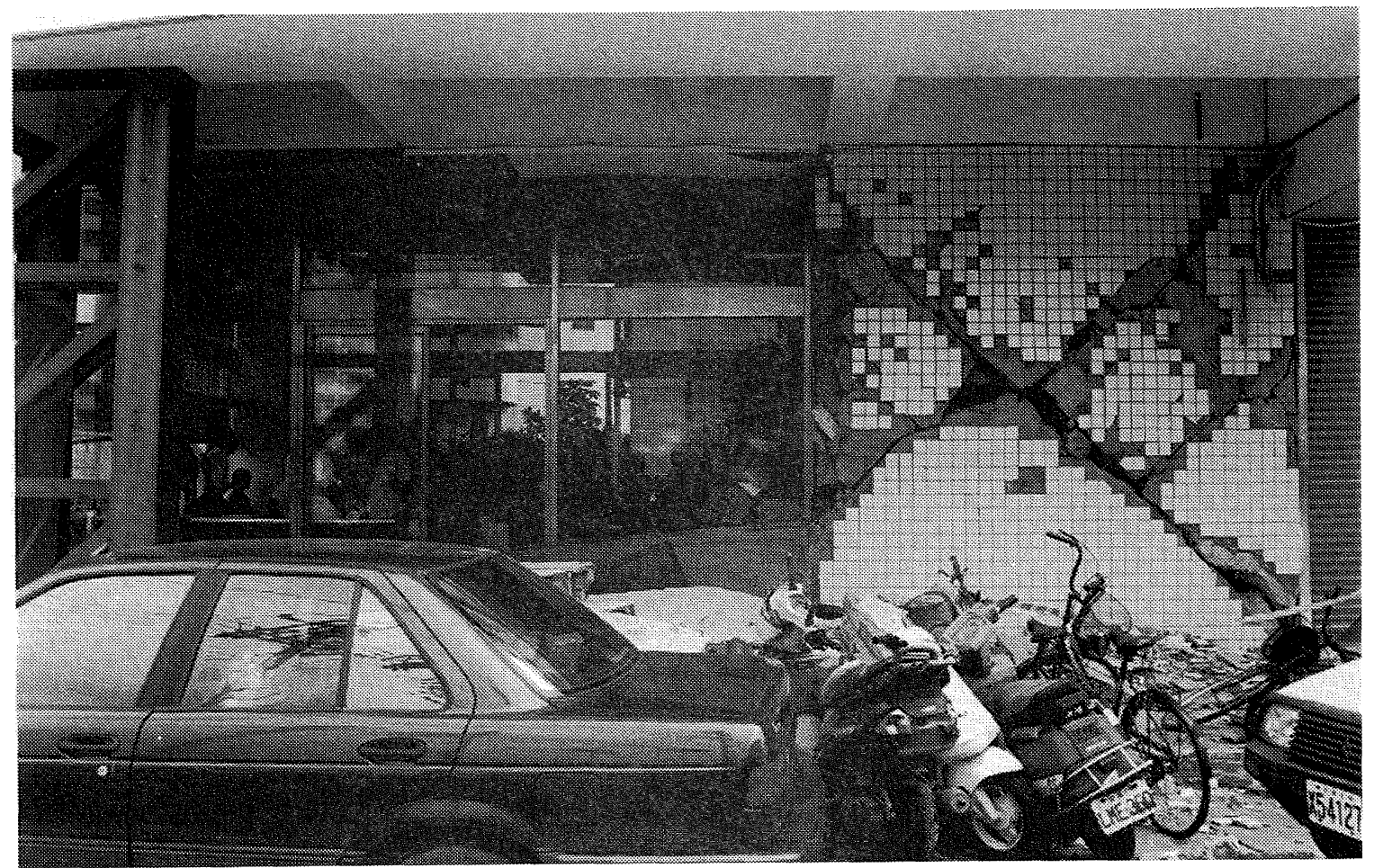

Figure 5.12: $\quad$ Detail of damage to single infill panel at ground level.

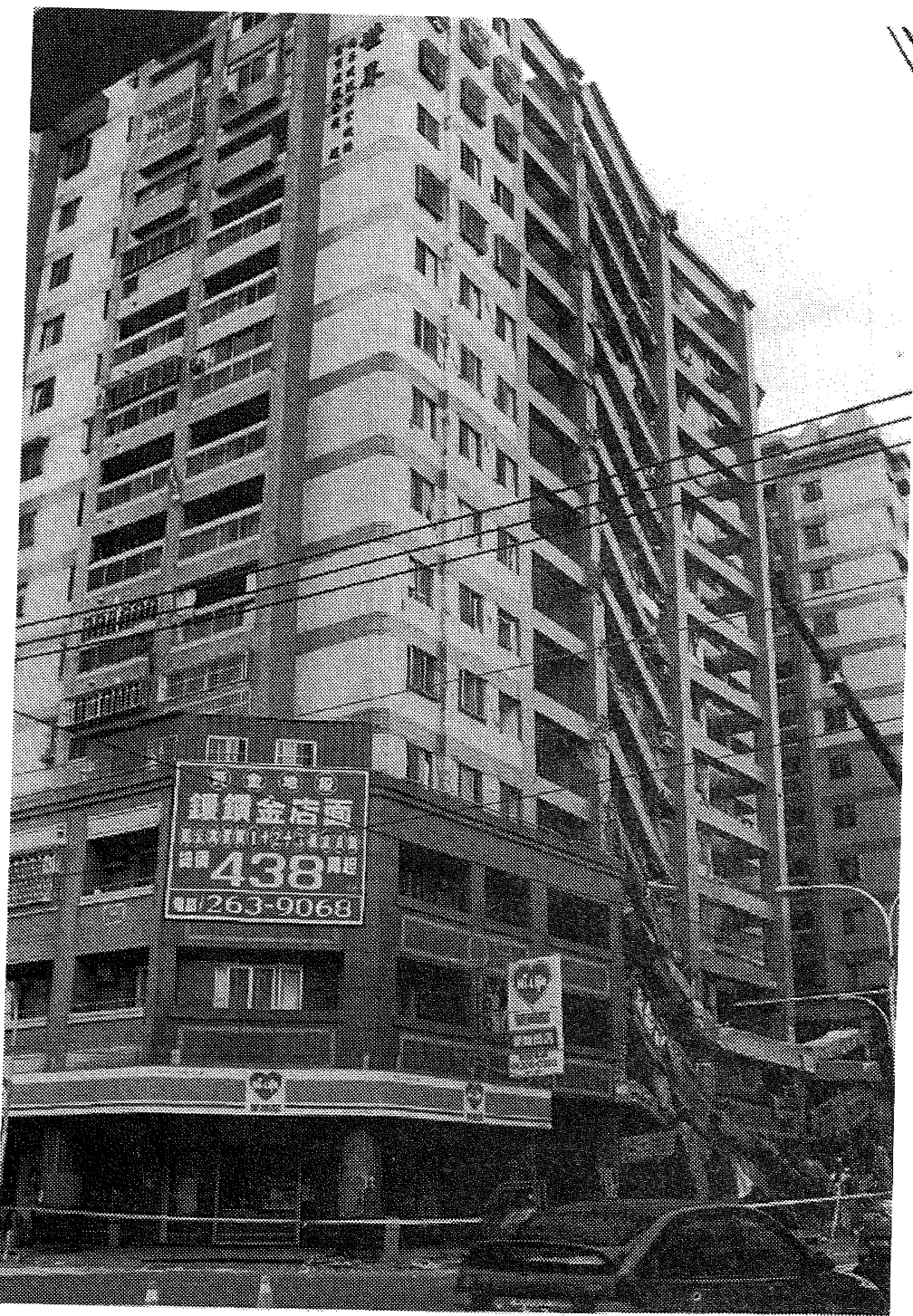

Figure 5.13: $\quad$ Overall view of "Oil Can Building" showing loss of storey over part of the building - Taichung. 


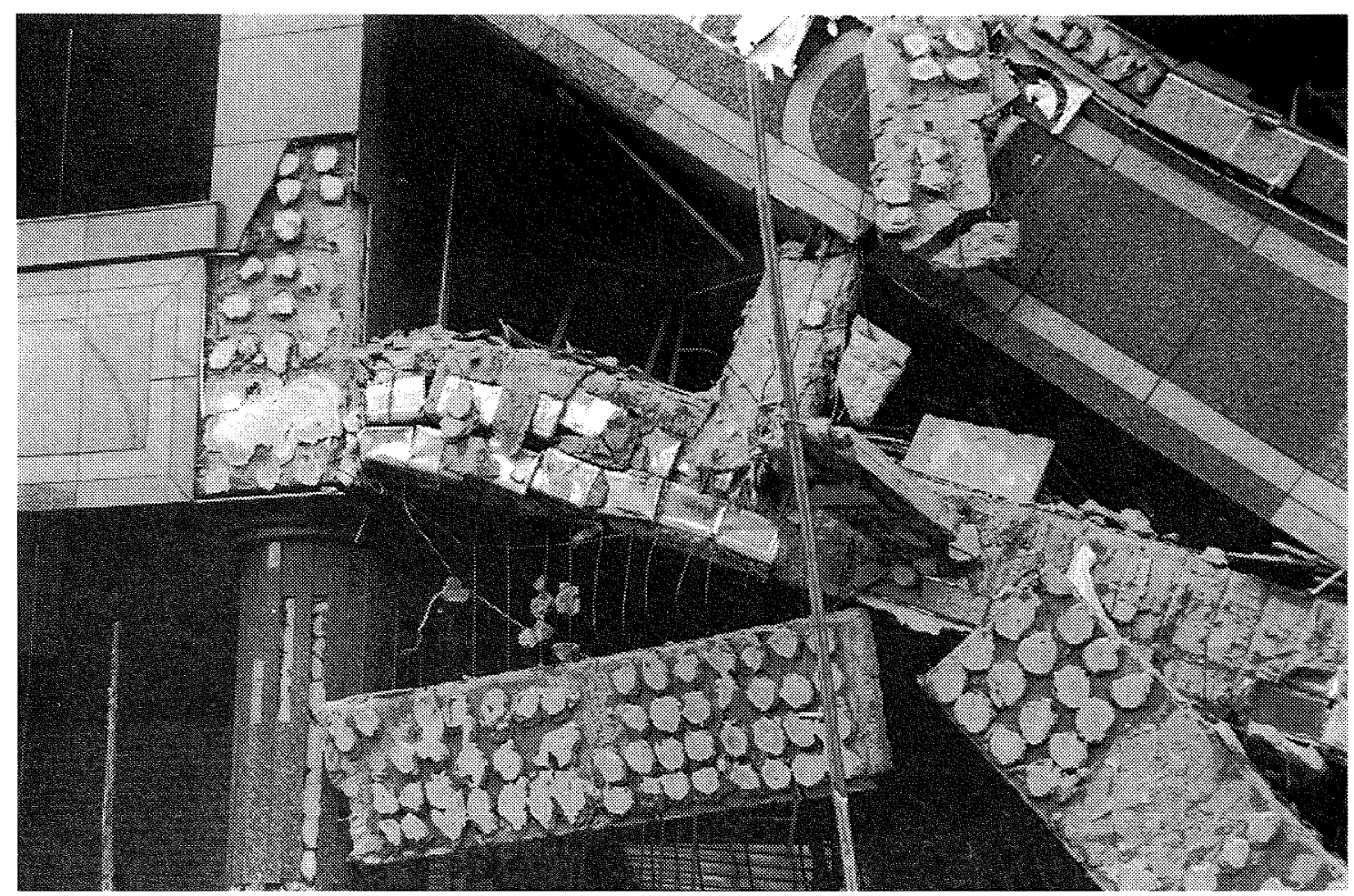

Figure 5.14: $\quad$ Detail of damage at first floor level of "Oil Can Building".

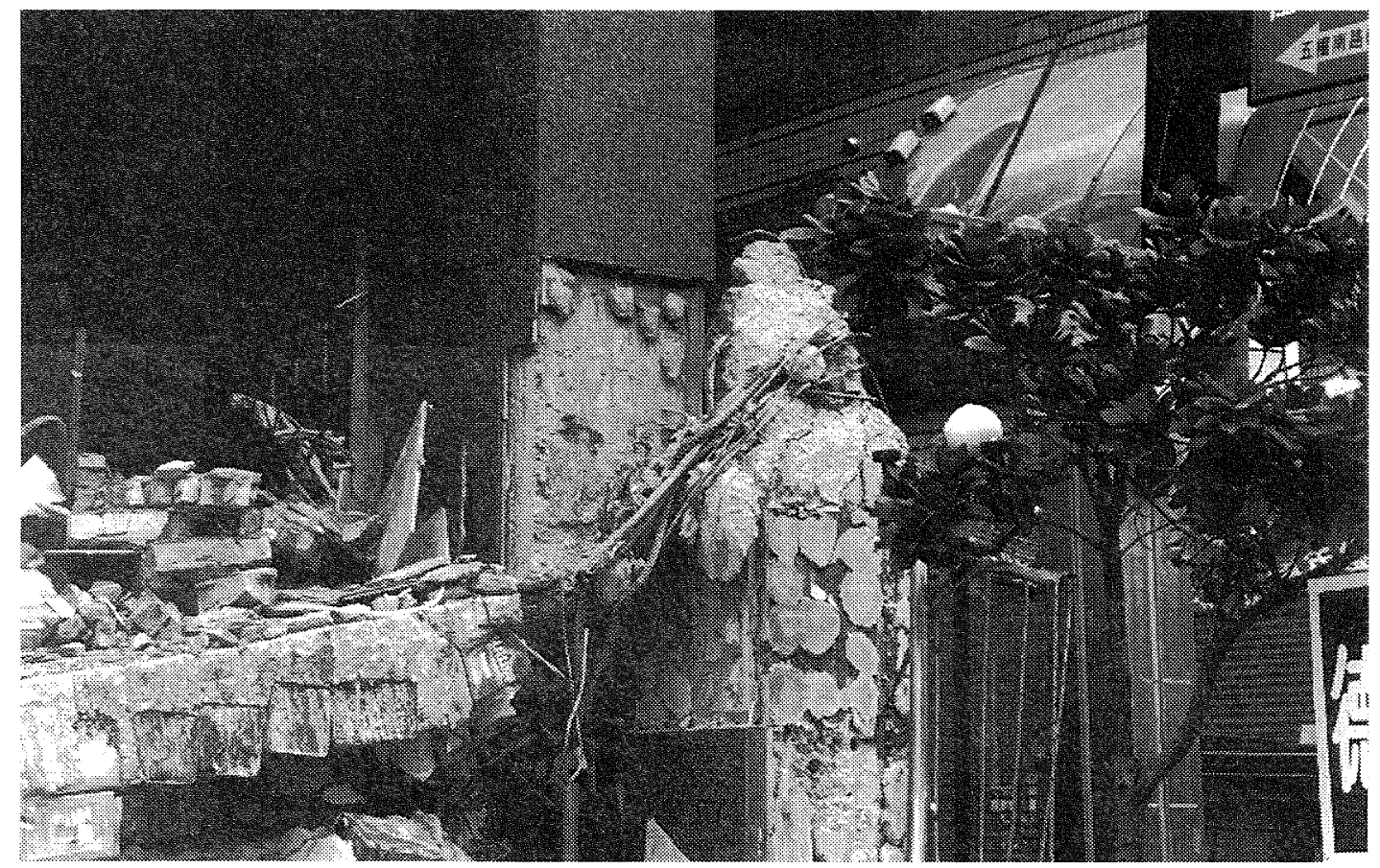

Figure 5.15: Detail of column offset in "Oil Can Building”. Note lack of confinement reinforcement. 


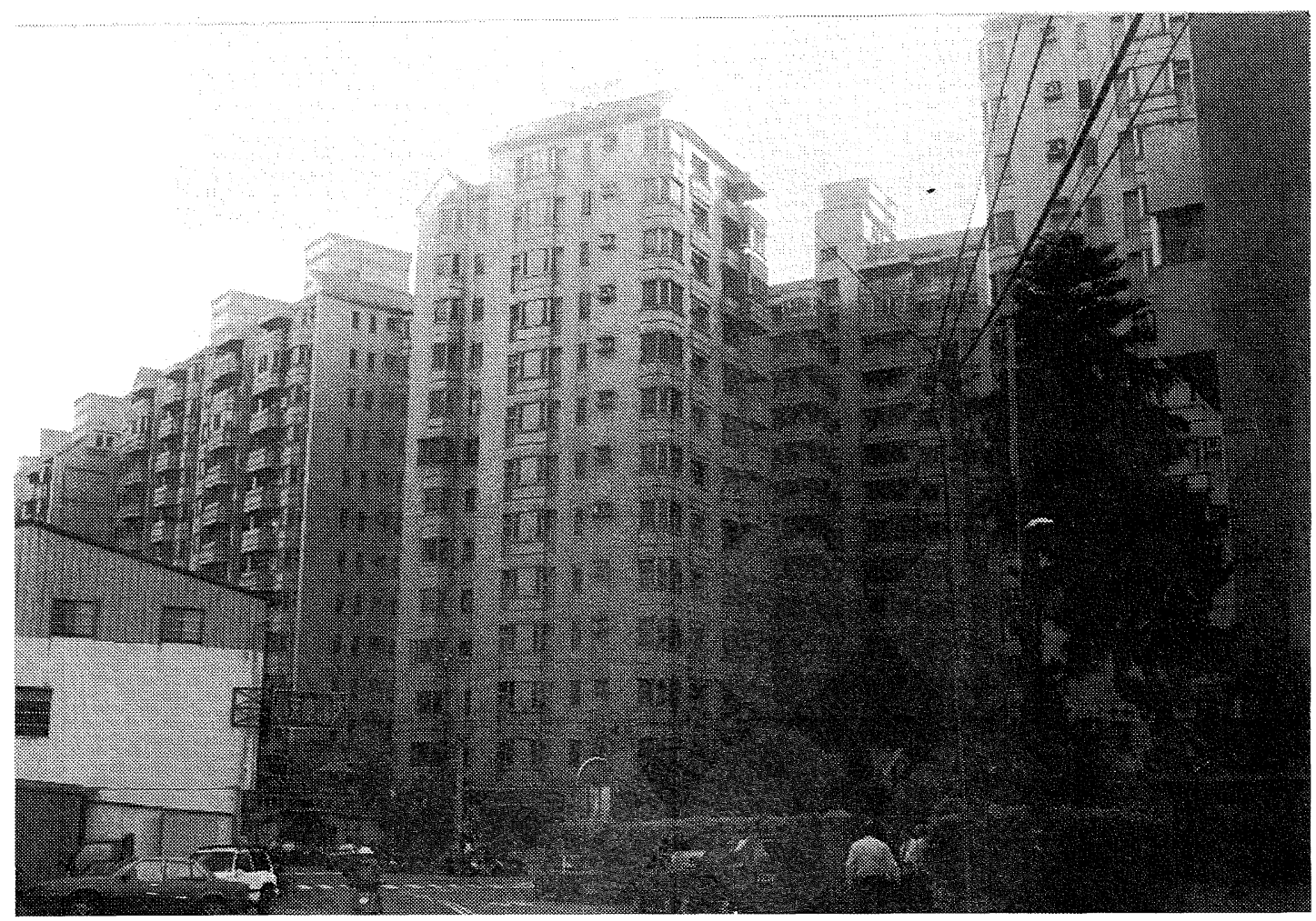

Figure 5.16: $\quad$ Apartment complex in Taichung. Basement carparking and ground floor apartments allow structural form to carry to ground level without significant stiffness variation. Non-structural panels present on all levels.

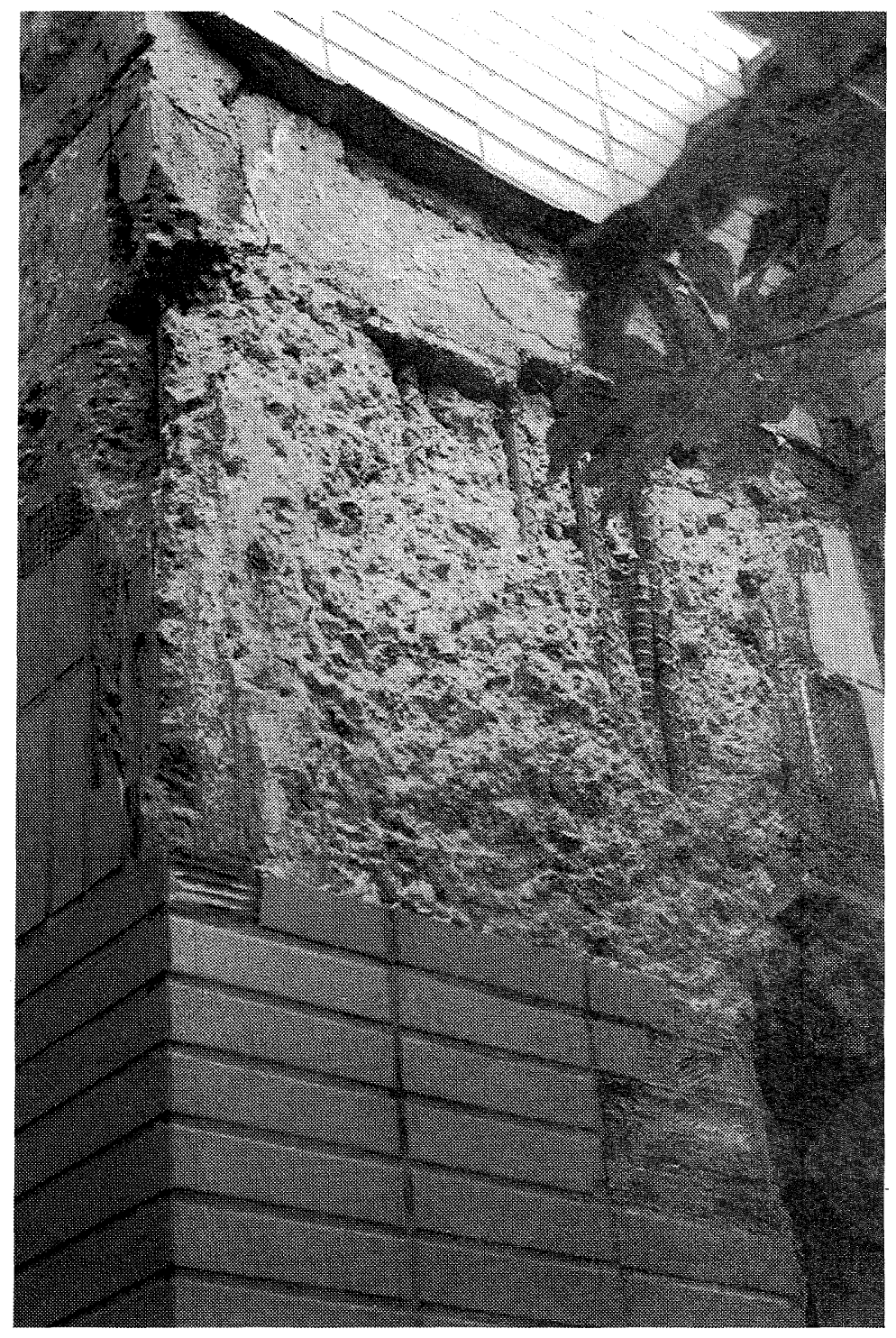

Figure 5.17: Damage to beam corner column junction at first floor level of complex shown in Fig 5.15. Inadequate joint ties and poor quality concrete evident. 


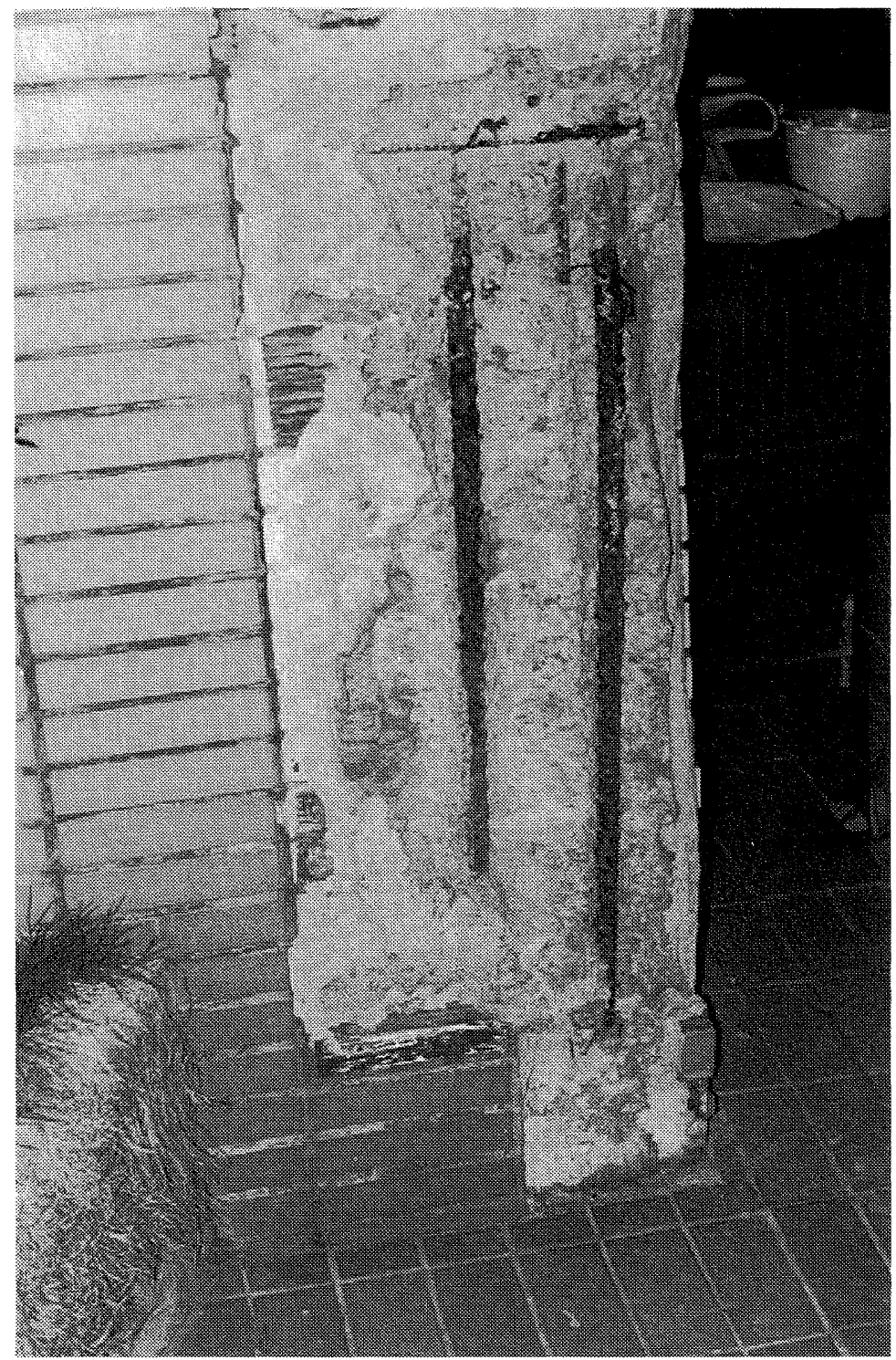

Figure 5.18: $\quad$ Same building as Fig 5.17 showing spalled cover to ground floor column at location of splice to longitudinal bars. Non confining reinforcement to the splice and inadequate cover.

\subsection{Multi-storeyed Commercial Buildings}

Most of the multi-storey commercial buildings (as opposed to residential buildings) observed by the team were located in the cities of Taipei and Taichung. Information was mainly gathered during the course of discussions with the occupants of such buildings.

Taipei and Taichung cities are located $120 \mathrm{~km}$ and $30 \mathrm{~km}$ respectively from the earthquake epicentre and were not affected by fault rupture. Consequently these cities did not experience severe shaking or large permanent ground deformations. For example, preliminary estimates of peak ground accelerations from strong motion recording stations in or near Taichung city were in the range $0.2-0.25 \mathrm{~g}$. Damaged observed to the limited numbers of masonry buildings seen in the city indicated a Modified Mercalli intensity of MMVII.

Commercial buildings in Taichung ranged up to 30 storeys high and appeared to commonly be steel or reinforced concrete frame construction. Most of these buildings have been constructed since the 1970s. There were no reports of collapses of large commercial buildings in Taichung. However there was evidence of localised non-structural damage to stiff partition walls and to cladding on a large number of buildings, and some buildings in central Taichung were closed for repair.

Figure 5.19 shows the headquarters of Chungwa Telecom Central Region in Taichung City. This building is a steel framed structure and had only been occupied a little over a year. Damage was minor, being limited to localised falling of ceiling tiles and demountable partitions and damage to office equipment.

\subsection{Industrial Facilities}

The papers reported that the major Science Park (approximately $100 \mathrm{~km}$ from the epicentre), where computer chips were manufactured suffered damage to the 
manufacturing processes. However, it is understood that operations were quickly reinstated and the main problem for the industry was the lack of electric power.

Light portal-framed buildings showed no signs of visible damage, with the exception of the structure in Figure 5.20. This two storey building was stacked with pallets of timber on both floors, and its collapse can be attributed to the fact that there was no bracing or framing in the longitudinal direction.

\subsection{School Buildings}

Virtually all school construction was of concrete due to the threat of typhoons, and typically of more than two storeys in city areas as a consequence of land constraints. School buildings had historically been designed and constructed to a higher standard than private sector buildings due to central government policies.

Damage was nevertheless severe and widespread. A total of 786 schools nationwide were damaged in some way, with 43 schools in the worst affected areas of Nantou and Taichung counties being condemned. Reconstruction and repairs are estimated to cost NZ $\$ 2.24$ billion, comprising

- $\quad \mathrm{NZ} \$ 1.2$ billion for 656 elementary and junior high schools

- $\quad \mathrm{NZ} \$ 0.6$ billion for 47 public and private colleges

- NZ\$0.5 billion for 83 senior high and vocational colleges

A new mandatory regulation stipulating that no school buildings will be able to be built on or directly adjacent to fault lines was rapidly introduced.

\subsection{Contents and Non-structural Elements}

The nature of our reconnaissance was such that not a lot of damage to contents and non-structural items was seen, but hearsay evidence was gathered.

One exception was at the Taipower switching station at Chungliao, where some cabinets within the control building had toppled over and contributed to the problems of reticulating power from southern to northern Taiwan. These and their failed holding down bolts are shown in Figures 5.21 and 5.22. Note the high level restraint subsequently installed to the nearby wall.

Most of the damage at the Hsin Chu Science-based Industrial park involved non-structural elements. Unbraced sprinkler pipe systems reportedly impacted in some buildings, causing a discharge of water onto valuable contents. Fire resulting from some standby generators burning out led to the contamination of 'clean room' environments given the absence of filtration due to the loss of power.

The hotel that the NZSEE team stayed at in Taichung reported that they lost $11 \mathrm{TV}$ sets from sliding off the units they were placed on. This hotel was about 10 storeys high and had some evidence of minor damage in the stairwell, as the stairs were not separated so as to allow sliding at floor level.

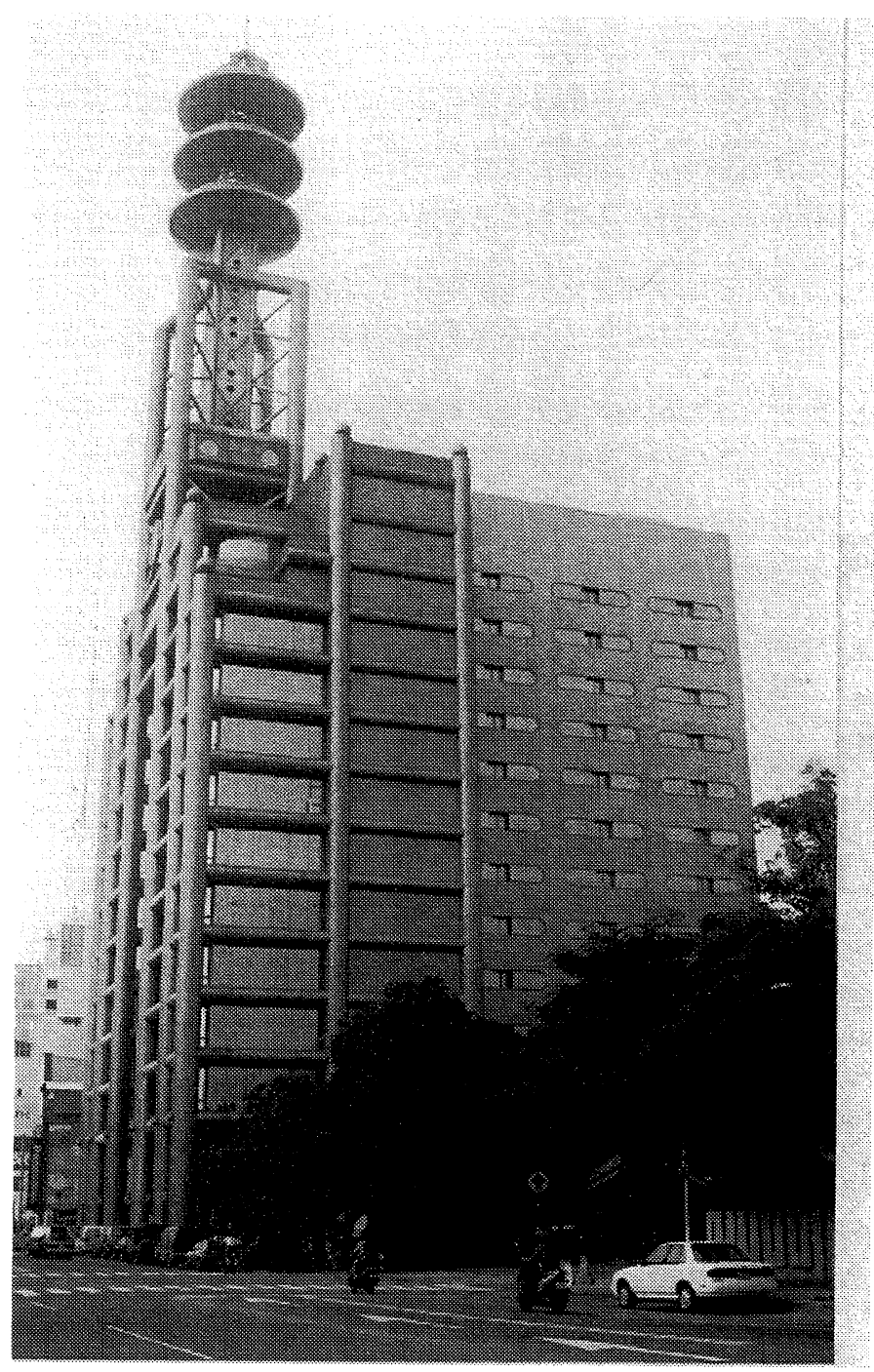

Figure 5.19: Commercial headquarters of Chunghwa Telecom in Taichung City. 


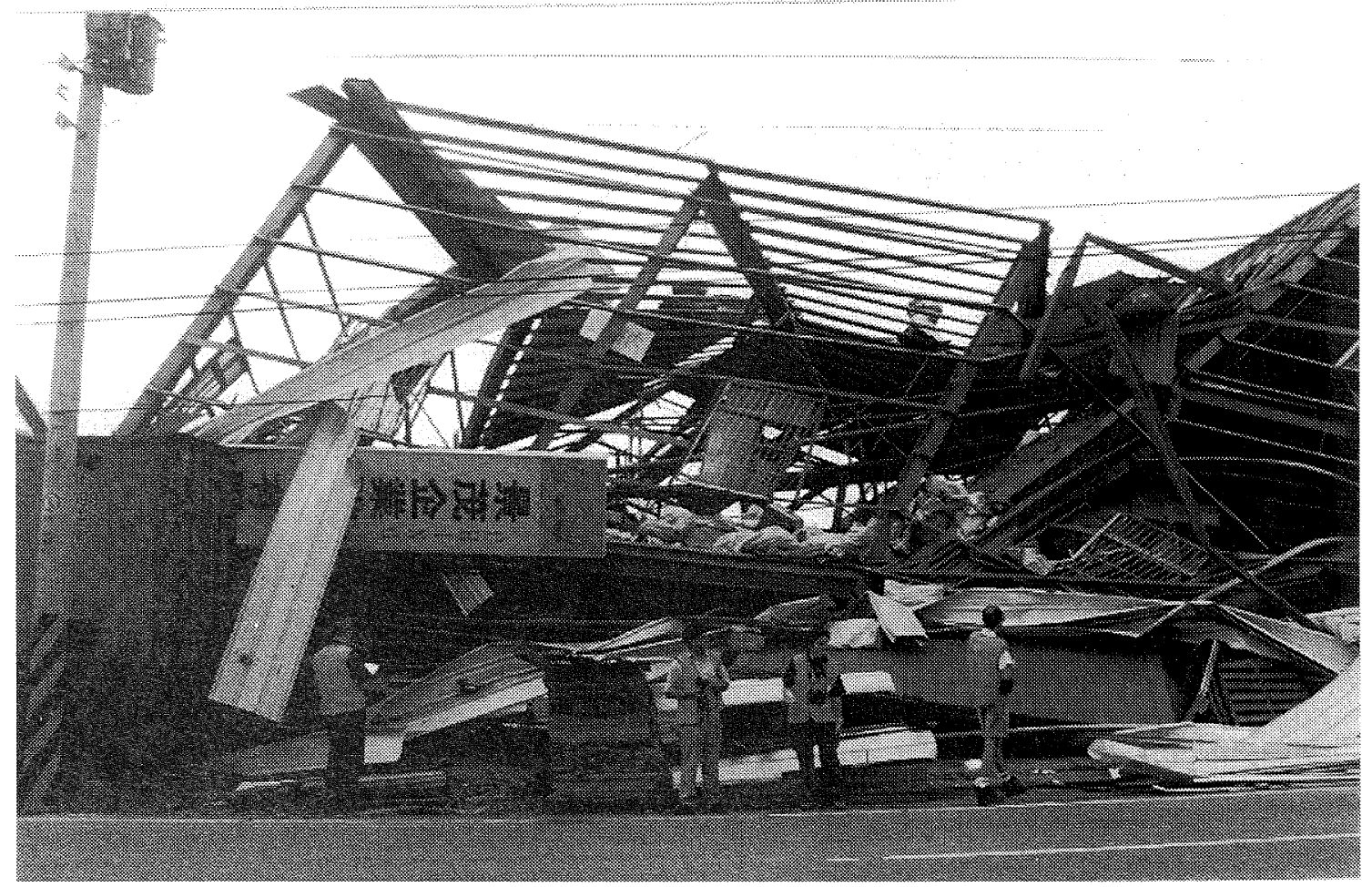

Figure 5.20: $\quad$ Collapse of steel framed building attributable to absence of any bracing or framing in the longitudinal direction.

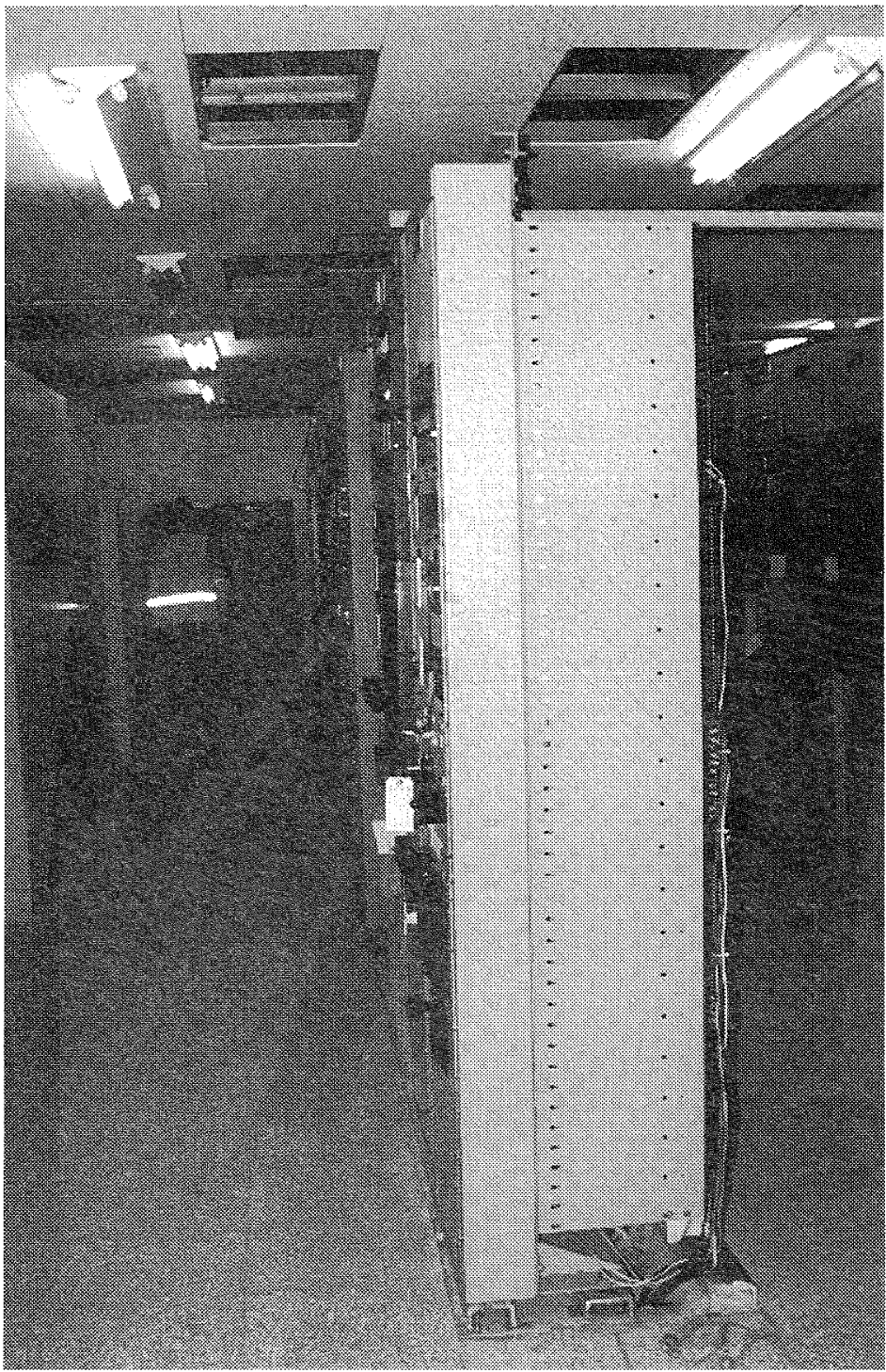

Figure 5.21: Control cabinets in Chungliao substation that toppled during the earthquake. 




Figure 5.22: $\quad$ Detail of failed holding down bolts that allowed cabinets to topple.

\section{BRIDGES}

\subsection{Design Codes and Standards}

Just as the design of buildings has followed the UBC code, the modern bridges are designed following the recommendations of the AASHTO code. The basic seismic zones are the same as for buildings, with the latest code being adopted in 1995.

In a recent draft Taiwanese code for railway bridges, peak ground accelerations for each of the seismic zones are increased by approximately $20 \%$. This code also has some aspects that are taken from Japanese requirements, particular the propagation of soil deformation from the bedrock to the ground surface.

In general the standard of construction seemed to be significantly better than was evident in the apartment building sector. However, there did not seem to be any substantial tie bolt connection between adjacent spans in some of the bridges that were damaged.

\subsection{Expressways and Arterial Routes}

The Taiwan Highway Bureau is responsible for the planning, construction and maintenance of the national highway network.

The majority of the bridges in the affected area are constructed from precast-prestressed concrete I beams with in-situ concrete decks. Rubber pads on concrete pier heads atop circular reinforced concrete piers support these beams.
In the vicinity of Taichung there is considerable expansion of the expressway system under construction. Much of this construction consists of precast-prestressed reinforced concrete box girders with some steel box girders for the main spanning elements. Some of these bridges use pot bearings instead of rubber bearings. There was no evidence of the use of lead rubber bearings.

In general these bridges performed well. In all instances of major damage there was evidence of major ground movement either by way of the actual fault trace or ground slumping/landslides.

Figures $6.1,6.2$ and 6.3 are all of the collapsed bridge crossing the Tachia Hsi River near Tungshih. The hillside above the right abutment had slumped, movements of about 8 $\mathrm{m}$ horizontally and $2 \mathrm{~m}$ vertically being visible within $150 \mathrm{~m}$ of this bridge. There is no evidence of any significant interconnection between the adjacent spans. Considering the size of the river channel the pipes under the temporary causeway would not be able to cope with a typhoon deluge.

Figure 6.4 is of the Chosui River Bridge and the damage to the abutment is attributable to the dislocation of the fault in the immediate vicinity. The loss of an abutment of a bridge on the Chi-Chi to Mingchien road near Shuli can be seen in Figure 6.5. In this instance the failure is associated with the loss of toe support to a retaining wall built on top of a slope.

Ground slumping of a canal wall can be seen in Figure 6.6. This also influenced the ground beneath the abutment of the bridge under construction and caused settlement. This in turn caused rotation of the bridge girders over the out of shot to the right. Beneath the bridge the movement to the right was about $600 \mathrm{~mm}$ as evidenced by the deformation of the soil around the pier. 
At another bridge under construction a pot bearing between a precast-prestressed concrete box girder and a blade wall pier failed (refer Figure 6.7). The bearing was supporting a segment of the bridge that was still under construction whereas the completed segment to the right of this photograph showed no signs of distress to these items.

\subsection{Other Bridges}

The Taichung City Council has 366 bridges within their control. A review of many of the bridges was undertaken by a team of Canadian engineers, and their report made available to the team.

An analysis of this report indicated that of 24 bridges inspected, 2 were destroyed and 7 were closed (including those destroyed), with a further 2 being rated as restricted use. Of these, 22 had damage due to the settlement of the approaches, damage to abutments or retaining walls.

Figure 3.18 shows typical minor settlement of the approach to the abutment of a bridge in Taichung City.

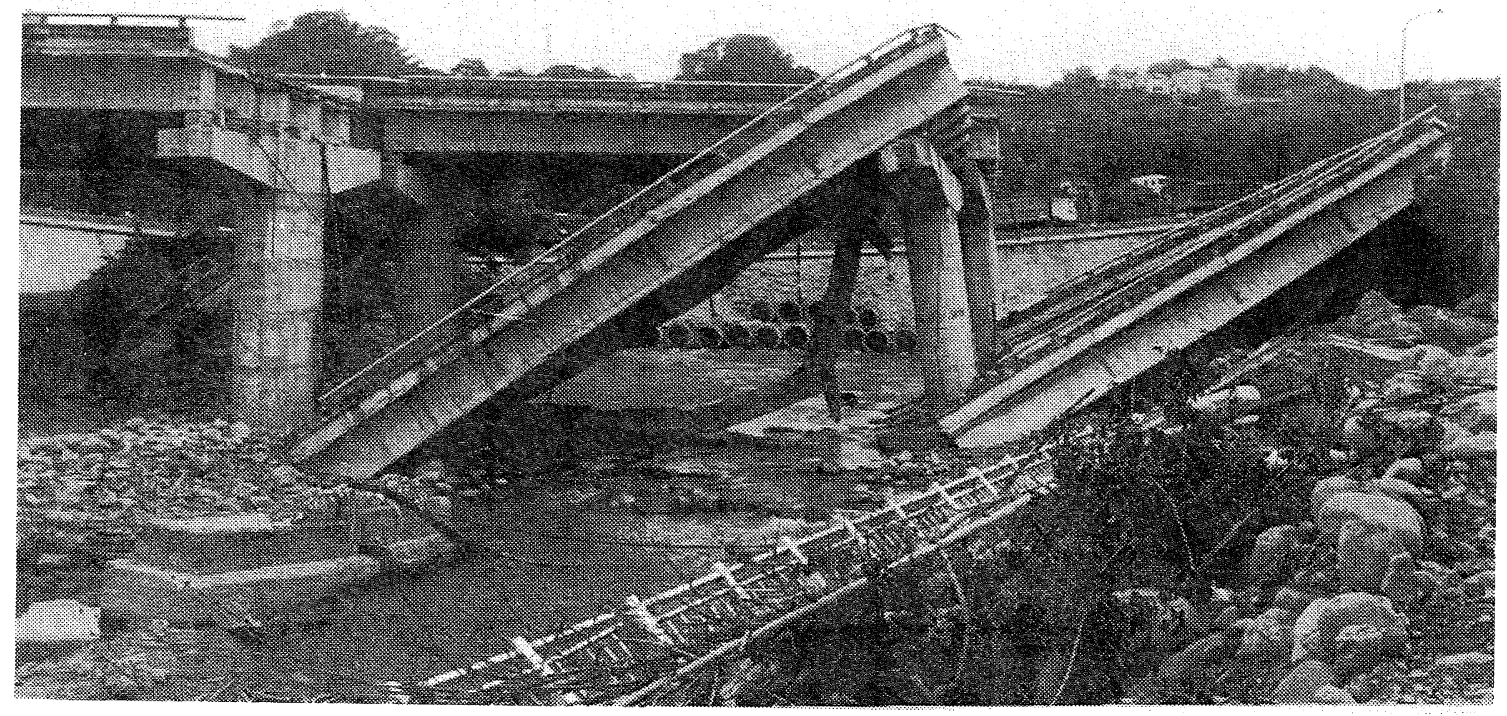

Figure 6.1: $\quad$ Collapsed spans of prestressed concrete I beam bridge crossing the Tachia Hsi river.

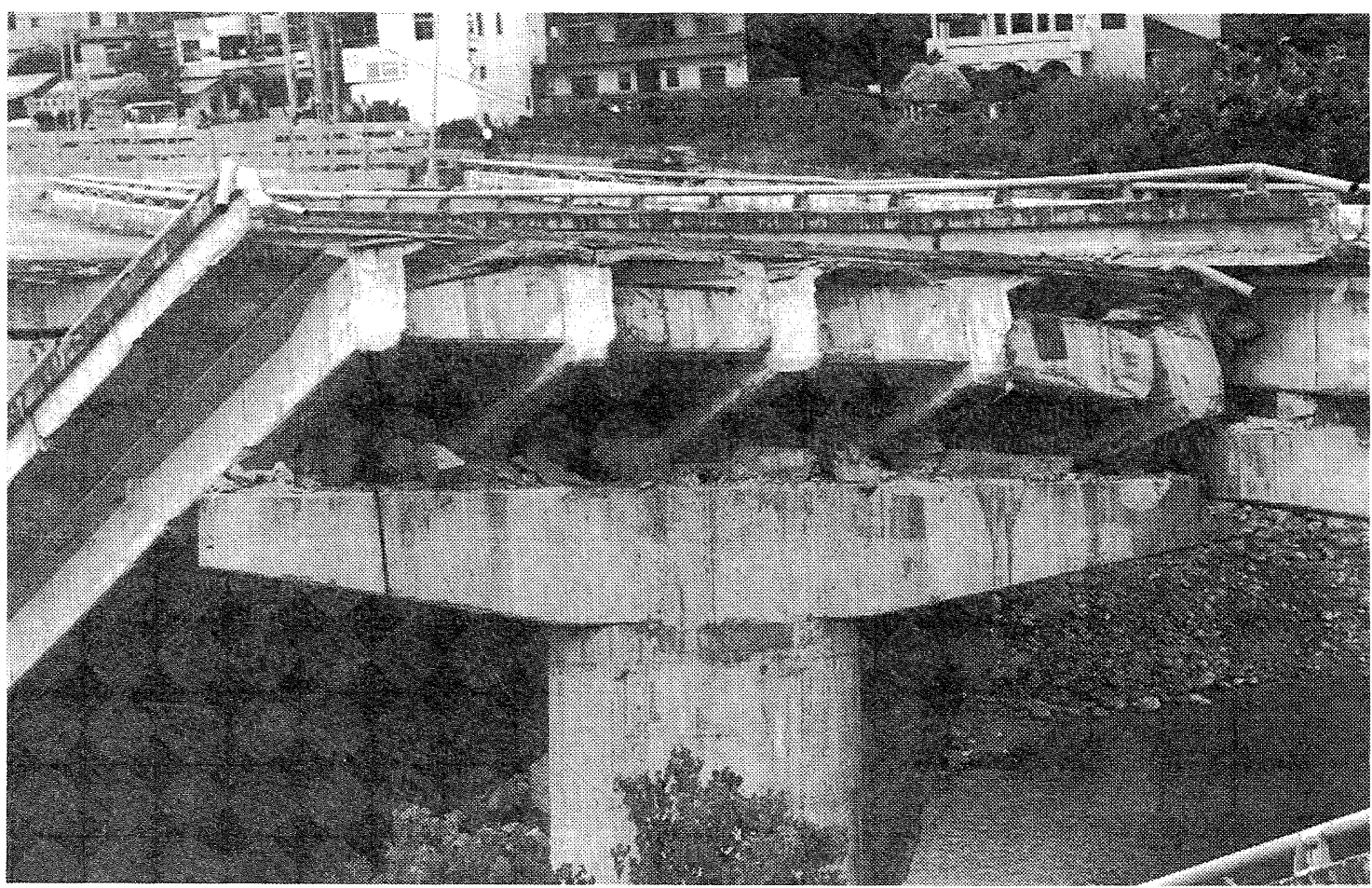

Figure 6.2: Detail of end of one of the collapsed spans. No evidence of any longitudinal interconnection between spans. 


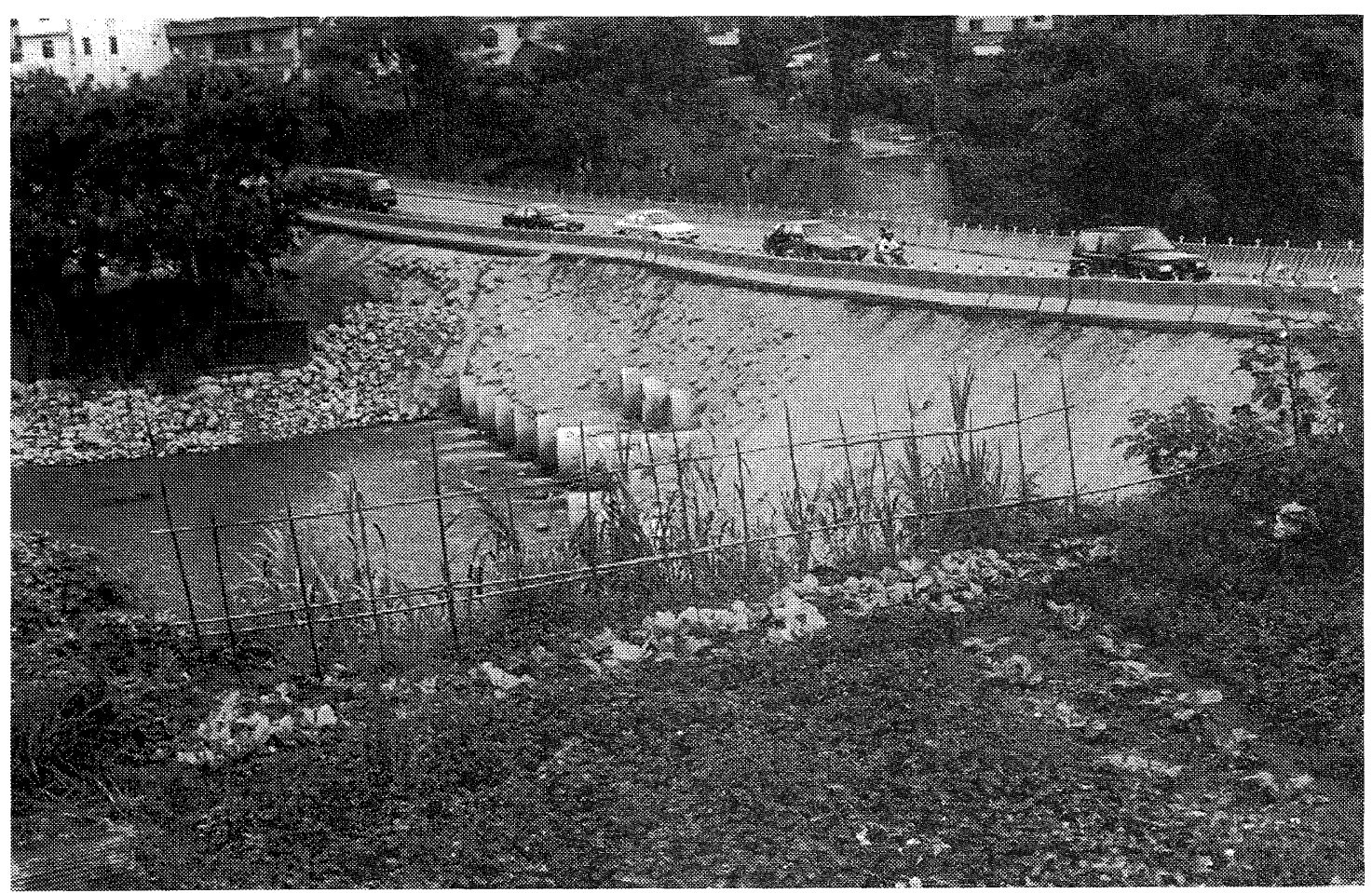

Figure 6.3: $\quad$ Temporary causeway constructed to establish a river crossing.

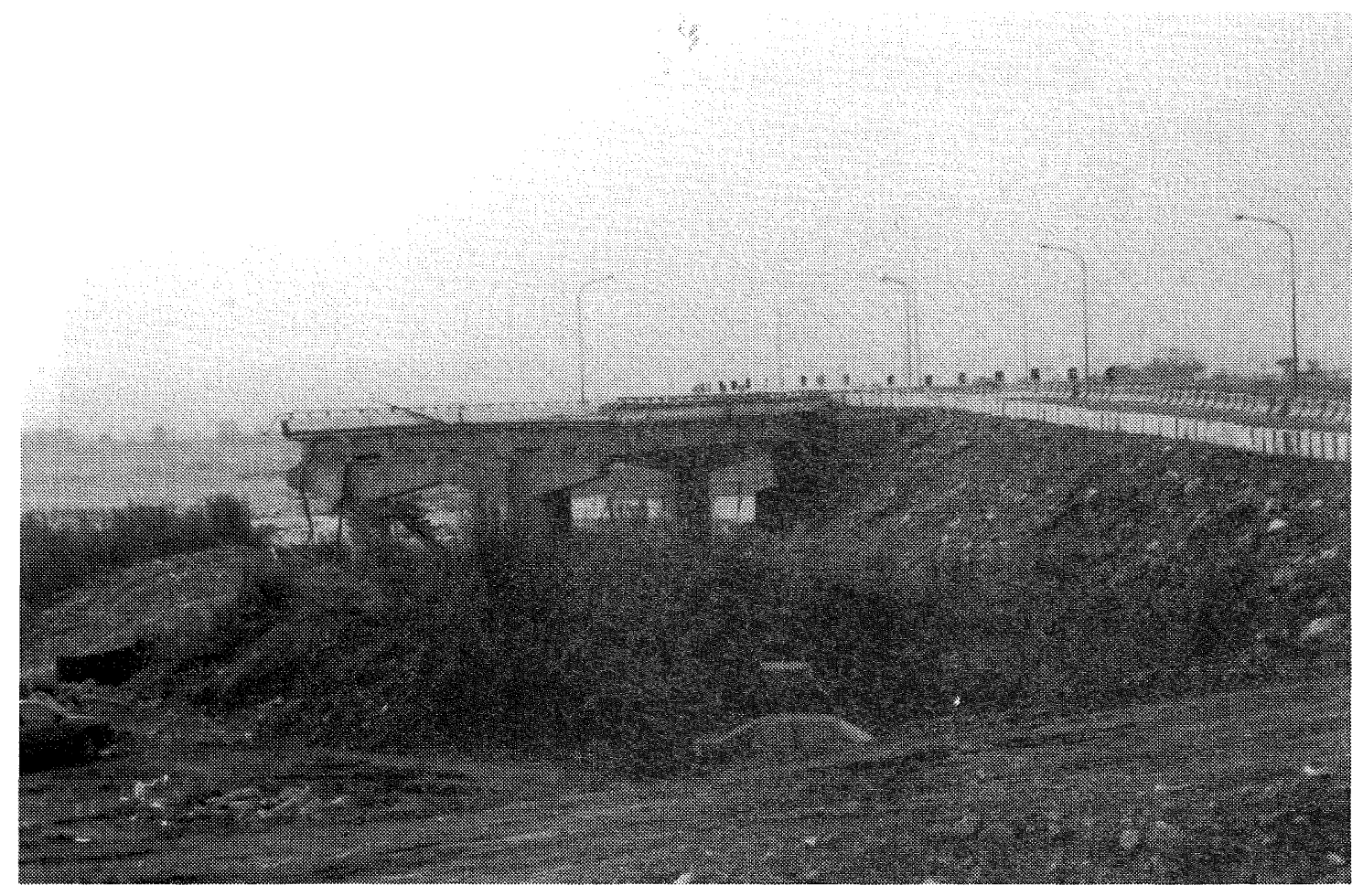

Figure 6.4: $\quad$ Damage to abutment span of bridge crossing the Chosui river. 


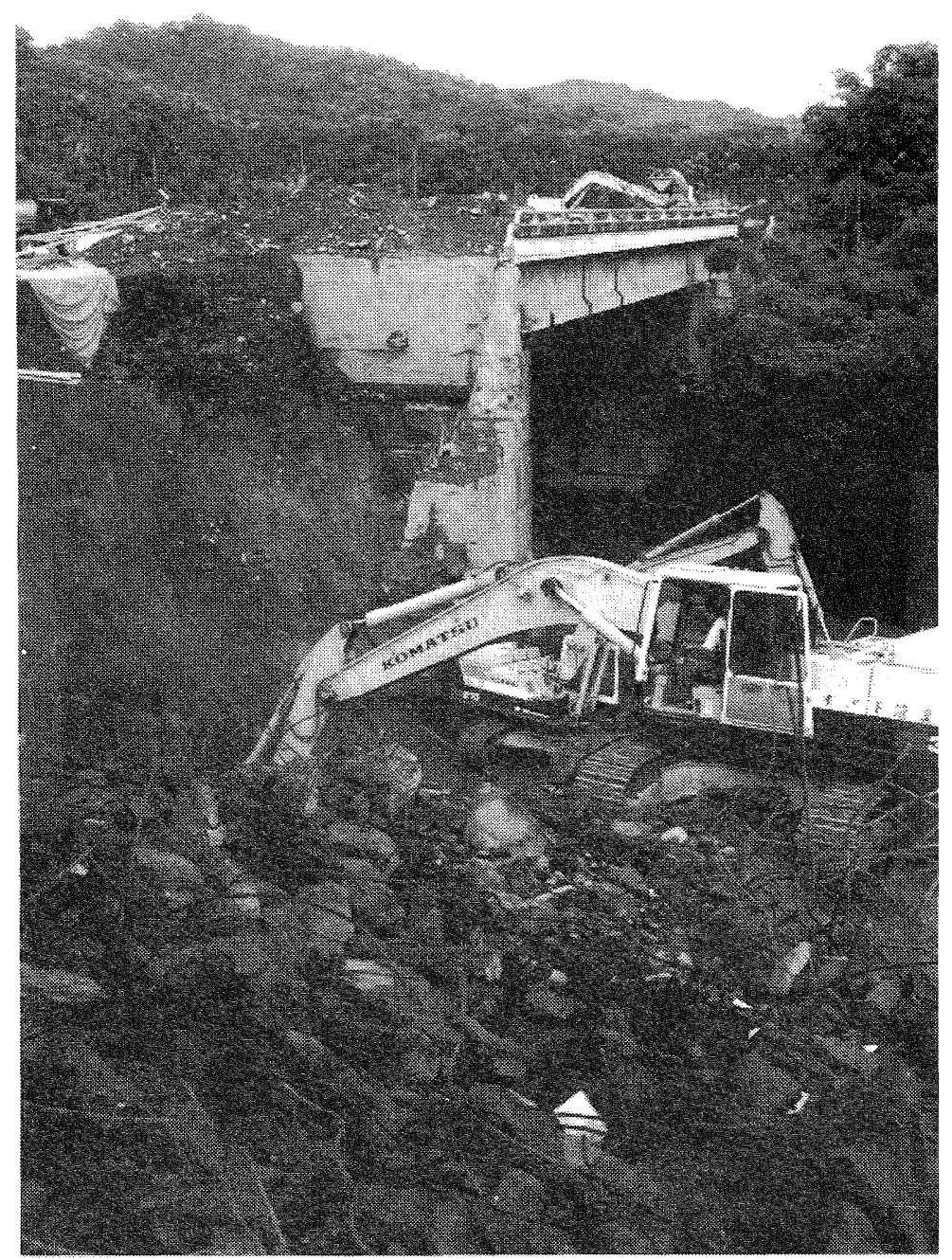

Figure 6.5:

Failed retaining wall led to the loss of the abutment of this bridge near Shuli.

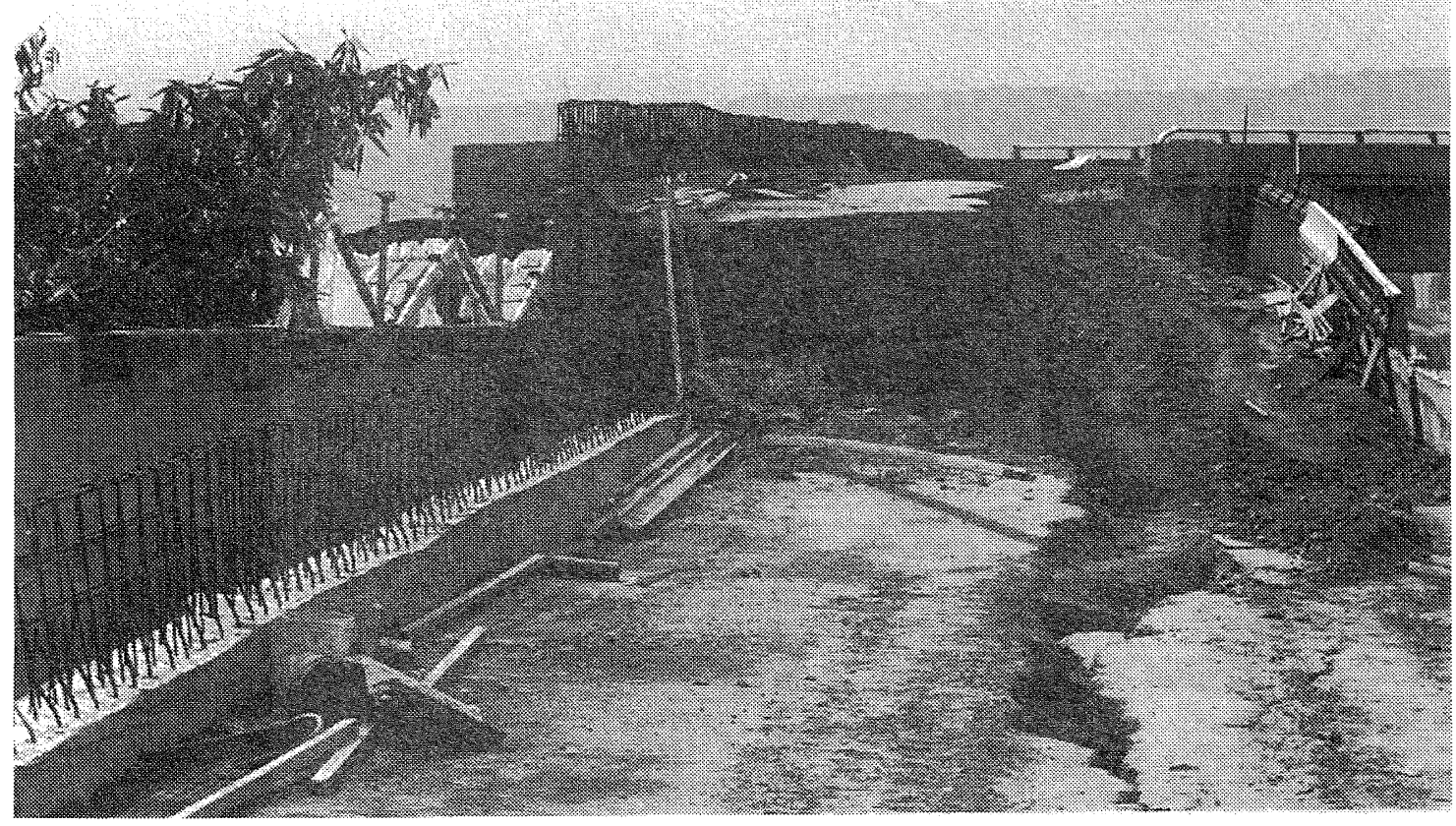

Figure 6.6:

Slumping and lateral spreading of these canal walls allowed movement of the bridge abutment in the background causing settlement, Nantou. 


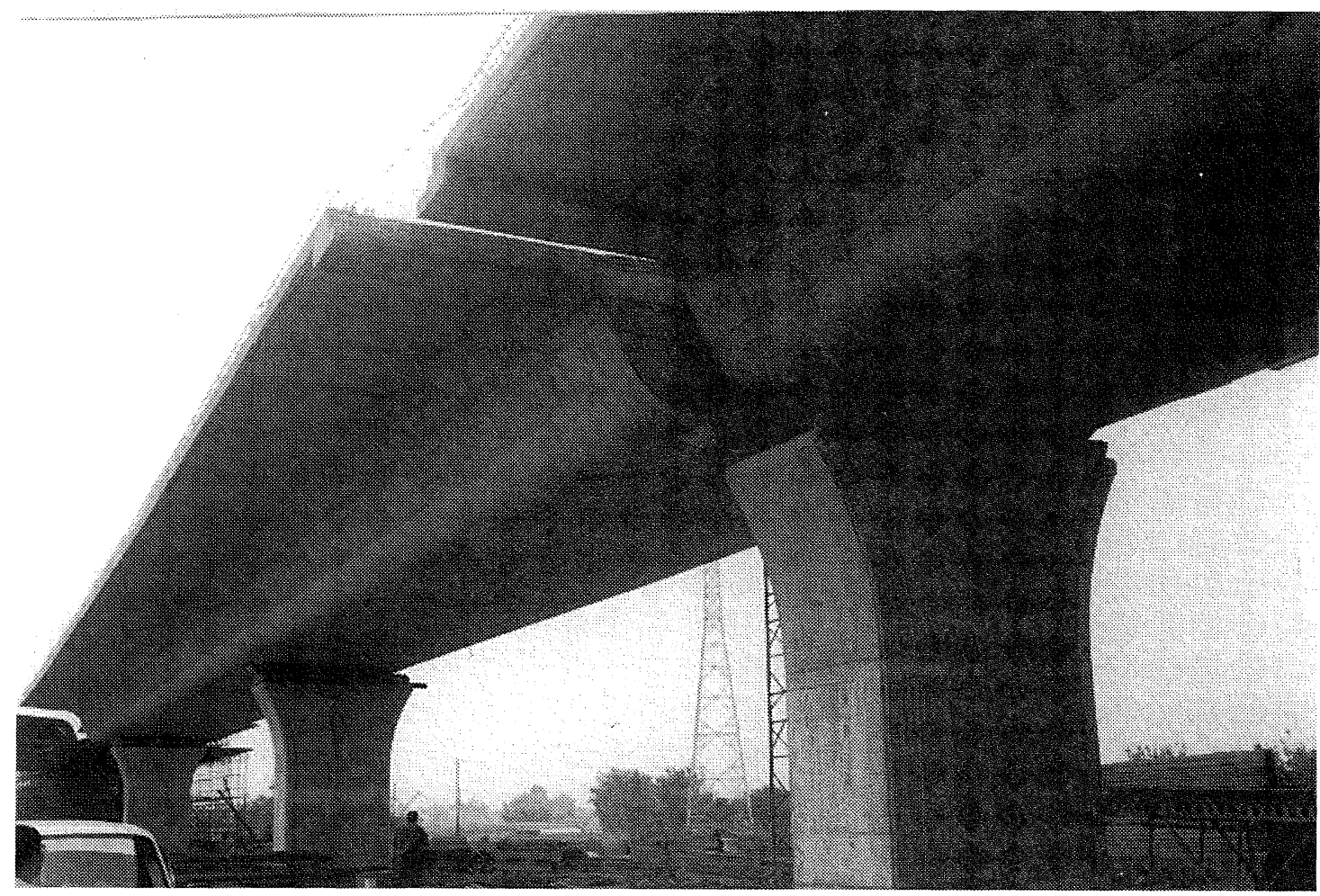

Figure 6.7: $\quad$ Failure of pot bearing on elevated expressway under construction near Fengyuan.

\section{OTHER CIVIL ENGINEERING STRUCTURES}

\subsection{Dams}

The reconnaissance team inspected the large Shihkang dam which is located on the lower reaches of the Tachia River. Construction of the dam began in 1974, and it was commissioned in 1977. It is a concrete gravity dam with radial spillway gates. The dam is designed to regulate river flows from a cascade of three upstream hydroelectric dams and was also used for water supply and recreation purposes. The fault passes through the dam near the south abutment. Fault deformation destroyed the dam with the part of the dam on the upthrust side of the fault displaced vertically by 8 to 9 $\mathrm{m}$ (refer Figures 7.1 and 7.2). An administration building on the north abutment survived with minor damage. The three upstream concrete gravity and arch dams were relatively undamaged.

There are a number of other concrete and earth dams in the affected area including some which were within $20 \mathrm{~km}$ of the epicentre and reportedly subjected to high PGAs (approximately $0.9 \mathrm{~g}$ ). These dams all survived with only minor damage. Foster and Campbell (2000) provide a detailed description of the response of dams to the earthquake.

\subsection{Port Facilities}

Taichung Port is located on the West Coast approximately 55 $\mathrm{km}$ from the epicentre. The port was built 25 years ago, much of it on reclaimed land. The PGA at the port, based on preliminary analyses of strong-motion instrument recordings, was in the range $0.1-0.2 \mathrm{~g}$. The port suffered liquefaction damage but remained largely functional. Seven piers (from a total of 40) constructed with reinforced concrete caissons were damaged by lateral displacement.

Liquefaction and washout of hydraulic fill behind the caissons caused settlements of up to $2 \mathrm{~m}$ with resulting damage to pavements, a warehouse building and a number of cargo handling cranes. It was reported that pile supported piers at the port performed better than the caisson retained piers.

\subsection{Retaining Walls}

Many of the engineered retaining walls observed during the visit were constructed of reinforced concrete and were vertical or near vertical. In many places there was evidence of liquefaction in the backfill of walls adjacent to streams and in abutment walls. This led to settlement of footpaths and damage to approach roads, but no damage to the wall facing was caused by this phenomenon (refer Figure 3.18). Most of the retaining walls observed during the visit had performed extremely well with virtually no serious damage. The exception was walls with high head slopes, some of which were destroyed.

An interesting and dramatic failure was observed near Nantou. The earthworks adjacent to the bridge were under construction at the time of the earthquake. The fill material was a gravelly silt and the day before the earthquake this had been compacted as part of the project. A retaining wall and canal lining failed and this is attributed to the combination of compaction, pore water pressures and excess pore pressures generated during the earthquake (refer Figure 6.6). There are 
extensive concrete lined flood canals in the west of the region. Some damage to the batters and lining from liquefaction (as mentioned above) and fault rupture was noted, but generally damage was very localised.

\subsection{Tanks and Silos}

Ten out of 11 cylindrical steel shell molasses storage tanks located at Taichung Port had their roofs and shell wall tops damaged as a result of earthquake induced sloshing. The tanks were reportedly near to full at the time of the quake.

The impact of the fault rupture on the tank facilities at the water treatment plant near Fengyuan township was noted in Section 4.4 .

A large proportion of the grain, cement and aggregate silos and hoppers observed by the team were damaged to various degrees (refer Figure 7.3).

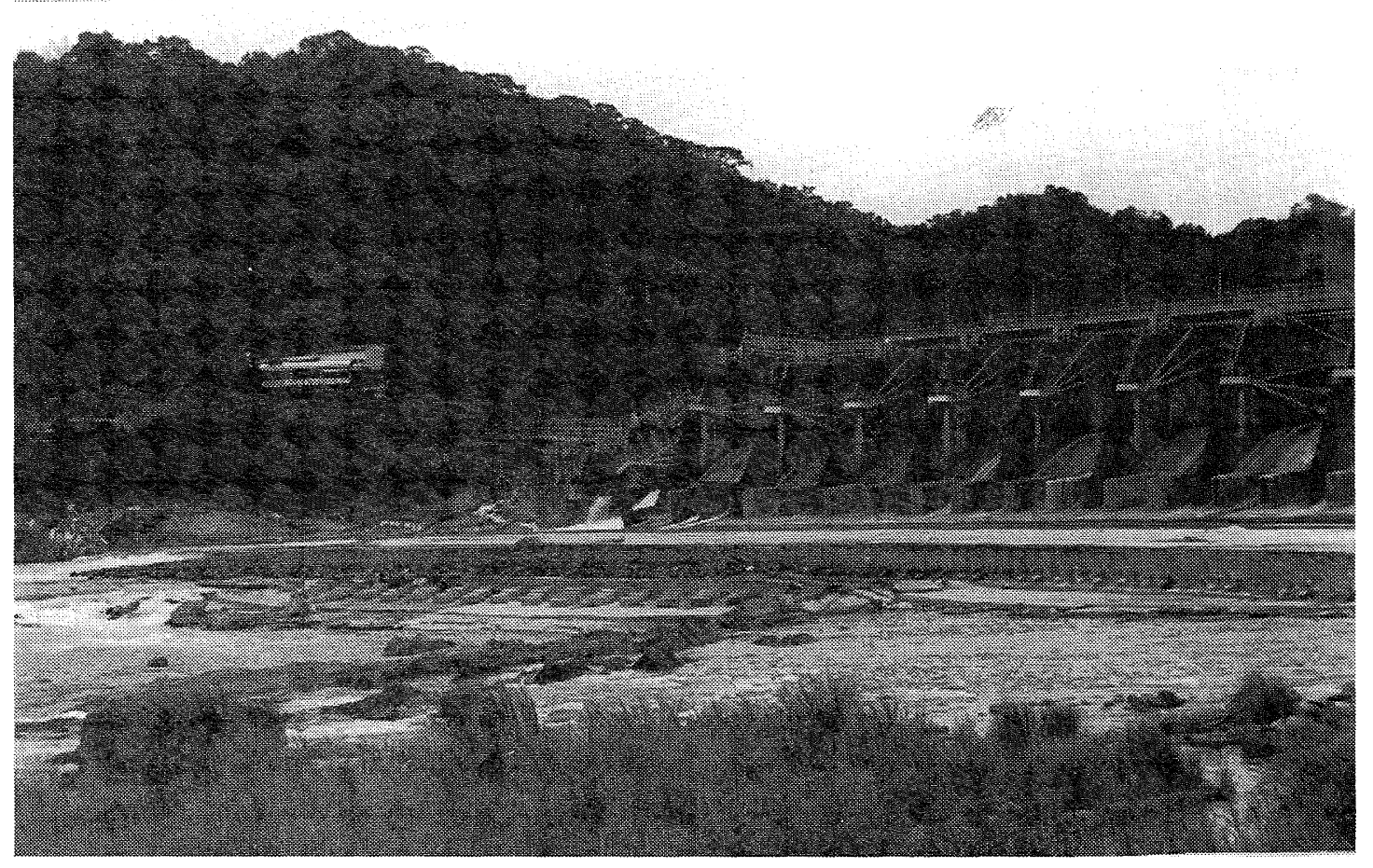

Figure 7.1:

Damage to Shih-kang Dam.



Figure 7.2: $\quad$ The fault cuts through the Shih-kang Dam, uplifting much of the dam by $8 \mathrm{~m}$. 


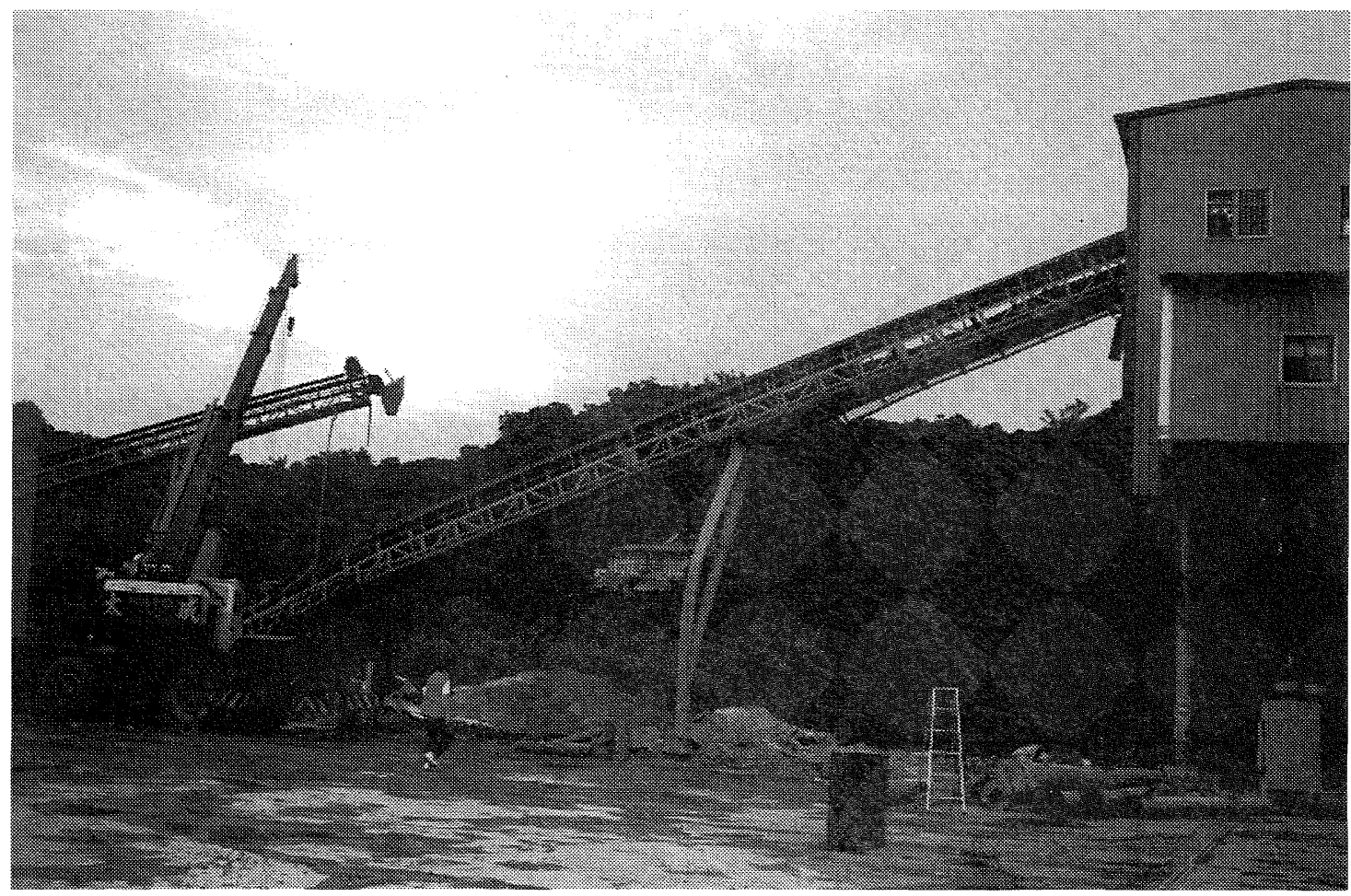

Figure 7.3: $\quad$ Damaged conveyors at concrete plant near Mingchien.

\section{SOCIAL AND ECONOMIC IMPACTS}

\subsection{Social Aspects}

The extent of disruption to households is a prime indication of the social impact of a disaster such as this. Approximately 49,000 household units were destroyed, with a further 42,000 units being in partially destroyed buildings.

The tent population peaked at approximately 23,000 , with a further 860 people being housed in army barracks. The team observed and interviewed a small number of affected persons who elected to remain in tents because of the trauma caused by the event and the aftershocks, particularly with respect to children. The expression 'refugees with cellphones' was coined, and appropriately summed up the situation.

The earthquake caused 134 children to become orphaned, and 95 senior citizens to be left with no families.

Welfare arrangements in Taiwan bear little resemblance to those in New Zealand, with little in the way of organised structure being apparent. Relief supplies were adequate but there were concerns with distribution methods, especially in the more rural areas. It is also important to note that relief supplies were provided by more than one source, namely:

- Private donation.

- Religious orders.

- Commercial organisations.

- Central Government.
Private donations totalled NZ $\$ 1.2$ billion (to the end of November 1999).

Religious and charitable organisations played a significant role in both the funding and construction of temporary housing. Approximately half of the temporary housing was funded and built by Buddhist monks, with the balance being funded by other charities. This work was well advanced at the time the NZSEE team was in Taiwan, with completion targets focusing on the key date of 25 days after the earthquake.

Inputs from commercial organisations extended to assistance with emergency water supplies as well as cash contributions.

Relief measures approved by Central Government five days after the earthquake included the following cash payments:

- $\quad \mathrm{NZ} \$ 60,000$ to the family of each deceased person

- $\quad \mathrm{NZ} \$ 12,000$ to each seriously injured person

- $\quad \mathrm{NZ} \$ 12,000$ to owners of collapsed houses

- NZ\$6,000 to owners of partially destroyed houses

Central Government was able to promptly provide such funds to the counties and cities for them to distribute. This put considerable pressure on the local government organisations to rapidly set up the necessary robust verification arrangements for claims.

An emergency fund of NZ $\$ 25$ million for forward relief operation command centres was allocated by Central Government. The central bank also allocated NZ\$6.3 billion to be offered by banks to the victims as emergency loans for reconstruction purposes. Loans of less than NZ\$94,000 were 
interest free, with 3\% annual interest applying for loans of between NZ\$94,000 and NZ\$188.000 (maximum repayment period of 20 years).

There was heartening evidence of community resilience despite considerable criticism of government and a clear expectation of greater levels of compensation. It was a humbling experience to see people who have lost everything determined to climb back. Figure 8.1 shows an occupant of the severely damaged "oil can" building in Taichung (refer Figures 5.13 to 5.15 ) being lowered by crane with some of his possessions. The removal of belongings from condemned apartment buildings was a common and thought-provoking sight during the time of our visit.

\subsection{Economic Impacts}

The 921 Chi-Chi earthquake is a major disaster that will inevitably have a significant impact on the economic wellbeing of the damaged Central Taiwan region, and on the national economic performance. It has also had an international impact through Taiwan's key role in the electronic component market.

These economic impacts arise from losses that can be categorised as direct losses associated with repairing and replacing damaged buildings and infrastructure, replacing damaged contents, providing temporary accommodation and business interruption losses to damaged industries and business; and indirect losses from the ripple effect of the damage onto customers and suppliers.

The economic effects of the earthquake will take months or years to become clear, and only some of the short-term effects could be quantified at the time of the reconnaissance visit and in the months that followed. Nevertheless, the reconnaissance visit did provide an opportunity to observe some of the factors that will impact at the micro and macroeconomic levels even if the net effects of these are not yet known.

The data presented in this report have been derived mainly from reports in the Taiwan press (Taipei Times and Taiwan News) and from international news agencies for the period 10 September 1999 to 14 October 1999.

\section{Direct Losses}

It is too early for accurate assessments of direct losses as these may take up to several years to finalise. As an indication of the scale of the losses, within four weeks of the event the government announced losses of NZ\$18 billion comprising the following:

damage to buildings and homes NZ\$12 billion
damage to infrastructure NZ $\$ 2$ billion
losses to manufacturing and agriculture NZ\$4
billion.

By the beginning of November, this loss estimate had risen to NZ $\$ 28$ billion, with final loss estimates being likely to vary upwards from these initial figures.
It is estimated that less than $0.4 \%$ of properties in Taiwan have earthquake insurance. Losses will therefore be carried primarily by the following sectors:

- businesses and individuals (either in the form of reduced savings or increased debt);

- $\quad$ banks (from non-performing loans)

- central government (relief payments, temporary shelter, reconstruction grants, low interest reconstruction loans, infrastructure reconstruction); and

- local government (relief payments, temporary shelter, infrastructure reconstruction)

The lack of earthquake insurance or any alternative planned reconstruction financing scheme is placing a great deal of pressure on these sectors.

\section{Indirect Losses}

The Chi-Chi earthquake has produced dislocations in economic sectors not sustaining direct damage. These indirect losses arise from earthquake damage impacts on suppliers and customers. A notable example is the impact on industrial production of the damage to the electricity supply system. Post-earthquake power outages and rationing either reduced the production or increased the cost of production in key industries such as the Information Technology and electronic component manufacturing industries. Conversely, the electricity producers will also have sustained losses due inability to supply their customers. At the international level, damage to the electricity system has resulted an increase in the cost of memory chips on the international market with computer manufacturers such as Hewlett-Packard anticipating some revenue losses.

\section{Impact on Specific Sectors}

\section{Manufacturing}

The electronics industry makes up one-third of Taiwan's exports and it accounts for $12 \%$ of the world production of semiconductors. The centre of the electronics industry (Hsinchu Industrial Park) is more than $100 \mathrm{~km}$ from the epicentre and it sustained light damage. There are no major export-oriented manufacturing industries in the damaged area.

The main impact on the electronics and other manufacturing industries was from power outages and rationing. Electricity was rationed to alternate days for at least three weeks after the event, and restrictions continued subsequently. The government did act to mitigate the effects of these shortages by giving key industries priority for available supplies.

\section{Agriculture}

The affected region has important agricultural production (tea and wine). It is estimated that 2,600 hectares of farmland were affected by landslides and other damage.

\section{Tourism}

The damaged region includes some of Taiwan's most popular natural tourist attractions. Damage to the infrastructure and hotels at these locations will have a major regional impact from reduced tourist numbers and income. At a national level, the industry reported $90 \%$ of inbound tours cancelled and $70 \%$ fewer foreign tourists 2 weeks after the event. This 
reduction in tourist numbers was attributed to the negative impacts of international media coverage of the earthquake.

\section{Construction}

Construction activity in Taiwan had been in decline as a result of the Asian economic downturn. Reconstruction work is expected to increase construction activity by $20 \%-25 \%$. The industry apparently has adequate capacity to meet the demand without foreign support.

\section{Financial Sector}

Initial estimates of outstanding mortgages on damaged houses held by banks are NZ2.5 - NZ $\$ 5$ billion, and very few of these are covered by earthquake insurance. Up to $25 \%$ of these loans and also a proportion of loans to businesses sustaining direct or indirect losses are expected to be defaulted. In addition, the government has directed banks to provide interest rate relief for damaged property. A number of banks with heavy exposure in Central Taiwan will be under severe pressure with collapse reported as a possibility in some cases.

Insured losses are forecast to exceed NZ $\$ 4$ billion, mostly from business interruption. Media reports suggest that these were adequately covered by reinsurance and hence will not seriously impact on the insurance industry.

\section{Stock Market}

The government closed the stock market for 4 days after the event and reduced the allowable limit for daily downward change from $7 \%$ to $3.5 \%$. On the day trading resumed, $90 \%$ of shares hit the $3.5 \%$ limit, although this reduced to $10 \%$ by 2.5 weeks. A comparable upward limit on change of $7 \%$ was set for companies in sectors likely to benefit such as construction.

At three weeks the market had lost $5.3 \%$ of its overall preevent value.

\section{Macroeconomic Effects}

On 5 October, rating agency Standard and Poor's forecast that Taiwan's economy would largely weather the impact of the earthquake with stimulation from infrastructure and construction spending offsetting the effect of damage and production losses on the economy. The following indicators were predicted:

- $\quad$ small impact on GDP $(<0.5 \%$ reduction on preearthquake forecasts)

- no effect on credit rating (AA+ before quake)

- minor effect on inflation and interest rates (ample supply of goods including building materials, good overseas reserves)

Time will tell whether these forecasts are correct although the credit rating remained at $\mathrm{AA}+$ with a stable outlook as at January 2000.

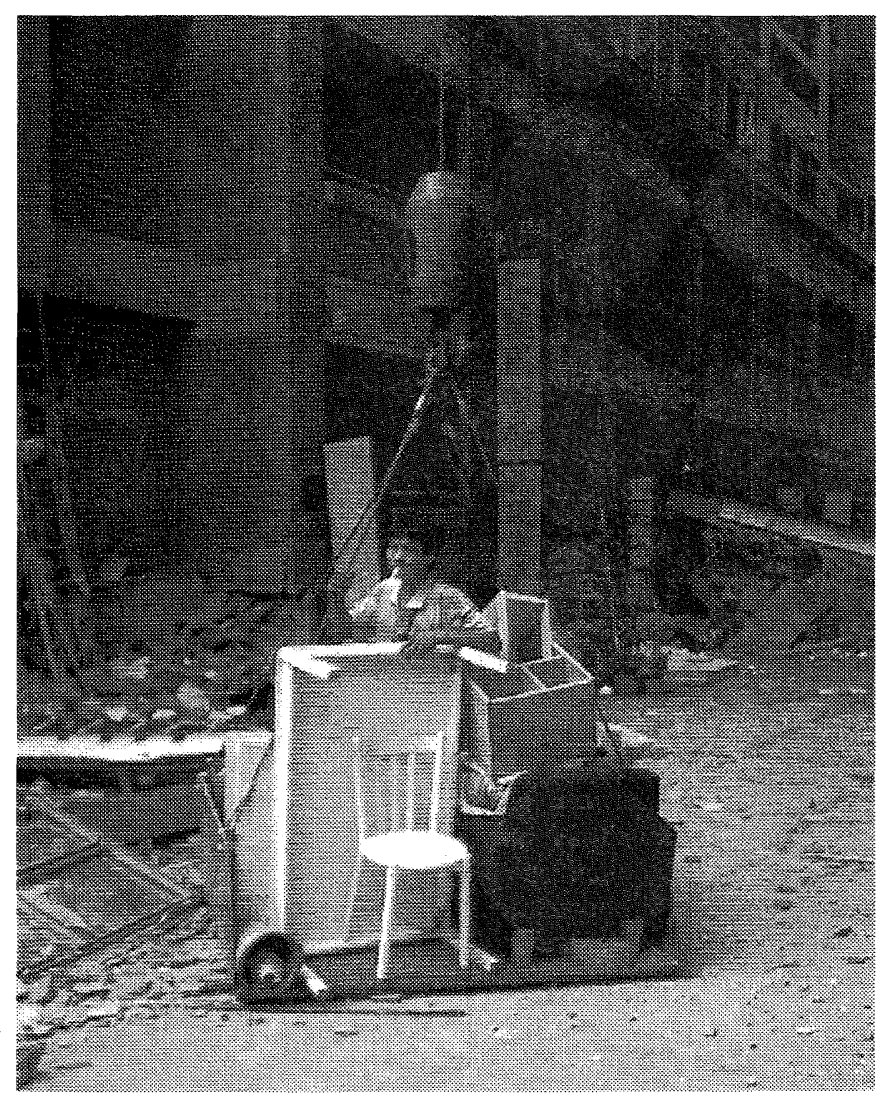

Figure 8.1: $\quad$ Occupant of the "oil can" building in Taichung removing his possessions by crane. 
9

\section{EMERGENCY MANAGEMENT}

\subsection{Organisational Structures and Preparations}

The National Fire Administration of the Ministry of the Interior is the principal emergency response agency in Taiwan. It was established as recently as March 1995, and has operational responsibilities which fall into three main categories:

- Fire prevention

- Disaster Relief

- Emergency medical services

The NFA is also expected to deal with chemical and nuclear emergencies.

Although Civil Defence legislation was first introduced into the Taiwan Parliament five years ago, it has not been passed. It is also interesting to note that Taiwan considers it is too small to support a separate Ministry for Emergency Management. There is however a resemblance in roles of the Director General of Taiwan Fire Administration and that of New Zealand's Director of the Ministry for Emergency Management.

The Fire Administration Headquarters is staffed on a 24 hours a day basis, and is effectively a National Emergency Centre. There are currently 6,000 paid fire-fighters in Taiwan with a further 21,000 volunteers. They are well resourced and trained.
Integration of agencies involved in emergency management was lacking, particularly with respect to regional scale emergencies. This was readily acknowledged as a matter for urgent attention.

Similarly, while the four core emergency management principles of Reduction, Readiness, Response and Recovery are recognised by officials in Taiwan, they did not appear to be widely practised. However evidence of mitigation and preparation was apparent in terms of the response and recovery actions underway at the time the NZSEE team was in Taiwan.

Officials and members of the wider community indicated there was a reasonable level of public awareness of emergency preparedness and response processes. Regular typhoon and flooding events ensured there was a good level of familiarity with emergency response processes. A preevent 'It won't happen to me' attitude with respect to earthquakes was however admitted by many of those spoken to.

\section{$9.2 \quad$ Response}

The principal response actions in the 24 hours following the earthquake are summarised in Table 9.1. The following comments in this section are based on field observations, interviews with government agencies, contact with local organisations and residents, news media articles and various reports.

Table 9.1: Major Actions in the First 24 Hours

\begin{tabular}{|l|l|}
\hline Time & \multicolumn{1}{|c|}{ Major Government Actions } \\
\hline $1: 47$ & Earthquake occurred. \\
\hline $1: 49$ & Central Weather Bureau provided earthquake information. \\
\hline $1: 50$ & Central Fire Protection Administration (FPA) formed emergency response task force. \\
\hline $1: 50$ & Taichung County Police Department formed Emergency Operation Centre (EOC) \\
\hline $2: 00$ & $\begin{array}{l}\text { Central Health Administration formed emergency medical task force. } \\
\text { Taichung Country Fire Department formed Disaster Operation Centre. } \\
\text { Nantou County, Taipei City and Yunlin Country formed Emergency Operation Centre. }\end{array}$ \\
\hline $2: 07$ & $\begin{array}{l}\text { FPA formed "921 Earthquake Management Centre (921EMC)" and ordered country Fire Departments to form } \\
\text { local command centres. }\end{array}$ \\
\hline $2: 04$ & Domestic news media began coverage. \\
\hline $2: 10$ & Foreign news media began coverage. \\
\hline $2: 30$ & Premier Hsiao arrived at 921EMC for briefing and giving directions. \\
\hline $3: 00$ & Provincial Governor went to Nantou and Puli areas to inspect. \\
\hline $3: 10$ & $\begin{array}{l}\text { Vice President Lien arrived at 921EMC and broadcast to the nation vowing government's determination to } \\
\text { rescue all earthquake victims. }\end{array}$ \\
\hline $4: 00$ & Military troops ordered to take part in rescue operations. \\
\hline $6: 00$ & $\begin{array}{l}\text { Defence Department formed Armed Force Emergency Command Centre and ordered Army to form Field } \\
\text { Emergency Command Post in Nantou. }\end{array}$ \\
\hline
\end{tabular}




\begin{tabular}{|c|l|}
\hline $7: 50$ & $\begin{array}{l}\text { Premier Hsiao arrived at Nantou by helicopter and ordered formation of the 921EMC Field Command Post in } \\
\text { Nantou and appointed Deputy Minister of Interior Ministry as commander. }\end{array}$ \\
\hline $9: 00$ & $\begin{array}{l}\text { Ministry of Economic Affairs formed emergency response task force and gathered representatives from water, } \\
\text { gas, electric, and industrial companies to assess damages. }\end{array}$ \\
\hline $9: 50$ & President Lee Teng-Huei arrived at Nantou to inspect the disaster areas. \\
\hline $17: 00$ & $\begin{array}{l}\text { Premier Hsiao called a Cabinet meeting to deliberate on post-earthquake operations, then announced 15-point } \\
\text { emergency measures for rescue, relief and civil security. }\end{array}$ \\
\hline $20: 30$ & $\begin{array}{l}\text { President Lee called top-level meeting and made live TV broadcast about government's actions against the } \\
\text { disaster. }\end{array}$ \\
\hline
\end{tabular}

Taiwan has a sophisticated seismic network which played an important role in the early assessment of the situation. Senior Fire Administration staff and the Taipei Emergency Control Centre were paged within 2 minutes of the event. The Premier arrived at the Emergency Centre by 0230 and the Vice President, who has responsibility for emergency response, arrived at 0330 .

The situation was assessed in sufficient time for a significant national response to commence at $0615 \mathrm{hrs}$, including activation of the military and aerial reconnaissance.

Local people also quickly realised that this was an enormous event. The earthquake is the largest recorded in Taiwan in the 20th century. Although attempts were made to state otherwise, indications are that the event overwhelmed local agencies. Telephone and radio communication links failed. In some instances failed communications were blamed for poor initial co-ordination.

Taichung County was administratively the largest province within the impact area. It faced considerable challenges in establishing communications with the remote areas and coordinating reconnaissance. They also had to share premises with Police during the early stages due to earthquake damage. However Taichung County managed to achieve communication links with all satellite stations, had initial reports on the situation and introduced a crude but basic means of co-ordination within six hours of the earthquake. This was an excellent result considering the situation. It is interesting to note that the Taichung County Fire Commander had held a scenario exercise several months prior to the event.

A State of Emergency was not declared until Saturday 25 September, some 4 days after the event. The declaration was finally ratified by the Taiwan Parliament on Tuesday 28 September. The principal reason given for the delay was reluctance on the part of Central Government for a perceived return to martial law and a possible negative public response. Declaration laws have only been used three times in Taiwan's history.

The Military were however very well received by the public, and our team observed them actively involved in many aspects of response and recovery. The Military were so effective that it was suggested disaster response should be a core duty. This was not accepted by Central Government who firmly stated this was the preserve of the Fire Administration. The constant threat of armed conflict with China was also a deciding factor.
The State of Emergency has a fixed duration of six months, with wide-ranging powers for essential services agencies, including:

- The ability to issue government bonds without legal ceilings

- The ability to reconstruct collapsed apartment buildings without reference to urban planning regulations

- Prison sentences for anyone hoarding materials or cornering the market in goods deemed to be essential

Taiwan recognised an inadequate heavy rescue capability. It was further felt that rescues after twenty-four hours were publicised miracles rather than practical alternatives, thereby casting some doubt on the viability of offshore rescue teams.

Taiwan was reported to suffer from the 'Poor Man - Rich Man' syndrome. While Taiwan has the second highest foreign reserves of any country on earth, it does not have an organised Heavy Rescue Team or the necessary specialised equipment. A proposal to form three such teams, United States trained and equipped, is now being considered.

\subsection{Recovery Planning}

The transition from response to recovery was a natural progression. Paid fire-fighters returned to normal duties as soon as the rescue operations were called off. Volunteer units remained on recovery duties and were paid a nominal wage. The Military are committed to recovery assistance for the duration of the State of Emergency declaration.

A five-year government recovery strategy was announced. While short on specifics it indicated a Central Government commitment to full recovery within that period.

Perhaps the greatest positive factor in Taiwan's recovery is the determination of its people to fully support the recovery initiative. 


\section{RESPONSE OF ENGINEERS AND SCIENTISTS}

\subsection{Earthquake Information}

The Taiwan Central Weather Bureau provided raw strong motion information to the National Fire Administration Headquarters within minutes of the earthquake. Due to the comprehensive array of instruments throughout the country, this information gave the emergency operations centre an accurate initial overview of the extent of the affected area.

\subsection{Damage Assessment and Scientific Reconnaissance}

The Bureau of Construction of the Ministry of the Interior sought information on the impact of the earthquake from a range of organisations. The National Centre for Research on Earthquake Engineering (NCREE) organised the following damage field survey groups:

$\begin{array}{ll}\text { Geology (active fault) } & \text { Lifelines Systems } \\ \text { Strong Ground Motion } & \text { Hydraulic Facilities } \\ \text { Geotechnics } & \begin{array}{l}\text { Industrial Facilities and } \\ \text { Hospitals }\end{array} \\ \text { Building Structures } & \text { Social Economics } \\ \text { Bridge Systems } & \end{array}$

Each of these groups was responsible for developing checklists and questionnaires.

\subsection{Building Safety Inspections}

A two-phase approach was adopted for building safety evaluations, summarised as follows:

Phase 1: - a rapid initial evaluation to placard buildings in the worst affected area with $\mathrm{red} /$ yellow/green notices

- this process typically took less than 30 minutes per building

- approximately 14,000 buildings were inspected in Taichung City alone during this phase.

- The focus was on multi-storey buildings, although any building would be assessed if requested by the owners or inhabitants

Phase 2: - a more detailed general evaluation to confirm and further categorise the initial red (dangerous) placards

'Dangerous' Class A - more than $75 \%$ of the floor area of a building is to be rebuilt

'Dangerous' Class B - 50 to $75 \%$ of the floor area of a building is to be rebuilt
'Dangerous' Class C approximately $50 \%$ of the floor area of a building is to be rebuilt

Taichung City had completed Phase 2 inspections by the time of the NZSEE visit. Following on from these inspections, the council sends out a building official to go through what needs doing with the owners of 'dangerous' buildings. This is an advisory role, not a statutory one. It was also intended that this process be followed for yellow-tagged buildings.

All inspection work was based on a national document "Emergency Assessment After Earthquake" which had been released just in April 1999. This document (text in Chinese) is understood to be broadly comparable to the 1998 NZSEE publication "Post-earthquake Building Safety Evaluation Procedures". Like the NZSEE guidelines, the Taiwanese document provides only a framework for local authorities and engineers rather than specifically detailed procedures. Also, as is the case in New Zealand, national pre-printed placards have yet to be created, so the wording on the placards varied from municipality to municipality.

It is understood that all repair and reconstruction work is required to be carried out in accordance with current code provisions. It was less clear as to what policy was being followed for the common situation where minor damage had highlighted major inherent problems (eg. loss of cover in lower columns revealing an absence of joint reinforcement).

\subsection{Briefing of Overseas Technical Teams}

NCREE took responsibility for briefing overseas technical teams. A comprehensive briefing session for several international reconnaissance teams was held the morning after the NZSEE team arrived in Taipei. This briefing covered aspects such as:

- Description of the earthquake mechanism and parameters

- Description of the extent and nature of damage

- Background to code development in Taiwan, and their relationship to international standards

- The provision of maps and points of contact

This briefing proved extremely valuable in terms of finetuning the team's itinerary. Given that NCREE has only approximately 30 full-time employees, and the demands placed on them by the Taiwan Government for the organisation of internal damage assessment teams, their hosting efforts were particularly impressive.

It is interesting to consider which organisation would carry out this function for international investigating teams here after a New Zealand earthquake.

\section{$10.5 \quad$ References}

"Post-earthquake Building Safety Evaluation Procedures Preparedness Checklist and Response Plan for Territorial Authorities", NZSEE, 1998 
11

LESSONS FOR NEW ZEALAND

\subsection{General}

There are geographic and geological features and event characteristics which make the lessons from this earthquake particularly relevant to New Zealand, most notably:

- Fault rupture over a length of $83 \mathrm{~km}$ (compared to possible rupture of up to $75 \mathrm{~km}$ on the Wellington fault, and from 100 to 400 $\mathrm{km}$ on the Alpine Fault)

- A mountainous central area that is prone to landsliding in close proximity to river valleys and flat alluvial coastal plains

- A number of rural towns and provincial cities were badly affected in addition to parts of metropolitan areas

- "Island nation" context

There are also significant differences between New Zealand and Taiwan, particularly in size of population, recent economic growth rates, financial reserves, cultural attitudes and forms of construction. While these differences mean that direct comparisons cannot be made, there are lessons that New Zealand can learn from the Taiwan experience to enable improved management of the physical and economic risks from earthquakes

\subsection{Principal Lessons}

\section{Seismological and Geotechnical}

The extent of physical damage due to ground deformation was the predominant feature of this earthquake. The only practical means of mitigating damage due to ground deformation on this scale is to avoid the construction of facilities close to the fault. The importance of accurately mapping fault location, activity and type is the principal finding of the reconnaissance ream. The identification of marginal slopes and areas of historical slope instability is also an important element of seismic hazard studies.

This event has highlighted the uncertainty associated with recurrence intervals, which were recently estimated at more than 10,000 years for the Chelungpu fault. The quantification of recurrence intervals and effects is secondary to the fact that a fault is identified.

Taiwan engineers have begun mapping the liquefaction hazard in the Taipei basin and intend extending this hazard assessment to the remainder of the island. In New Zealand, a similar regional approach has been adopted. While still likely to be more effective than determining the hazard on a project by project basis for low cost buildings, further consideration needs to be given to how broader-scale liquefaction hazard information should be used by planners and designers.

\section{Lifelines}

The appreciable damage and disruption to physical lifeline elements due to permanent ground deformation has graphically illustrated the vulnerability of this sector in New Zealand infrastructure. There is a clear need for lifelines organisations to have comprehensive plans in place for rapid initial repairs.

The major indirect losses arising from failure of the Taiwan electricity distribution network reminds us of the need to continue and extend the lifelines risk assessment/management work that is underway in a number of regions. It also highlights the need for utility organisations to take an interest in the vulnerability of their suppliers and customers to earthquake damage.

\section{Buildings}

This earthquake has once again underscored the need to tackle with urgency the problem of early concrete and steel buildings designed prior to modern standards. NZSEE has been working with the Building Industry Authority over the past five years to develop proposed changes to the earthquake prone provisions of the Building Act. These changes, which widen the scope of these provisions from just unreinforced masonry to any form of construction which has significantly inadequate seismic resistance, are currently before the Minister of Internal Affairs for consideration. Irrespective of whether the proposed changes to the earthquake prone provisions of the Building Act are accepted, the current change of use provisions require that older buildings be structurally upgraded when being converted, and these must be more systematically applied

It is however important to appreciate that engineers can only identify those early concrete and steel buildings that fall into "high risk" categories - that is, those buildings that are more likely to collapse than others.

Dislocation rather than force caused most of the damage to structures. This suggests that framed structures designed on an elastic basis should still have some confinement reinforcement to enable them to sustain vertical load when highly distorted.

While the monitoring of construction by engineers in New Zealand has generally also been to reasonable standards during this period, the Taiwan earthquake has highlighted the importance of maintaining a presence by the designer during construction. Also, given the limited inspectorial resources of local authorities in New Zealand, monitoring the nature and quality of repairs to buildings with minor damage will be difficult following a significant earthquake.

\section{Bridges}

Ground dislocation effects at or near the fault meant that several bridges were either destroyed or completely unusable. In the New Zealand context, this has implications for bridges on main arterial routes in regions of the country that have few alternative routes.

Most of the damage to bridges was however of a minor nature and related to the approaches or abutments.

For the immediate safety evaluations, emphasis is as much on confirming which bridges are open for general or emergency traffic as on establishing which bridges need to be closed. 
There is some uncertainty over the adequacy of New Zealand's current arrangements to effectively carry out such inspections over a hundred kilometres of highways and arterial routes, and this capability should be tested by a realistic scenario exercise.

\section{Other Civil Engineering Structures}

Piers at Taichung Port constructed with caisson walls performed very poorly in view of the apparently relatively low peak ground acceleration they were subjected to. Poor performance of these types of structures was also experienced in the Kobe earthquake. These experiences confirm that caissons and other gravity type seawall structures are potentially highly vulnerable to earthquake damage.

\section{Social and Economic Aspects}

There is an urgent need to review New Zealand's Emergency Welfare System. The Taiwanese event shows that people will get on with their lives. New Zealanders will do the same. How can those people affected by a disaster best be assisted?

Table 11.1 provides a comparison between the two countries, and also a comparison of estimated building damage losses for the Wellington Fault earthquake which is considered to be the probable maximum loss event for New Zealand (Works Consultancy Services, 1995) and the Chi-Chi earthquake.

Table 11.1: New Zealand/ Taiwan Economic Impact Comparison

\begin{tabular}{|lcc|}
\hline & Taiwan & New Zealand \\
\hline Total Population & 22 million & 3.7 million \\
GDP & NZ\$450 billion & NZ\$89 billion \\
Agriculture (\%GDP) & $2.7 \%$ & $9 \%$ \\
Industry (\%GDP) & $35.3 \%$ & $25 \%$ \\
Services (\%GDP) & $62 \%$ & $66 \%$ \\
& & Wellington Fault \\
Earthquake scenario & Chi-Chi & 0.4 million \\
Population within $50 \mathrm{~km}$ epicentre & 5 million & NZ $\$ 6$ billion \\
Estimated damage losses to buildings only & NZ\$12 billion & $6.7 \%$ \\
Building damage losses (\%GDP) & $2.7 \%$ & \\
\hline
\end{tabular}

It can be seen that the estimated losses from the Chi-Chi earthquake are forecast to be greater than the Wellington fault event, but that the Wellington fault losses are a much larger proportion of GDP. On the other hand a large proportion of the Wellington building damage losses are reinsured offshore which should reduce the impact on the NZ economy. The table does not show the indirect losses (through lack of data), but it can be surmised that these are likely to be more significant for the smaller New Zealand economy.

New Zealand is fortunate to have a comprehensive residential property earthquake insurance scheme as provided by the Earthquake Commission in place. There is however a need to produce a concise outline of the whole claims handling process (for major residential and all commercial building claims) so that affected owners, etc. can immediately appreciate the various steps involved and how they will interact with territorial authority requirements, etc.

The Chi-Chi earthquake provides a number of lessons for managing the economic impacts of a major earthquake. The impact of the earthquake on individuals, businesses, banks and government would have been substantially reduced if direct losses had been covered by insurance. In a study on the economic effects of a major earthquake in Wellington, the NZ Institute of Economic Research (Savage, 1997) concluded that the macroeconomic effects are also very sensitive to the levels of insurance and more particularly offshore reinsurance. New Zealand does have a very good domestic property insurance scheme, and reportedly fairly high levels of commercial and industrial property insurance. However the NZIER report has identified that the true levels of insurance and reinsurance coverage are apparently not known. An assessment of the proportion of total losses that would be covered by insurance and reinsurance, and on whom the non-insured losses would fall may be needed.

While it is difficult for the tourist sector to counter the negative effects of media coverage of earthquake disasters, contingency plans may be necessary to pro-actively restore New Zealand's image as a desirable destination as soon as possible after the event.

\section{Response of Engineers and Scientists}

The value of high-quality real-time earthquake data in rapidly establishing the scale of a major earthquake has been demonstrated by this event.

The advantages in having an established common building safety evaluation process across different local authorities in place are apparent. Taiwan's experiences have shown that problems with non-uniform placarding will arise when a large number of local authorities are affected. New Zealand is currently in the same position Taiwan was in prior to the event - a national building safety evaluation framework has been developed, but specific detailed mechanisms and resourcing arrangements in place in only a few areas. 
Individual territorial local authorities musr develop specific plans for carrying out building safety evaluations based on a national framework such as that proposed by NZSEE.

Processes for the hosting and briefing of international reconnaissance teams in New Zealand also need to be developed.

\section{Emergency Management}

Like Taiwan, New Zealand does not have an adequate heavy rescue response capability. Can we rely on Australian expertise, or do we have a responsibility to be more selfreliant? It is apparent that a heavy rescue strategy must be developed for New Zealand, including a management plan for handling international rescue teams.

The role played by the armed forces in Taiwan has some implications for New Zealand. As well as their immediate response functions, they were fulfilling an important function in controlling access during the commencement of the reconstruction phase at a time when all resources were fully stretched.

Central Government must accept the lead management role in a major earthquake situation. Public expectation will demand positive professional leadership at a national level. It must be ensured that the Ministry for Emergency Management has the capability to lead the response on which all those involved in the emergency response process will be judged.

\subsection{References}

Works Consultancy Services Ltd (1995), "Earthquake Risk Assessment Study", Report for the Wellington Regional Council.
Savage, J. (1997), "Economic effects of a Major Earthquake", Report for EQC, NZ Institute for Economic Research, Wellington.

\section{ACKNOWLEDGEMENTS}

The members of the Reconnaissance Team are appreciative of the opportunity to gain valuable first-hand experience of the impact of the $921 \mathrm{Chi}-\mathrm{Chi}$ earthquake. The financial support of the Earthquake Commission is particularly acknowledged

The enthusiastic support of the Deputy Director of the NZ Commerce and Industry Office in Taipei, Paul Ash, and his team was extremely valuable, as was the assistance of Ministry of Foreign Affairs and Trade representatives in Wellington.

The Team is also most grateful for the information and assistance provided by Professor C. H. Loh and his colleagues at the National Centre for Research on Earthquake Engineering. Information from their presentation at the feature session on the Taiwan earthquake at the $12^{\text {th }}$ World Conference on Earthquake Engineering in Auckland in February 2000 has been included in this report. The geological and seismological information and field guidance provided by Professor Chyi Tyi Lee (National Central University), Professor Chia $\mathrm{Yu} \mathrm{Lu}$ (National Taiwan University) and Mr. Li-Min Chi (National Central University) was also particularly appreciated.

The support and guidance of the NZSEE Reconnaissance Team Leader, David Hopkins, in establishing the team is also acknowledged. 